\title{
Glacier speed-up events and subglacial hydrology on the lower Franz Josef Glacier, New Zealand
}

by

Laura M. Kehrl

\author{
A thesis \\ submitted to Victoria University of Wellington \\ in fulfilment of the \\ requirements for the degree of \\ Master of Science \\ in Geology.
}

Antarctic Research Centre

Victoria University of Wellington 



\begin{abstract}
The contribution of glacier mass loss to future sea level rise is still poorly constrained (Lemke and others, 2007). One of the remaining unknowns is how water inputs influence glacier velocity. Short-term variations in glacier velocity occur when a water input exceeds the capacity of the subglacial drainage system, and the subglacial water pressure increases. Several studies (Van de Wal and others, 2008; Sundal and others, 2011) have suggested that high ice-flow velocities during these events are later offset by lower ice-flow velocities due to a more efficient subglacial drainage system. This study combines in-situ velocity measurements with a full Stokes glacier flowline model to understand the spatial and temporal variations in glacier flow on the lower Franz Josef Glacier, New Zealand. The Franz Josef Glacier experiences significant water inputs throughout the year (Anderson and others, 2006), and as a result, the subglacial drainage system is likely well-developed. In March 2011, measured ice-flow velocities increased by up to $75 \%$ above background values in response to rain events and by up to $32 \%$ in response to diurnal melt cycles. These speed-up events occurred at all survey locations across the lower glacier. Through flowline modelling, it is shown that the enhanced glacier flow can be explained by a spatially-uniform subglacial water pressure that increased during periods of heavy rain and glacier melt. From these results, it is suggested that temporary spikes in water inputs can cause glacier speed-up events, even when the subglacial hydrology system is well-developed (cf. Schoof, 2010). Future studies should focus on determining the contribution of glacier speed-up events to overall glacier motion.
\end{abstract}





\section{Acknowledgments}

I would like to thank a number of people who have helped me over the last year. First, thanks to my supervisors - Huw Horgan, Andrew Mackintosh, Brian Anderson, and Ruzica Dadic - for their support, constructive criticism, and challenging questions. I benefited from their varied expertise and skills, and each one of them helped me with a different component of this thesis.

I would also like to thank everyone who helped me in the field. The Department of Conservation (DoC) permitted access to the glacier. Karen McKinnon, Martina Barandun, Ruzica Dadic, Huw Horgan, Brian Anderson, Wolfgang Rack, and Oliver Marsh helped haul equipment and take measurements. The Franz Josef Glacier guides let us use their carved pathways on the glacier, which made access to the glacier easier and safer.

Lastly, thanks to my family and friends. My parents provided emotional support as I adjusted to a new country. My officemates - Sanne, Denise, Kathi, Karen, Richard, and Lloyd - always managed to put a smile on my face, even when the dark days of GPS processing nearly consumed my life. I would not be studying glaciers today if it wasn't for my undergraduate advisor, Bob Hawley, who first sparked my interest in glaciology. He remains a great mentor and friend.

Funding for the fieldwork component of this project was arranged by Andrew Mackintosh and came from a variety of sources, including an ANZICE contract. The Fulbright program and Antarctic Research Centre provided financial support for my time in New Zealand. The staff at the NZ Fulbright office deserve a special thanks for their support, encouragement, and help over the last year. 


\section{Contents}

1 Introduction 1

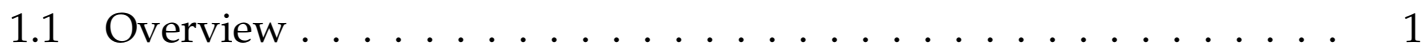

1.2 Glacier dynamics ......................... 2

1.2.1 Glacier flow ................... 2

1.2.2 Glacier hydrology ................. 3

1.2.3 Spatial variations in glacier flow . . . . . . . . . 5

1.2.4 Intra-annual variations in glacier flow . . . . . . . . 5

1.3 Motivation for this study . . . . . . . . . . . . . . . 7

1.3.1 Franz Josef Glacier . . . . . . . . . . . . . . . 7

1.3.2 Research Questions . . . . . . . . . . . . . . . 9

2 Methodology 11

2.1 Water inputs to the glacier bed . . . . . . . . . . . . 12

2.1 .1 Field methods . . . . . . . . . . . . . 12

2.1.2 Energy balance model . . . . . . . . . . . 16

2.1 .3 Discharge model ... . . . . . . . . . . 23

2.2 Ice-flow velocities . . . . . . . . . . . . . . . . 24

2.2.1 Field methods . . . . . . . . . . . . . . . . . 24

2.2 .2 GPS processing . . . . . . . . . . . . . 27

2.2.3 Uncertainty estimates at the GPS stations . . . . . . . . . . 29

2.3 Finite element glacier model . . . . . . . . . . . . . . . . 33

2.3.1 Governing equations . . . . . . . . . . . . 33

2.3.2 Boundary conditions . . . . . . . . . . . . 35

2.3.3 Glacier geometry and mesh . . . . . . . . . . . . 36 
2.4 Summary ............................. 39

3 Results $\quad 41$

3.1 Water inputs to the glacier bed . . . . . . . . . . . . 41

3.1.1 Measured rain events . . . . . . . . . . . . . 4 41

3.1.2 Measured ablation rates . . . . . . . . . . . . . 42

3.1.3 Energy balance model . . . . . . . . . . . . . 42

3.1.4 Discharge model . . . . . . . . . . . . . . 44

3.2 Ice-flow velocities . . . . . . . . . . . . . . . . . . 46

3.2.1 Background ice-flow velocities and strain rates . . . . . . . 46

3.2.2 Short-term variations . . . . . . . . . . . . . . 48

3.3 Glacier model . . . . . . . . . . . . . . . . . . 55

3.3.1 Sensitivity to parameters $A_{s}$ and $C \ldots \ldots 55$

3.3.2 Sensitivity to boundary conditions in Zone 1 . . . . . . . 59

3.3.3 Modelled subglacial water pressures . . . . . . . . . . . 60

3.4 Summary of key results . . . . . . . . . . . . . . . 62

4 Discussion $\quad 65$

4.1 Glacier dynamics of the Franz Josef Glacier . . . . . . . . . . . . 65

4.1 Water inputs . . . . . . . . . . . . 65

4.1 .2 Glacier motion . . . . . . . . . . . . . . 66

4.2 Glacier speed-up events on the Franz Josef Glacier . . . . . . . . . . 67

4.2.1 Measured glacier speed-up events . . . . . . . . . . . 67

4.2.2 Modelled subglacial water pressures . . . . . . . . . . . 69

4.2.3 Inferred subglacial hydrology . . . . . . . . . . . . 70

4.3 Glacier speed-up events in overall glacier motion . . . . . . . . . 72

5 Conclusions $\quad 75$

5.1 Answered research questions . . . . . . . . . . . . 75

5.2 Future work . . . . . . . . . . . . . . . 77 


\section{List of Figures}

1.1 Subglacial hydrology systems . . . . . . . . . . . . . . 3

1.2 Franz Josef Glacier . . . . . . . . . . . . . . . . . 8

2.1 Study site . . . . . . . . . . . . . . . . 13

2.2 Photo of Franz Josef Glacier in March 2011 . . . . . . . . . . . . . 14

2.3 Franz Josef Catchment . . . . . . . . . . . . . . . . . . 24

2.4 GPS setup . . . . . . . . . . . . . . . . . . 25

2.5 Temporal overview of instrumental data collection . . . . . . . . 26

2.6 GPS position estimates before and after processing . . . . . . . . . 28

2.7 Six-hour coordinate anomalies from the mean position at G07 . . . 31

2.8 Velocity uncertainty estimates from G07 and the gradient methods 31

2.9 Ice-flow velocities at G07 . . . . . . . . . . . . . . . 32

2.10 Glacier flowline cross section $\ldots \ldots$. . . . . . . . . . . 34

2.11 Shape factor $F$ along the flowline . . . . . . . . . . . 35

2.12 Glacier flowline . . . . . . . . . . . . . . . . . . 38

2.13 Glacier surface and bed elevations along the flowline . . . . . . . . 39

3.1 Rain event totals . . . . . . . . . . . . . . . . . . . 42

3.2 Ablation rates . . . . . . . . . . . . . . . 43

3.3 Spatial variability in ablation rates . . . . . . . . . . . . 43

3.4 Measured vs. modelled ablation rates . . . . . . . . . . . . . 44

3.5 Ablation rates at sediment-covered stakes . . . . . . . . . . . . . 45

3.6 Modelled discharge vs. measured stage at Waiho Bridge . . . . . . 45

3.7 Modelled discharge vs. measured stage in June 2010 . . . . . . . . . 46 
3.8 Background ice-flow velocities . . . . . . . . . . . . . . 47

3.9 Background strain rates . . . . . . . . . . . . . . . . 48

3.10 Horizontal ice-flow magnitudes . . . . . . . . . . . . . . . . . 49

3.11 Changes in ice-flow velocities from the daily mean . . . . . . . . . 52

3.12 Time of peak ice-flow velocity . . . . . . . . . . . . . . 53

3.13 Velocity direction at G02 and G07 . . . . . . . . . . . . . . . 54

3.14 Estimated $A_{s}$ values at the GPS stations $\ldots \ldots \ldots$. . . . . . . 56

3.15 Glacier surface speed along the flowline . . . . . . . . . . . 57

3.16 Best-fit combinations of $A_{s}$ and $C$ values . . . . . . . . . 57

3.17 Glacier speed as a function of subglacial water pressure for different combinations of $A_{s}$ and $C$ values . . . . . . . . . . 58

3.18 Modelled velocities along the flowline . . . . . . . . . . . 58

3.19 Sensitivity of model results to different boundary conditions in Zone $1 \ldots \ldots \ldots \ldots$

3.20 Modelled velocities and subglacial water pressures . . . . . . . 61

4.1 Velocity percent increase as a function of modelled discharge . . . . 68 


\section{List of Tables}

2.1 Instrument locations $\ldots \ldots \ldots \ldots \ldots \ldots \ldots$

2.2 Ablation stake descriptions $\ldots \ldots \ldots \ldots \ldots \ldots$

2.3 Values for the constants in the energy balance model that differ from those in Anderson and others (2010) . . . . . . . . . . 17

3.1 Background ice-flow velocities $\ldots \ldots \ldots \ldots \ldots$. . . . . . 47

3.2 Ice-flow velocity increases after rain events $\ldots \ldots \ldots \ldots$. . . 50

3.3 Diurnal variations in ice-flow velocities . . . . . . . . . . . 53 


\section{List of Symbols}

\section{Energy balance model}

$\begin{array}{cl}c_{p} & \text { specific heat of air } \\ c_{w} & \text { specific heat of water } \\ d & \text { snow depth } \\ d * & \text { characteristic snow depth scale (11 mm w.e.) } \\ d T / d h & \text { atmospheric lapse rate } \\ I & \text { incoming shortwave radiation } \\ g & \text { acceleration due to gravity } \\ k_{E} & \text { exchange coefficient for latent heat } \\ k_{H} & \text { exchange coefficient for sensible heat } \\ k_{0} & \text { von Kármán's constant } \\ L_{f} & \text { latent heat of fusion } \\ L_{v} & \text { latent heat of evaporation } \\ L_{i n} & \text { incoming longwave radiation } \\ L_{o u t} & \text { outgoing longwave radiation } \\ N & \text { day number from } 1 \text { January } \\ n & \text { cloudiness } \\ M & \text { melt rate } \\ P & \text { precipitation rate } \\ p & \text { air pressure } \\ Q_{E} & \text { latent heat flux } \\ Q_{H} & \text { sensible heat flux } \\ Q_{G} & \text { ground heat flux } \\ Q_{m} & \text { energy available for melt } \\ Q_{R} & \text { heat flux supplied by the rainfall } \\ q & \text { vapour pressure of air } \\ q_{s} & \text { vapour pressure of air at the glacier surface } \\ R_{b} & \text { Richardson stability criterion } \\ S & \text { solar constant } \\ s & \text { time since the last snowfall event } \\ T & \text { absolute temperature } \\ T_{a} & \text { absolute atmospheric temperature } \\ T_{s} & \text { glacier surface temperature } \\ T_{t} & \text { absolute terrain temperature } \\ t * & \text { timescale in albedo calculations } \\ t_{a} & \text { transmissivity of the atmosphere } \\ t_{c} & \text { transmissivity of the clouds } \\ U & \text { wind speed at a height of } 2 \mathrm{~m} \\ & \end{array}$




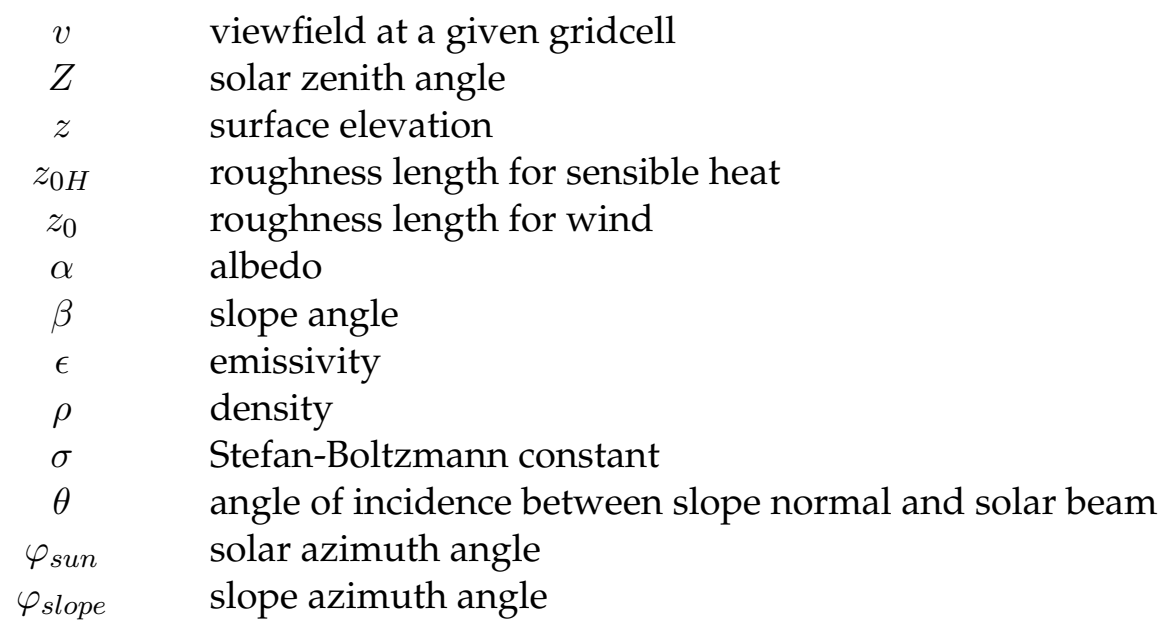

\section{Discharge model}

$\begin{array}{cl}D(t) & \text { glacier discharge } \\ k_{s} & \text { reservoir storage constant } \\ R(t) & \text { rate of water flowing into the reservoir } \\ V(t) & \text { reservoir's volume }\end{array}$

\section{Flowline model}

A Glen's flow parameter

$A_{s} \quad$ sliding coefficient in the absence of cavitation

$C$ coefficient that is less than the maximum local positive bed slope

$F \quad$ shape factor

$\vec{f} \quad$ body force that describes valley wall drag

$\vec{g} \quad$ gravity vector

$H \quad$ glacier height

$N \quad$ effective pressure

$n \quad$ Glen's flow law exponent

$\vec{n}_{s} \quad$ unit vector normal to the glacier surface

$P \quad$ wetted perimeter

$P_{w} \quad$ subglacial water pressure

$S \quad$ glacier cross-sectional area

$\overrightarrow{t_{s}} \quad$ unit vector tangent to the glacier surface

$\vec{u} \quad$ velocity vector

$u_{b} \quad$ sliding speed

$w \quad$ glacier width

$x \quad$ horizontal coordinate

$z \quad$ vertical coordinate

$\alpha \quad$ valley wall slope angle

$\dot{\vec{\epsilon}} \quad$ strain rate tensor

$\rho \quad$ ice density

$\vec{\tau} \quad$ deviatoric stress tensor

$\tau_{e} \quad$ second invariant of the deviatoric stress tensor

$\tau_{b} \quad$ basal drag

$\theta \quad$ glacier slope angle 


\section{Chapter 1}

\section{Introduction}

\subsection{Overview}

Sea level rise in the 21st century will likely displace hundreds of millions of people from their homes, threaten sensitive marine ecosystems, and increase the incidence of storm-related flooding (Lemke and others, 2007). To mitigate these effects, it is important that we accurately predict future sea level rise (SLR). The Intergovernmental Panel on Climate Change (IPCC) Fourth Assessment predicts sea level rise of 0.18 to 0.60 metres $(\mathrm{m})$ by 2100 , but that prediction excludes the effects of future changes in glacier dynamics on glacier mass balance, as the processes are still too poorly understood (Lemke and others, 2007). Paleoclimate studies (e.g., Overpeck and others, 2006) have shown multimetre per century rises in sea level in the past, and similar rates have been suggested for the 21st century when changes in glacier dynamics are taken into account (e.g. Hansen, 2007). In an attempt to estimate the possible contribution from glacier dynamics, Pfeffer and others (2008) concluded that glaciers and ice caps could provide up to an additional $0.47 \mathrm{~m}$ SLR by 2100 . When the dynamics of the major ice sheets are included in this approach, predicted SLR is one metre greater than when those processes are neglected (Pfeffer and others, 2008).

An improved understanding of glacier dynamics is therefore important for future adaptation and mitigation in response to climate change. The Franz Josef Glacier in the Southern Alps of New Zealand provides a unique opportunity to 
observe the dynamics of a fast-flowing, maritime glacier. To date, very few studies have explored the dynamics of this type of glacier; most, in fact, have focused on continental mountain glaciers that experience a strong seasonal cycle in water inputs to the glacier bed. At the Franz Josef Glacier, significant rain- and meltwater reach the bed year round (Anderson and others, 2006). As variations in water inputs are often correlated with variations in glacier flow (e.g., Iken and Bindschadler, 1986; Jansson, 1995; Mair and others, 2001), the glacier dynamics of the Franz Josef Glacier might differ from those of other glaciers. In this study, the effects of varying water inputs on the daily and diurnal dynamics of the Franz Josef Glacier are considered.

\subsection{Glacier dynamics}

\subsubsection{Glacier flow}

"Glacier dynamics" refers to the "dynamic processes" that govern glacier flow. Glaciers flow from the accumulation area to the ablation area through two primary mechanisms: (1) internal deformation and (2) basal motion. Rates of internal deformation depend primarily on the glacier surface slope, ice thickness, and temperature (Paterson, 1994), although longitudinal deviatoric stresses can be important for some mountain glaciers (e.g. Hubbard, 1997). As these parameters change with mass balance and climate, large variations in the rate of internal deformation usually occur over time periods of a year or more (Vincent and others, 2009).

Variations in glacier flow over shorter timescales typically result from changes in the rate of basal motion. Basal motion consists of both sediment deformation and glacier sliding. Many studies indicate a relationship between glacier sliding and effective pressure (e.g., Lliboutry, 1958, 1968; Iken and Bindschadler, 1986; Hooke and others, 1989). Effective pressure is the difference between ice overburden pressure (proportional to ice thickness) and the subglacial water pressure. As the subglacial water pressure increases, the effective pressure decreases and the 

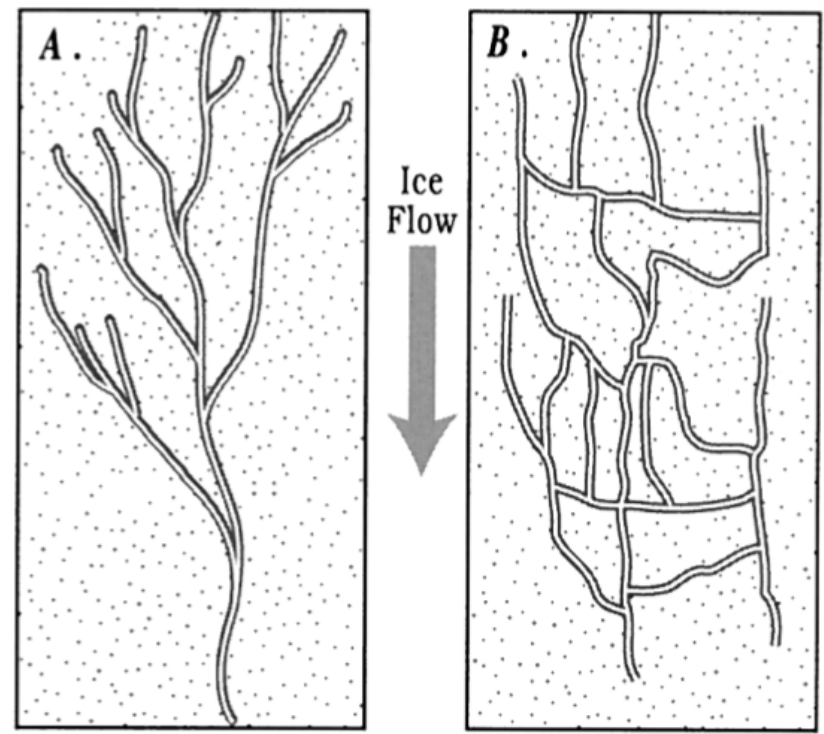

Figure 1.1: Subglacial hydrology systems after Fountain and Walder (1998): (A) a "fast," arborescent system and (B) a "slow," linked-cavity system.

ice column tends towards flotation. High subglacial water pressures increase the rate of basal sliding through two different processes. First, high subglacial water pressures cause separation of the ice and bedrock, also known as "cavitation" (Lliboutry, 1968). This decreases friction where subglacial water pressures are high, thereby increasing the basal shear stress on the parts of the glacier that remain in contact with the bed (Bindschadler, 1983). Second, high subglacial water pressures in cavities exert a force in the down-glacier direction, a process known as "hydraulic cavitation" or "hydraulic jacking" (Iken, 1981). As a result, fluctuations in the subglacial water pressure can affect ice-flow velocities on a short timescale (seasonal, daily, and diurnal).

\subsubsection{Glacier hydrology}

The subglacial water pressure depends on both the water input to the glacier bed and the subglacial drainage system. A "fast" (channelized) drainage system can evacuate water more efficiently than a "slow" (linked-cavity) system. Consequently, the subglacial water pressure remains lower in a fast system than in a slow system for the same water input (Figure 1.1; Raymond and others, 1995). 
In a slow, linked-cavity system, water travels through a system of naturallyoccurring cavities linked by narrow orifices (Lliboutry, 1968; Kamb, 1987) and a thin film of water at the bed (Weertman, 1964; Walder, 1982). These cavities form in the lee of steps in the bedrock and increase in number and size as bed roughness and sliding speed increase (Nye, 1970). This system is stable when water inputs to the glacier bed are low (Kamb, 1987).

In a fast, channelized system, water is routed primarily through relatively straight, semicircular channels at the glacier bed. These channels can either be incised into the ice (R-channels; Röthlisberger, 1972) or into the hard bed (Nchannels; Nye, 1973). For the R-channels to remain open, melting from the heat dissipated by the flowing water must balance or exceed the inward creep of the ice (Kamb, 1987). A fast system is therefore stable only when water inputs to the system are sufficiently high. When water inputs drop below a certain level, the conduits will close due to ice creep, and the drainage system will return to a slow system (Kamb, 1987).

The subglacial drainage system evolves in response to varying water inputs throughout the year. In the winter, when water inputs are low, a slow system dominates. The cavities may become constricted due to sediment build-up but will remain open throughout the winter as long as the glacier continues to slide along its bed (Fountain and Walder, 1998). When water inputs increase in the spring, the slow system becomes unstable (Kamb, 1987). Initially, the drainage system cannot handle the increased water input and the subglacial water pressure increases, potentially leading to glacier uplift (e.g., Iken and others, 1983). This event is known as a "spring event" (Mair and others, 2001). Over time, crevasses, orifices, and remnants of last year's channels start to incise. As the subglacial water pressure is lower in a larger channel, the pressure gradient causes water flow away from smaller channels towards the larger ones. After the spring event, subglacial water pressures drop abruptly and remain low as long as discharge levels remain high. The transition from a slow system to a fast system moves up glacier to higher elevations as the melt season progresses (e.g., Nienow, 1994). 


\subsubsection{Spatial variations in glacier flow}

Spatial variations in the subglacial drainage system often correlate with spatial variations in glacier flow. Areas of low subglacial water pressure act as "sticky spots" (Alley, 1993; Iken and Truffer, 1997; Fischer and others, 1999) and increase the basal drag at that location. Basal drag refers to the resistive force acting at the base of the glacier, and consequently, high basal drag leads to low rates of basal sliding. As the subglacial water pressure changes, sticky spots and their counterparts - "slippery spots" - can be destroyed or created (Fischer and others, 1999). The impact of these "spots" on nearby surface velocities extends beyond their immediate location as the ice column "smooths" basal motion as it is transferred to the surface (Kamb and Echelmeyer, 1986). This is a result of longitudinal stress-coupling, or the "pulling" and "pushing" of ice nearby. The length scale over which variations in basal drag affect surface velocities is still poorly understood (Harbor and others, 1997). Balise and Raymond (1985) showed through an analytical model of a planar parallel-sided slab that basal velocity perturbations applied over a length scale of less than one ice thickness did not influence surface velocities. From field data, Mair and others (2001) concluded that sticky spots must be at least four ice thicknesses away for a high velocity event to occur at a given location on Haut Glacier d'Arolla, Switzerland. These results point to the importance of understanding the spatial distribution of subglacial water pressures and basal drag across the bed when interpreting intra-annual variations in surface flow velocities.

\subsubsection{Intra-annual variations in glacier flow}

Intra-annual variations in surface flow velocities can occur on a seasonal, daily, or diurnal timescale. On a seasonal timescale, summer velocities are often greater than winter velocities (e.g., Hooke and others, 1983; Iken and others, 1983). Spring events usually mark the transition between the two. During this transition, iceflow velocities are high as the subglacial drainage system evolves to a more efficient system. At the toe of Haut Glacier d'Arolla, ice-flow velocities increased 
at all stakes by about 300-400\% over a seven-day spring event in 1994 (Mair and others, 2001). The increased surface motion occurred at a time of glacier uplift and rising discharge in the proglacial stream, which was a result of high air temperatures and heavy rain. Glacier uplift suggests increased separation between the glacier and the bed, which would lead to reduced basal drag and high rates of basal sliding. After the spring event, rises in river discharge did not correlate with increases in the surface velocity, indicating that the subglacial drainage system remained at a lower water pressure during these events. This suggests that the system had evolved to an efficient, fast drainage system during the spring event (Mair and others, 2001).

Daily variations in ice-flow velocities, which last only a few hours or days, can occur anytime of the year, even after a spring event. These events tend to be more pronounced in the early part of the summer when the drainage system is still poorly developed (e.g., Hooke and others, 1989). Ice-flow velocities at White Glacier (Canada), Findelengletscher (Switzerland), and Midtdalsbreen (Norway) have increased by up to 400\% (Iken, 1974), 300\% (Iken and Bindschadler, 1986), and 900\% (Willis, 1995) of background speeds, respectively, during these events. In the early summer, daily events often occur during periods of significant surface melt and in the late summer with periods of heavy rainfall (Willis, 1995).

Similarly, diurnal cycles in ice-flow velocities tend to occur on days with pronounced diurnal meltwater inputs and thereby subglacial water pressures. At Findelengletscher, maximum daily borehole water pressures correlated with maximum velocities (Iken and Bindschadler, 1986). Nienow and others (2005), on the other hand, found that peak velocities occurred during rising water pressures at Haut Glacier d'Arolla. At Gornegletscher in Switzerland, diurnal fluctuations in borehole water pressures occurred (Röthlisberger, 1976), but there were no changes in ice-flow velocities (Iken, 1974). Fischer and Clarke (1997) explained these varying results in terms of a "stick-slip relaxation process" at the glacier bed. Subglacial water pressures rise until locally-accumulated strain in the ice is released, perhaps as a result of a failure of a sticky spot. This process causes an increase in the sliding rate. Once the ice has "relaxed" from the strain re- 
lease, sliding velocities decrease despite higher subglacial water pressures. With this interpretation, strain release occurred at maximum water pressure at Findelengletscher and at a rising water pressure at Haut Glacier d'Arolla. The necessary water pressure for strain release did not occur at Gornegletscher, and consequently, the sliding velocity did not increase as a result of the diurnal variations in the subglacial water pressure. Not all glaciers experience diurnal variations in ice-flow velocities (Iken, 1974), and these variations often do not occur in the winter.

As the above studies demonstrate, intra-annual variations in ice-flow velocities usually occur when the water flux exceeds the capacity of the subglacial drainage system (Willis, 1995). Consequently, if a fast drainage system exists beneath the glacier, transient speed-up events are less likely to occur. To date, most studies have focused on intra-annual variations in glacier speed on continental mountain glaciers, which have pronounced seasonal variations in water inputs and temperature. What if a glacier experiences significant melt and rain year round? Will the intra-annual variations in ice-flow velocities disappear if the subglacial drainage systems remains well-developed throughout the year? As more glaciers become subject to increased melt and rain year round as a result of climate change (e.g., Schuenemann and Cassano, 2010), it is important that we answer these questions.

\subsection{Motivation for this study}

\subsubsection{Franz Josef Glacier}

The Franz Josef Glacier is a temperate, maritime glacier on the western flank of

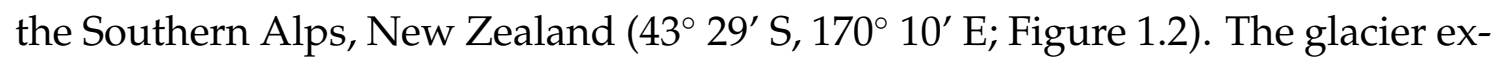
tends $11 \mathrm{~km}$ from an altitude of $2900 \mathrm{~m}$ to $300 \mathrm{~m}$ above sea level (m.a.s.l.). Mean ablation rates at the glacier tongue are $20 \mathrm{~m} \mathrm{a}^{-1}$ water equivalent (w.e.), and precipitation rates range from about $7 \mathrm{~m}$ w.e. $\mathrm{a}^{-1}$ at the toe to about $12 \mathrm{~m}$ w.e. $\mathrm{a}^{-1}$ at 600 m.a.s.l (Anderson and others, 2006). The high rates of accumulation and 


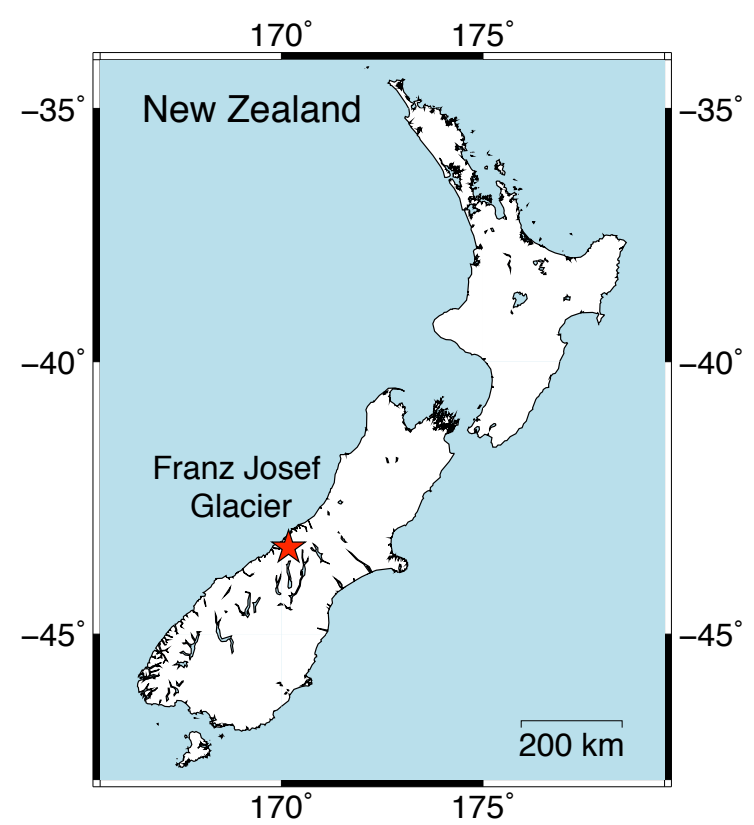

Figure 1.2: Location of the Franz Josef Glacier on the West Coast of the Southern Alps, New Zealand.

ablation lead to fast response times of 9 to 20 years (Oerlemans, 1997) and velocities on the order of $1000 \mathrm{~m} \mathrm{a}^{-1}$ (Anderson, 2004). At the glacier terminus, melt and heavy rainfall occur year round. Very few supraglacial streams exist on the surface of the glacier, suggesting that water is routed to the bed at most locations.

Very few studies have explored the dynamics and hydrology of the Franz Josef Glacier. Anderson and others (in prep) used previously collected data to address the intra-annual and decadal variations in ice-flow velocities. They concluded that diurnal, daily, and seasonal variations likely occurred at the Franz Josef Glacier, but it was difficult to determine the magnitude of these events as the time interval between velocity measurements was not consistent. At nearby Fox Glacier, Purdie and others (2008) found short-term velocity increases within 24 hours of heavy rainfall. Velocities during these events reached up to $44 \%$ greater than background velocities, which is significantly less than the magnitude of daily events previously discussed on Midtsalbreen, Findelengletscher, and other continental glaciers (Purdie and others, 2008). Purdie and others (2008) did not address diurnal variations as velocities were measured daily at Fox Glacier. 


\subsubsection{Research Questions}

The objective of this study is to improve our understanding of the relationship between water inputs and short-term variations in glacier speed on the Franz Josef Glacier. In particular, I hope to answer the following questions:

1. How do ice-flow velocities vary spatially and temporally across the lower Franz Josef Glacier? Are there daily or diurnal variations in ice-flow velocities?

2. Why do ice-flow velocities vary at this glacier? What do these results suggest about the subglacial hydrology of the Franz Josef Glacier?

3. How do the dynamics of this glacier differ from those of other glaciers, and what does this tell us about glacier dynamics in general?

The following chapters detail my approach to address these questions. In the next chapter, the methodology is described. I combine in-situ measurements and ice flow modelling to understand the relationship between ice-flow velocities, water inputs, and the subglacial hydrology system on the lower Franz Josef Glacier. The results of this analysis are presented in Chapter 3 and discussed in Chapter 4. Finally, conclusions and recommendations for future work are addressed in Chapter 5. 


\section{Chapter 2}

\section{Methodology}

To address the research questions outlined in Section 1.3.2, the relationship between ice-flow velocities and water inputs must be examined at the Franz Josef Glacier. Two approaches can be taken to determine this relationship: a statistical approach and a modelling approach. A statistical approach compares the timing and magnitude of observed glacier speed-up events to water inputs. If glacier speed increases during periods of significant water input, it can be inferred that subglacial water pressures increased during that time (e.g., Iken and Bindschadler, 1986). Water inputs can be assessed by examining river discharge (e.g., Naruse and others, 1992) or borehole water pressures (e.g., Iken and Bindschadler, 1986; Nienow and others, 2005). A modelling approach, on the other hand, moves beyond this statistical analysis in an attempt to understand the physical processes behind the relationship.

Both of these approaches are employed in this study. First, observational data from March 2011 are used to understand the relationship between water inputs and glacier velocity. Glacier velocity is determined by measuring the location of a marker in the ice over time. Water inputs are harder to quantify, as water reaches the bed from a variety of sources, such as runoff from the valley walls, rain, and surface melt. As a result, this study combines point measurements and modelling to determine water inputs to the glacier bed. Second, a full Stokes flowline model is used to help interpret the observational data. The model incorporates a Coulomb friction law (Schoof, 2005; Gagliardini and others, 2007) that relates 
the subglacial water pressure, $P_{w}$, to the sliding speed, $u_{b}$. The observational data can then be used to infer spatial and temporal variations in the subglacial water pressure. The following sections describe the in-situ measurements followed by the glacier flowline model.

\subsection{Water inputs to the glacier bed}

Rain, seasonal snow melt, and glacier melt constitute the primary water inputs to the glacier bed. To quantify these inputs, in-situ measurements are combined with a distributed energy balance model. The energy balance model makes it possible to investigate water inputs across the entire glacier rather than at select measurement locations. The melt calculated from the energy balance model is used to drive a lumped-sum discharge model at the glacier tongue, following the methods of Anderson and others (2010). The resulting discharge curve provides an estimate of the total water in the glacier system over time.

\subsubsection{Field methods}

\section{Rain}

Precipitation totals can differ significantly between Franz Josef Village and the glacier terminus (Anderson and others, 2006). To quantify the precipitation at the glacier terminus, a tipping-bucket rain gauge was installed on Champness Rock, a rock outcrop about $300 \mathrm{~m}$ down-valley from the glacier terminus (Figure 2.1). The rain gauge had a resolution of $0.2 \mathrm{~mm}$. The number of tips was totalled every minute.

\section{Ablation rates}

To measure ablation, a stake network of 20 2-m-long white PVC tubes was installed across the lower glacier on March 4-6 (Figure 2.1). Each tube was drilled into the ice with a kovacs ice drill until it was flush with the glacier surface. These "ablation stakes" were placed on ice with different slope angles, sediment cover, 


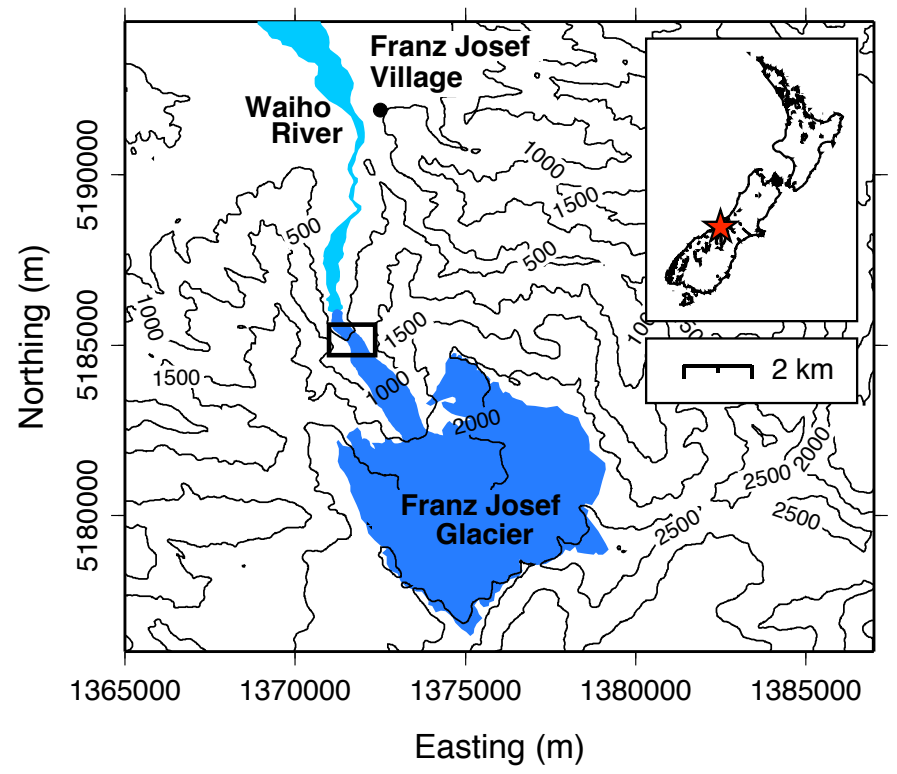

(a)

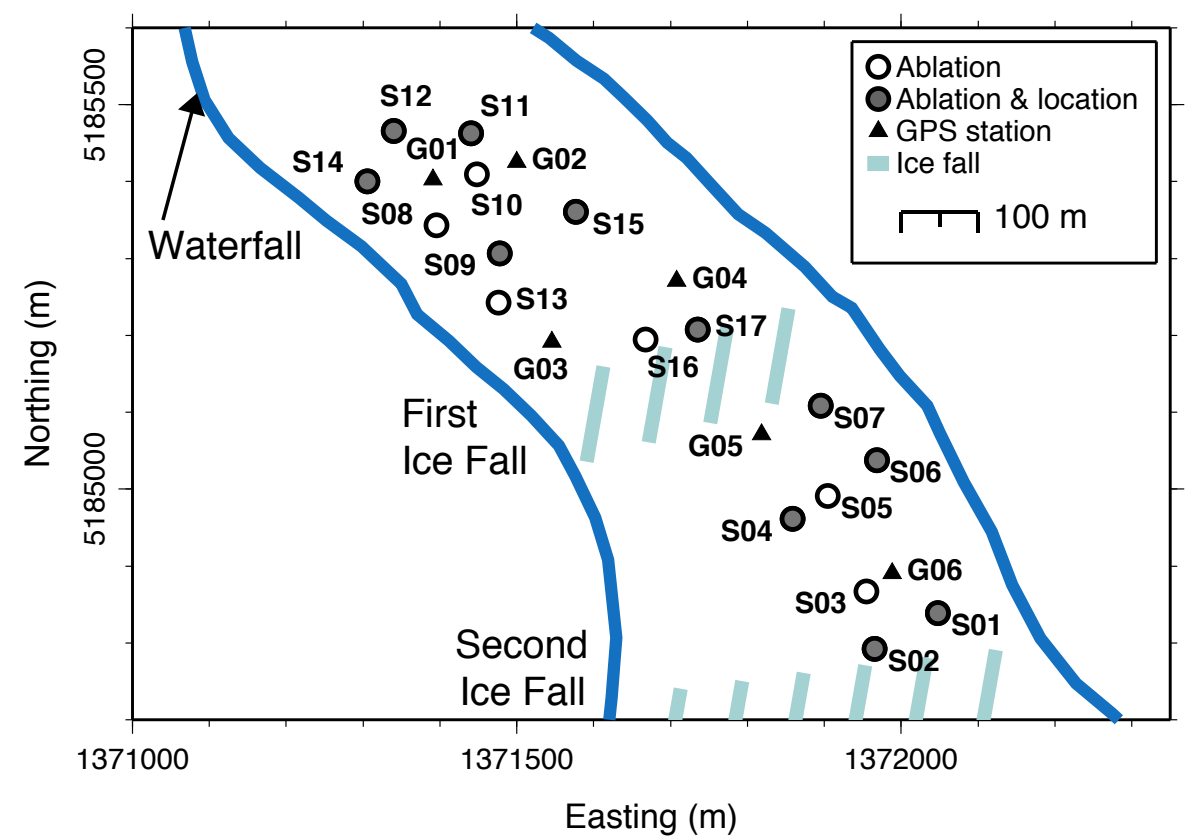

(b)

Figure 2.1: Study site. (a) The inset map shows the location of the Franz Josef Glacier in New Zealand. Franz Josef Village is $7 \mathrm{~km}$ north of the glacier. The Waiho River originates from the glacier terminus. The black box on the lower glacier indicates the region of focus in this study and is enlarged in (b). (b) Black triangles, grey circles, and white circles indicate GPS stations, ablations stakes where both ablation and GPS location were measured, and ablation stakes where only ablation was measured. Light blue lines indicate the position of the "first" and "second" ice falls (Figure 2.2). "Waterfall" marks the location of a large point source of water (often called "Arthur's Cataract") on the lower glacier. Coordinates are given in the New Zealand Transverse Mercator (NZTM) system. Table 2.1 lists the coordinates for each instrument. 
Table 2.1: NZTM coordinates of GPS stations (G01-G07), GPS base station (MTP), ablation stakes (S01-S17), and rain gauge installed on the lower Franz Josef Glacier in March 2011. Ablation stakes S18-S20 were installed near G01.

\begin{tabular}{|c|r|r|}
\hline Instrument & Easting & Northing \\
\hline \hline G01 & 1371391 & 5185402 \\
\hline G02 & 1371500 & 5185425 \\
\hline G03 & 1371545 & 5185191 \\
\hline G04 & 1371708 & 5185271 \\
\hline G05 & 1371818 & 5185071 \\
\hline G06 & 1371988 & 5184890 \\
\hline G07 & 1370929 & 5187748 \\
\hline MTP & 1385224 & 5198418 \\
\hline S01 & 1372050 & 5184840 \\
\hline S02 & 1371970 & 5184797 \\
\hline S04 & 1371862 & 5184962 \\
\hline S06 & 1371971 & 5185040 \\
\hline S07 & 1371897 & 5185111 \\
\hline S09 & 1371476 & 5185309 \\
\hline S11 & 1371440 & 5185467 \\
\hline S12 & 1371340 & 5185470 \\
\hline S14 & 1371308 & 5185404 \\
\hline S15 & 1371578 & 5185364 \\
\hline S17 & 1371734 & 5185212 \\
\hline Rain gauge & 1371038 & 5186475 \\
\hline
\end{tabular}

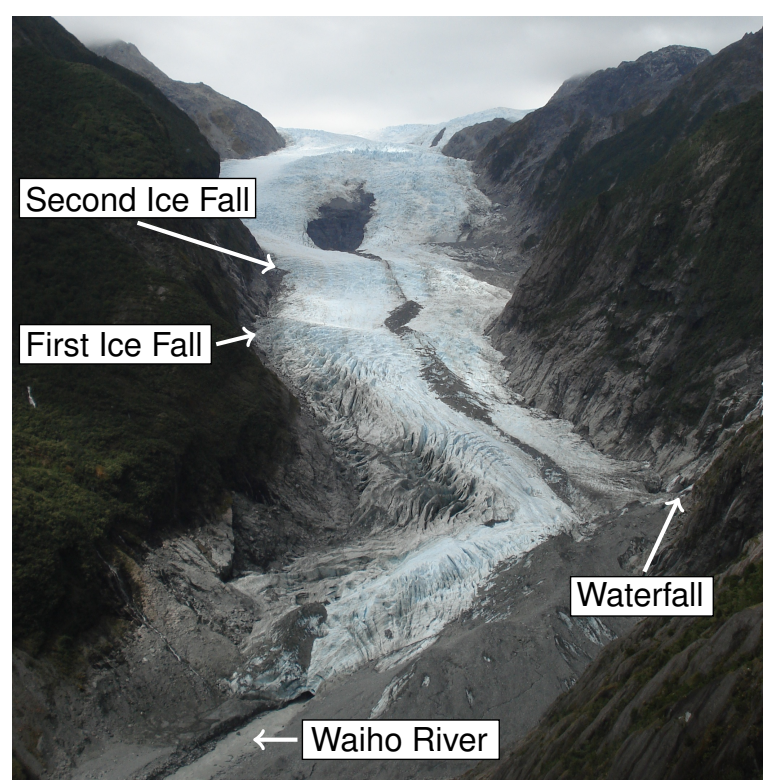

Figure 2.2: Franz Josef Glacier in March 2011. Arrows point to the locations of the waterfall, first and second ice falls, and Waiho River (Figure 2.1). 
Table 2.2: NZTM coordinates, glacier slope angle, debris cover, and ice properties at each installed ablation stake. Four of the 20 stakes (S09, S18-S20) were located on debris-covered ice on the medial moraine.

\begin{tabular}{|c|c|c|c|c|c|}
\hline Stake & NZTM N & NZTM E & Slope & Debris & Surface description \\
\hline S01 & 5184653 & 1372045 & flat & none & blue \& bubble free ice \\
\hline S02 & 5184616 & 1371969 & flat & none & small \& medium crystals \\
\hline S03 & 5184679 & 1371943 & low & none & small \& medium crystals \\
\hline S04 & 5184776 & 1371852 & $\sim 20^{\circ}$ & dispersed sand & $\begin{array}{l}\text { hummocky surface, medium crystals } \\
\text { w/ veins of large crystals }\end{array}$ \\
\hline S05 & 5184808 & 1371900 & $\sim 20^{\circ}$ & dispersed sand & medium crystals, meltwater pools \\
\hline S06 & 5184857 & 1371966 & flat & none & medium crystals \\
\hline S07 & 5184925 & 1371893 & flat & dispersed pebbles & $\begin{array}{llll}\text { small-medium crystals } \mathrm{w} / \text { veins of } \\
\text { large crystals }\end{array}$ \\
\hline S08 & 5185160 & 1371394 & low & none & small \& medium crystals \\
\hline S09 & 5185126 & 1371475 & low & medial moraine & no ice exposed, large rocks and pebbles \\
\hline S10 & 5185230 & 1371446 & low & minimal dust & large crystals, $\sim 30 \%$ blue ice \\
\hline S11 & 5185285 & 1371438 & $\sim 10^{\circ}$ & minimal dust & small crystals w/ veins of large crystals \\
\hline S12 & 5185287 & 1371343 & $\sim 20^{\circ}$ & dust on ridges & $\begin{array}{l}\begin{array}{l}\text { hummocky } \\
\text { drainage }\end{array} \\
\text { surface } \mathrm{w} / \text { meltwater } \\
\end{array}$ \\
\hline S13 & 5185059 & 1371475 & $\sim 30^{\circ}$ & none & medium crystals \\
\hline S14 & 5185218 & 1371300 & $\sim 10^{\circ}$ & dispersed sand & hummocky surface \\
\hline S15 & 5185181 & 1371576 & low & none & $\begin{array}{l}\text { medium crystals, mostly blue ice w/ } \\
\text { white striations }\end{array}$ \\
\hline S16 & 5185020 & 1371664 & steep & none & $\begin{array}{l}\text { partway up crevasse, medium \& small } \\
\text { crystals }\end{array}$ \\
\hline S17 & 5185029 & 1371736 & low & none & large crystals \\
\hline S18 & near G01 & near G01 & $\sim 20^{\circ}$ & medial moraine & $\begin{array}{l}\text { about } \sim 10 \% \text { covered by pebbles and } \\
\text { rocks }\end{array}$ \\
\hline S19 & near G01 & near G01 & $\sim 20^{\circ}$ & medial moraine & about $\sim 80 \%$ covered by pebbles \\
\hline S20 & near G01 & near G01 & $\sim 20^{\circ}$ & medial moraine & no ice exposed, pebbles, rocks, \& mud \\
\hline
\end{tabular}

and physical appearance to collect a wide range of ablation rates. Table 2.2 describes the surface appearance at each stake. Three stakes (S18-S20) were installed in varying sediment cover on the medial moraine to assess the effect of debris cover on ablation rates. This is important because the energy balance model (see Section 2.1.2) does not take debris cover into account when calculating glacier melt. Average spacing between the remaining stakes (S1-S17) was 100-200 m.

To be consistent between ablation measurements, ablation was measured to the nearest centimetre from the top of an ice-axe placed up-glacier of the ablation stake. Lying an ice axe over the surface "smoothed" the centimetre-scale variations in ablation around the stake and provided a more representative ablation rate for that stake. A constant ice density of $917 \mathrm{~kg} \mathrm{~m}^{-3}$ was assumed to convert the measured ablation rates to water equivalent (w.e.) values. This allowed the measured ablation rates to be compared to the modelled ablation rates calculated by the energy balance model. 


\subsubsection{Energy balance model}

To understand ablation rates across the entire glacier, glacier melt is calculated on an hourly timestep using a spatially-distributed energy balance model developed by Anderson and others (2010). The energy balance at the glacier surface is given by:

$$
Q_{m}=I(1-\alpha)+L_{o u t}+L_{i n}+Q_{H}+Q_{E}+Q_{R}+Q_{G},
$$

where $Q_{m}$ is the energy available for melt, $I$ is the incoming shortwave radiation, $\alpha$ is the surface albedo, $L_{\text {out }}$ is the outgoing longwave radiation, $L_{\text {in }}$ is the incoming longwave radiation, $Q_{H}$ is the sensible heat flux, $Q_{E}$ is the latent heat flux, $Q_{R}$ is the heat flux supplied by rain, and $Q_{G}$ is the ground heat flux. Energy fluxes towards the glacier surface are positive and energy fluxes away from the surface are negative. The melt rate, $M$, is then calculated from the available energy:

$$
M=\frac{Q_{m}}{\rho_{w} L_{f}},
$$

where $\rho_{w}$ is the density of water $\left(1000 \mathrm{~kg} \mathrm{~m}^{-3}\right)$ and $L_{f}$ is the latent heat of fusion of ice $\left(3.34 \times 10^{5} \mathrm{~J} \mathrm{~kg}^{-1}\right)$.

The model requires a surface digital elevation model (DEM) and meteorological data, including temperature, precipitation, wind speed, relative humidity, and incoming shortwave radiation. This study uses the most-recent DEM obtained by the Shuttle Radar Topography Mission (SRTM), which was acquired in 2000. It has a resolution of $90 \mathrm{~m}$, which is then resampled to the $100 \mathrm{~m}$ resolution of the energy balance model. Hourly meteorological data are from a climate station run by the New Zealand National Institue for Water and Atmospheric Research (NIWA). The climate station is located in Franz Josef Village, $7 \mathrm{~km}$ north of the glacier $\left(43^{\circ} 21^{\prime} 56^{\prime \prime} \mathrm{S}, 170^{\circ} 8^{\prime} 3.4^{\prime \prime} \mathrm{E}\right.$; Figure 2.1). The temperature record from the village is adjusted for altitude at the glacier, using a mean lapse rate, $d T / d h$, of $-0.005{ }^{\circ} \mathrm{C} \mathrm{m}^{-1}$, which was measured by Anderson and others (2006) between Franz Josef Glacier and the village. Precipitation is interpolated across the glacier using precipitation data from the village and a mean annual precipitation surface developed by Stuart (2011). The precipitation surface is derived from a network 
Table 2.3: Values for the constants in the energy balance model that differ from those in Anderson and others (2010).

\begin{tabular}{crl} 
Constant & Value & Units \\
\hline \hline$d T / d h$ & -0.005 & ${ }^{\circ} \mathrm{C} \mathrm{m}^{-1}$ \\
$z_{\text {ice }}$ & 0.027 & $\mathrm{~m}$ \\
$z_{\text {snow }}$ & 0.0012 & $\mathrm{~m}$
\end{tabular}

of climate stations across the Southern Alps and describes the mean spatial distribution of precipitation from 1971-2000. The model calculates snow accumulation from the precipitation data using a threshold of $1^{\circ} \mathrm{C}$ to differentiate between rain and snow. This value has been used previously in snow modelling studies in New Zealand (e.g., Anderson and others, 2006). The values for relative humidity and windspeed are assumed to be the same at the village and on the glacier.

Using these inputs, the energy balance model is run from April 1, 2010 to March 31, 2011. The following sections are modified from Anderson and others (2010) and describe how the energy fluxes are calculated from the climate data. A list of parameter values can be found in Table 2.3.

\section{Shortwave radiation}

Incoming solar radiation at a given location, $I$, depends on the solar constant, cloudiness, atmospheric composition, and shadowing by surrounding slopes. It includes a direct component, $I_{d i r}$, and a diffuse component, $I_{d i f}$. In complex terrain, diffuse radiation can originate from (1) radiation reflecting off nearby slopes, (2) backscattered radiation from the atmosphere, and (3) radiation initially scattered through the atmosphere, known as "sky radiation" (e.g., Dozier, 1980; Hock, 2005). In this study, diffuse radiation originating from nearby slopes is neglected. The resulting diffuse component can then be described as (Oerlemans, 1992):

$$
I_{d i f}=[0.8-0.65(1-n)] S \sin \left(\frac{\pi}{2}-Z\right),
$$

where $n$ is the cloudiness, $S$ is the solar constant, and $Z$ is the solar zenith angle. The solar constant, which describes the total amount of energy falling at normal 
incidence outside the earth's atmosphere, changes throughout the year as a result of changes in the Earth-Sun distance:

$$
S=1365\left[1+0.034 \cos \left(\frac{2 \pi N}{365}\right)\right]
$$

where $N$ is the day number from 1 January.

The direct component of the incoming shortwave radiation, $I_{d i r}$, is only calculated for unshaded gridcells (Corripio, 2003; Oerlemans, 1992):

$$
I_{\text {dir }}=[0.2+0.65(1-n)] S \cos \theta,
$$

where $\theta$ is the incidence angle between the slope normal and the solar beam given by Garnier (1968):

$$
\cos \theta=\cos \beta \cos Z+\sin \beta \sin Z \cos \left(\varphi_{\text {sun }}-\varphi_{\text {slope }}\right),
$$

where $\beta$ is the slope angle, and $\varphi_{\text {sun }}$ and $\varphi_{\text {slope }}$ are the solar and slope azimuth angles, respectively.

The distribution between direct and diffuse shortwave radiation depends on the cloudiness, $n$, as scattering increases with water vapour in the atmosphere. It is given by (Oerlemans, 1992):

$$
I=t_{a} t_{c}\left(I_{d i f}+I_{d i r}\right),
$$

where $t_{a}$ and $t_{c}$ are the transmissivity of the atmosphere and of the clouds, respectively. Following Oerlemans (1992), these values are approximated as:

$$
t_{a}=(0.79+0.000024 z)\left[1-0.08\left(\frac{\frac{\pi}{2}-\varphi_{\text {sun }}}{\frac{\pi}{2}}\right)\right]
$$

and

$$
t_{c}=1-(0.41-0.000065 z) n-0.37 n^{2}
$$

where $z$ is the surface elevation. To calculate cloudiness, $n$, cloudiness is increased 
from zero until the calculated and measured incoming solar radiation at Franz Josef Village are equal (Arnold and others, 1996).

\section{Albedo}

The magnitude of absorbed incoming shortwave radiation depends largely on the surface albedo (Equation 2.1). The surface albedo at a given location on the glacier, $\alpha$, depends on the snow albedo, ice albedo, and snow depth:

$$
\alpha=\alpha_{\text {snow }}+\left(\alpha_{\text {ice }}+\alpha_{\text {snow }}\right) e^{-\frac{d}{d *}}
$$

where $\alpha_{\text {snow }}$ is the snow albedo, $\alpha_{i c e}$ is the ice albedo (0.34), $d$ is the snow depth in mm water equivalent (w.e.) and $d *$ is the characteristic snow depth scale (11 $\mathrm{mm}$ w.e.). The values for constants were determined for Morteratschgletscher, Switzerland (Oerlemans and Knap, 1998) and match well with experimental results at nearby Brewster Glacier (Anderson and others, 2010).

The snow albedo varies both in space and time due to differences in sediment concentration, crystal structure, and solar elevation (e.g., Wiscombe and Warren, 1980; Warren, 1982). Although local variations in sediment cover are important for understanding differences in ablation over short distances, debris cover is neglected in this study. Snow crystal structure changes with time, and as a result many albedo models parameterise snow albedo as a function of time. Snow albedo is calculated following the methods of Oerlemans and Knap (1998), in which snow albedo is dependent on the time since the last snowfall event:

$$
\alpha_{\text {snow }}=\alpha_{\text {firn }}+\left(\alpha_{\text {frsnow }}+\alpha_{\text {firn }}\right) e^{\frac{s}{t *}},
$$

where $\alpha_{\text {firn }}$ is the firn albedo (0.53), $\alpha_{\text {frsnow }}$ is the fresh snow albedo (0.9), $s$ is the time since the last snowfall event (days), and $t *$ is a timescale (21.9 days) that determines how quickly the snow albedo decreases after a snowfall event. 


\section{Longwave radiation}

The Stefan-Boltzmann law describes the longwave radiation emitted from a blackbody:

$$
L=\epsilon \sigma T^{4}
$$

where $L$ is the longwave radiation, $\epsilon$ is the emissivity, $\sigma$ is the Stefan-Boltzmann constant $\left(5.6704 \times 10^{-8} \mathrm{~W} \mathrm{~m}^{-2} \mathrm{~K}^{-4}\right)$, and $\mathrm{T}$ is the absolute temperature of the object. Outgoing longwave radiation from the glacier, $L_{\text {out }}$, is constant $\left(317 \mathrm{~W} \mathrm{~m}^{-2}\right)$, assuming the glacier surface is at the melting point and the emissivity of snow is 1 .

Incoming longwave radiation, $L_{i n}$, is emitted by the atmosphere and the surrounding terrain. The partitioning between these sources is dependent on the sky viewfield, $v$, defined as the fraction of unobstructed sky at each gridcell (Corripio, 2003):

$$
L_{i n}=\epsilon_{e f f} \sigma T_{a}^{4} v+\epsilon_{t} \sigma T_{t}^{4}(1-v)
$$

where the first term describes the longwave radiation from the atmosphere and the second term describes the contribution from the terrain. Here $\epsilon_{\text {eff }}$ is the effective atmospheric emissivity, $T_{a}$ is the air temperature, and $\epsilon_{t}$ is the terrain emissivity (0.4; Plummer and Phillips, 2003). The terrain temperature, $T_{t}$, is set to atmospheric temperature for terrain that is not covered by snow or ice and to 273 $\mathrm{K}$ for terrain that is ice- or snow-covered. The effective atmospheric emissivity, $\epsilon_{e f f}$, is given by Konzelmann and others (1994):

$$
\epsilon_{e f f}=\epsilon_{c}\left(1-n^{p}\right)+\epsilon_{o c} n^{p}
$$

where the clear-sky emissivity, $\epsilon_{c}$, is

$$
\epsilon_{c}=0.23+0.484\left(\frac{e_{a}}{T_{a}}\right)^{\frac{1}{8}}
$$

The term $n$ is the cloudiness, $\epsilon_{o c}$ is the emissivity of an overcast sky (0.924), and $e_{a}$ is the vapour pressure.. The exponent, $p=1$, is used following experimental re- 
sults at nearby Brewster Glacier (Anderson and others, 2010). Brewster Glacier is also located on the West Coast of New Zealand and therefore experiences similar atmospheric conditions to Franz Josef Glacier.

\section{Turbulent heat fluxes}

The turbulent heat fluxes, $Q_{H}$ (sensible heat) and $Q_{E}$ (latent heat), are caused by temperature and moisture gradients between the glacier surface and overlying air and by the wind (Brutsaert, 1982). In this study, the parameterisation of Oke (1987) is used:

$$
\begin{gathered}
Q_{H}=\rho c_{p} k_{H} U\left(T_{a}-T_{s}\right), \\
Q_{E}=0.622 \rho k_{E} U L_{v} \frac{q-q_{s}}{p},
\end{gathered}
$$

where $\rho$ is the air density, $c_{p}$ is the specific heat capacity of air, $k_{H}$ and $k_{E}$ are the exchange coefficients, $U$ is the wind speed at $2 \mathrm{~m}$ above the surface, $T_{s}$ is the surface temperature, $L_{v}$ is the latent heat of vaporisation $\left(2.3 \times 10^{6} \mathrm{~J} \mathrm{Kg}^{-1}\right), q$ is the vapour pressure of the air, $q_{s}$ is the vapour pressure of air at the glacier surface, and $p$ is the air pressure. The glacier surface temperature, $T_{s}$, is assumed to be $0{ }^{\circ} \mathrm{C}$. The exchange coefficients for sensible and latent heat, $k_{H}$ and $k_{E}$, determine the effectiveness of the heat transfer and relate the turbulent flux to the temperature and wind speed gradients. They depend on the roughness length for momentum, $z_{0}$, roughness length for temperature, $z_{0 H}$, roughness length for water vapour, $z_{O E}$, and the atmospheric stability. The atmospheric stability is calculated after Oke (1987):

$$
\begin{aligned}
k_{H} & =\frac{k_{0}^{2}}{\log \frac{z}{z_{0}} \log \frac{z}{z_{0 H}}}\left(1-5.2 R_{b}\right)^{2}, \\
k_{E} & =\frac{k_{0}^{2}}{\log \frac{z}{z_{0}} \log \frac{z}{z_{0 E}}}\left(1-5.2 R_{b}\right)^{2},
\end{aligned}
$$

where $k_{0}$ is von Kármàn's constant $(0.4), z$ is the measurement height $(2 \mathrm{~m}$ above the surface), and $R_{b}$ is the Richardson stability criterion. The stability correction term in Equation $2.18\left(\left(1-5.2 R_{b}\right)^{2}\right)$ is only used for stable stratification $(R b<0)$. When $R_{b}>0$ or $U<1$, the stability correction term is removed. Unreasonably 
high bulk Richardson numbers can occur when wind speeds are low $(U<1)$, which in Oke's model, lead to the disappearance of turbulence and to a decoupling of the snow surface from the atmosphere above (Oke, 1987). The Richardson stability number, $R_{b}$, is given by:

$$
R_{b}=\frac{g}{T_{a}} \frac{\left(T_{a}-T_{s}\right)\left(z-z_{0}\right)}{U^{2}}
$$

where $g$ is the acceleration due to gravity $\left(9.81 \mathrm{~m} \mathrm{~s}^{-2}\right)$. The model assumes a constant roughness length for momentum, temperature, and water vapour, which varies over snow and ice (Anderson and others, 2010). The roughness length for snow, $z_{\text {snow }}$, is set to 0.0012 after Anderson and others (2010) on Brewster Glacier. The roughness length for ice, $z_{i c e}$, is tuned to $0.027 \mathrm{~m}$ to minimise the difference between modelled and measured ablation rates by Brian Anderson from 20102011.

\section{Rainfall heat flux}

Assuming the rain and air temperatures are the same, the rainfall heat flux, $Q_{R}$, is given by:

$$
Q_{R}=c_{W} P T_{a}
$$

where $c_{W}$ is the specific heat of water $\left(4.186 \mathrm{~J} \mathrm{~g}^{-1}{ }^{\circ} \mathrm{C}\right)$ and $P$ is the rate of rainfall $\left(\mathrm{m} \mathrm{h}^{-1}\right)$.

\section{Ground heat flux}

The ground heat flux is the heat flux from the glacier surface to depth. It is difficult to calculate as it depends on the available subsurface energy and the temperature profile within the glacier, which are usually not known. In this model, it is assumed that the glacier remains at $0{ }^{\circ} \mathrm{C}$, which is a reasonable approximation for a temperate mountain glacier (Oerlemans, 1992). The ground heat flux, $Q_{G}$, is then set to $1 \mathrm{~W} \mathrm{~m}^{-2}$ (Neale and Fitzharris, 1997; Anderson and others, 2010). 


\subsubsection{Discharge model}

Discharge is calculated from the modelled glacier melt using a linear-reservoir model (Baker and others, 1982; Hock and Noetzli, 1997). This model is not spatiallydistributed. The glacier is split into three reservoirs: snow, firn, and ice. The snow reservoir encompasses all water inputs above $2000 \mathrm{~m}$, the firn reservoir includes water inputs between $1800 \mathrm{~m}$ and $2000 \mathrm{~m}$, and the ice reservoir includes water inputs below $1800 \mathrm{~m}$ as well as all inputs off the glacier (Anderson and others (2010)). The water that enters each reservoir is a combination of the modelled ice melt, seasonal snow melt, and precipitation within the catchment (Figure 2.3). The rate of change of each reservoir's volume is given by:

$$
\frac{d V}{d t}=R(t)-D(t)
$$

where $R(t)$ is the rate of water flowing into the reservoir. The discharge at the glacier terminus, $D(t)$, is proportional to the reservoir's volume, $V(t)$, at time $t$ :

$$
D(t)=k_{s} V(t)
$$

where $k_{s}$ is the storage constant. Each reservoir has a different storage constant, with $k_{\text {snow }}=350, k_{\text {firn }}=30$, and $k_{\text {ice }}=16$, following values tuned at Storglaciären (Hock and Noetzli, 1997) and at nearby Brewster Glacier (Anderson and others, 2010). As discharge was not measured during the study period, it is not possible to tune these values to the Franz Josef Glacier. Consequently, the storage constants used in this study may not be correct for the Franz Josef Glacier, although Hock and Noetzli (1997) suggested that the discharge model may be relatively insensitive to the chosen storage constants (see Section 4.1.1). Combining the above equations and solving for discharge leads to:

$$
D\left(t_{2}\right)=D\left(t_{1}\right) e^{-\frac{1}{k_{s}}}+R\left(t_{2}\right)-R\left(t_{2}\right) e^{-\frac{1}{k_{s}}}
$$

The resulting discharge curve is qualitatively compared to stage data recorded by a sonic ranger at the Waiho Bridge, which is $6 \mathrm{~km}$ downstream from the Franz 


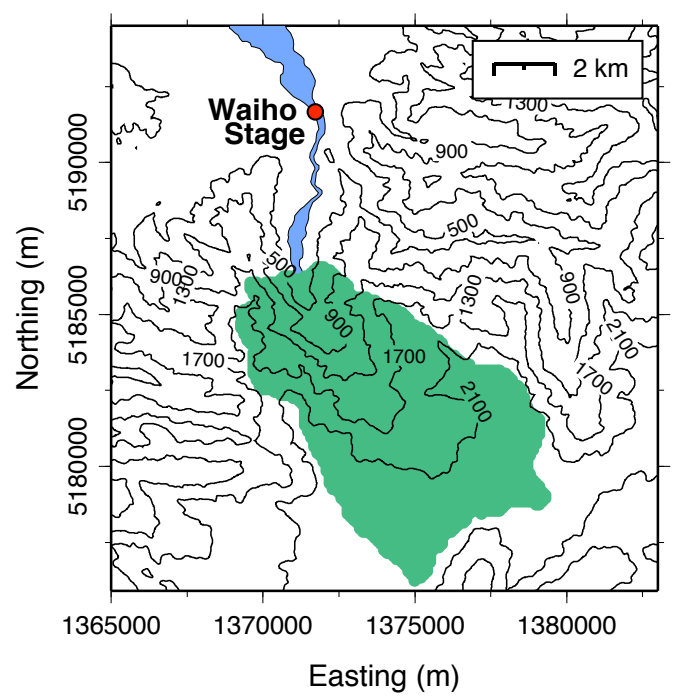

Figure 2.3: Franz Josef Catchment used in the discharge modelling. River stage was recorded at the Waiho Bridge, $6 \mathrm{~km}$ downstream from the glacier terminus.

Josef Glacier (Figure 2.3). Stage is recorded at this location to monitor flooding events, and Stefan Beaumont from the West Coast Regional Council provided the data for this study. Discharge values cannot be calculated from the stage data as stream velocity and bed geometry are not known. Furthermore, the Waiho River is a braided river, and the location and bed geometry of the major channels can change quickly (Davies, 1997). Modelled discharge values are used only qualitatively in this study.

\subsection{Ice-flow velocities}

To determine the spatial and temporal variations in glacier flow, six GPS stations were installed on the lower glacier. Repeat point measurements were also taken at 11 ablation stakes to improve the spatial resolution of the velocity measurements.

\subsubsection{Field methods}

\section{GPS stations}

Six GPS stations (1 Trimble 5700 and 5 Trimble Net RS units; G01-G06) were installed on the lower glacier on March 3-4 and removed from the glacier on 


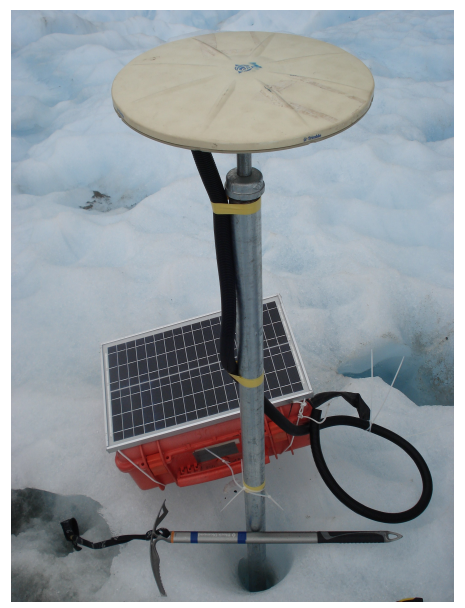

Figure 2.4: Each GPS station included a zephyr antenna, solar panel, 2-m-long metal pole, and GPS receiver (in the orange box). The ice axe is for scale.

March 19, 2011 (Figure 2.1 and Table 2.1). To capture the small-scale spatial variations in glacier flow, GPS stations were positioned 1-2 ice thicknesses apart (Truffer, 2004; Gudmundsson and Raymond, 2008). Four of the stations (G01-G04) formed a grid below the first ice fall with an average spacing of $150 \mathrm{~m}$ (Figures 2.1 and 2.2). The remaining two stations (G05-G06) were installed roughly along centerline above the first ice fall, with a spacing of $200 \mathrm{~m}$.

Each GPS station included a 33 AH battery, 20 W solar panel, solar controller, GPS receiver, and zephyr antenna installed on a 2-m-long metal pole that extended about $0.5-1.0 \mathrm{~m}$ above the glacier surface (Figure 2.4). Due to the high ablation rates on the Franz Josef Glacier, the metal pole had to be re-drilled at all stations on March 10. The stations recorded position every 15 seconds.

A GPS base station (G07) was also installed on Teichelmanns Rock, a vegetated rock outcrop about $1.5 \mathrm{~km}$ down-valley from the glacier terminus. The addition of a base station permitted a double-differencing (DD) algorithm to be utilised during GPS processing (see Section 2.2.2). Unfortunately, it was later discovered that the satellite coverage at Teichelmanns Rock was poor (typically 4-6 satellites) and that processing the kinematic stations against a GeoNet station on the 11-km-distant Mt. Price (MTP) provided better results. The GPS station on Mt. Price recorded position every 30 seconds, so the GPS units on the glacier had to be down-sampled to that rate.

On March 9, the GPS stations started to turn off due to low battery voltage, as 


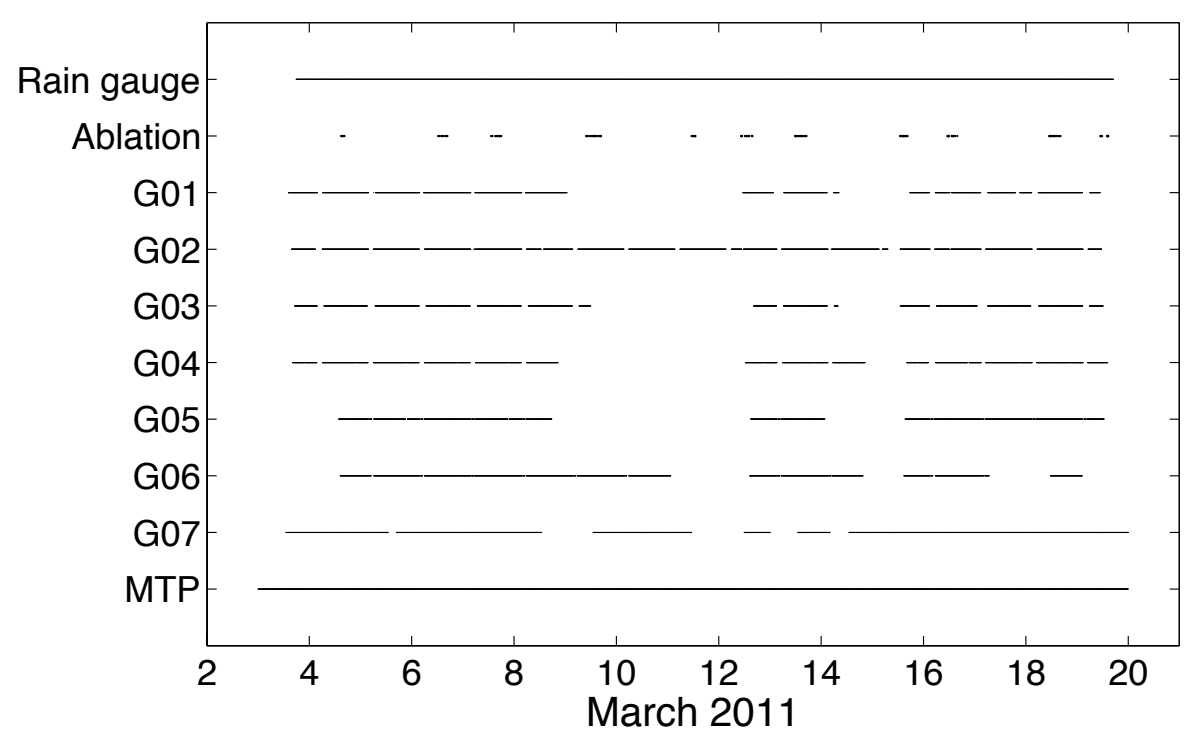

Figure 2.5: Temporal overview of instrument data collection. The GPS stations (G01-G07) shut down at various times due to low battery voltage. The dashed appearance of G01-G04 is a result of the satellite coverage dropping to 3 satellites from 03:00-05:00 each day; consequently, position estimates cannot be determined during that time. Ablation rates were recorded every 1-2 days.

the solar panels were not providing adequate power to recharge the batteries. On March 15-16, batteries were replaced at five of the stations (G01-G05) and an additional solar panel was installed at the remaining station (G06). After this point, all stations, except G06, recorded data for the rest of the study period. Figure 2.5 shows when the various instruments, including the GPS stations, collected usable data.

\section{Repeat stake location measurements}

To supplement the GPS stations, stake locations were recorded with a Trimble GNSS handheld GPS unit at 11 of the 20 ablation stakes every 2-4 days (Figure 2.1). The stake locations were chosen to increase the spatial coverage and resolution of the background velocity and strain rate datasets. The sampling rate was $1 \mathrm{~Hz}$. Stake occupations during the point measurement readings ranged from 10-20 minutes depending on the reported satellite coverage from the Trimble GNSS unit. 


\subsubsection{GPS processing}

\section{GPS stations}

The kinematic GPS data are processed with TRACK (version 1.24; Chen, 1998), the kinematic module of the GAMIT/GLOBK software package (King and Bock, 2010). TRACK uses a DD approach to determine the integer phase ambiguity at each epoch. The phase ambiguity, which is a multiple of the carrier phase, must be resolved to a new integer value after every cycle slip. TRACK calculates initial ambiguity estimates using the Melbourne-Wubena Wide Lane (MW-WL; Melbourne, 1985; Wubbena, 1985), which determines the difference between the L1 and L2 phases. These estimates do not have to be integer values. Integer ambiguities are then resolved through a "relative rank" algorithm, which compares the "best" and "next best" choices for the integer phase ambiguity based on their "chi-squared" values. The chi-squared value depends on (1) the match of the ionosphere-linear combination (LC) to the estimated value, (2) the match of the MW-WL to the average MW-WL value, and (3) the closeness of the ionospheric delay to zero. If the difference in chi-squared values between the two choices is large, then the ambiguity is resolved to the best choice integer. TRACK then applies a Kalman smoothing filter to the position estimates.

There are several ways to improve the results from TRACK, including estimating a priori coordinates for the base and kinematic stations before processing. Base station coordinates are calculated using a precise point positioning (PPP) algorithm implemented by NASA's online Automatic Precise Positioning Service (APPS), which uses the GIPSY /OASIS software (version 5; Zumberge and others, 1997). Rough, initial coordinates for the kinematic receivers are estimated with a module in GLOBK that calculates point position using GPS code range data. These rough estimates are iterated to more precise coordinates with subsequent runs of TRACK.

The kinematic stations are then processed with the estimated locations, LC combinations, and precise ephemerides provided by the International GPS Service. GPS motion is loosely constrained in the east, north, and vertical directions 


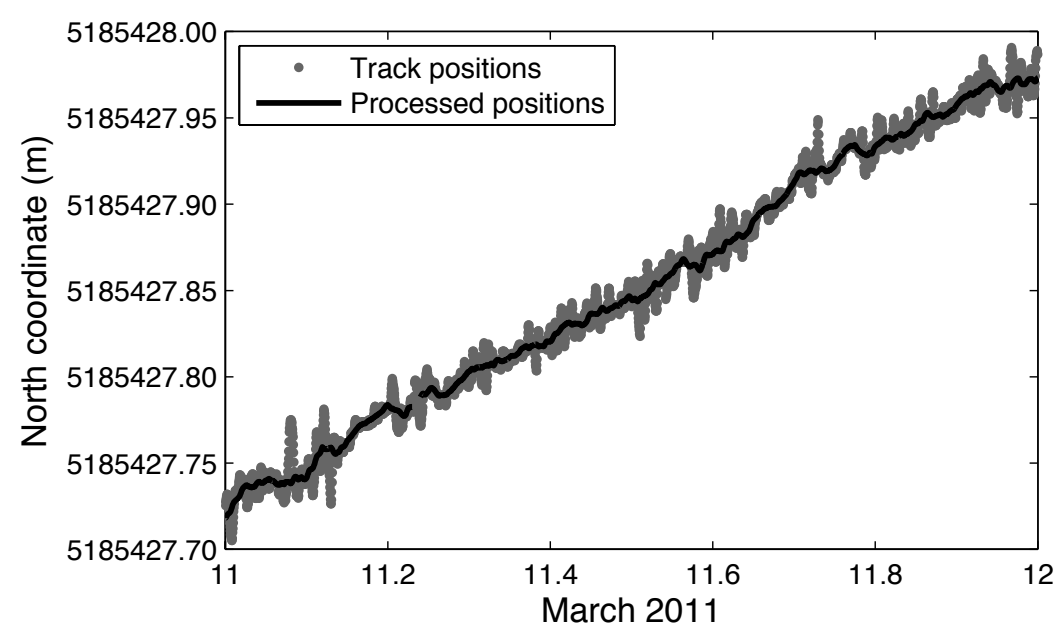

Figure 2.6: GPS position estimates in the north coordinate at GPS station G02 before (grey dots) and after post-processing (black line) on March 11, 2011.

at $1 \mathrm{~cm}$ per epoch $\left(28.8 \mathrm{~m} \mathrm{~d}^{-1}\right)$, which is an order of magnitude greater than the glacier motion at these sites. Even after processing, some of the carrier phase ambiguities remain unresolved. If phase ambiguities are not resolved due to insufficient rank but appear accurate as a result of ionospheric delay and position values, those integer phase ambiguities are resolved manually. Unresolved integer phase ambiguities that cannot be fixed through this process are left unresolved and are not removed from the dataset. As the satellite coverage at Franz Josef Glacier is already poor, removing satellites with unfixed phase ambiguities decreases the time span of calculated positions at each GPS station. Unresolved phase ambiguities are infrequent, but when they do occur, they increase the position uncertainty at that time. These increased uncertainties are accounted for in the error estimates (see Section 2.2.3).

After processing, TRACK RMS errors are less than $20 \mathrm{~mm}$, suggesting a robust solution (Tom Herring, personal communication). TRACK provides the processed coordinates in WGS84, which are then projected into the New Zealand Transverse Mercator (NZTM) coordinate system. Spikes in the estimated coordinates that deviate more than two standard deviations from an one-hour running mean are removed from the data. Finally, the data are smoothed with a 30-minute running mean and any remaining spikes are removed manually. Figure 2.6 shows the position estimates before and after this process. 
To calculate velocities, the GPS station is assumed static over 10 minutes (20 position estimates) and a mean position is calculated for that time. A best linear least-squares fit is then determined for six hours of "static" locations. The slope of this fit is the velocity. Through this process, ice-flow velocities are calculated every 10 minutes. Velocities are averaged over six hours to eliminate high frequency noise from the velocity timeseries and highlight the more prominent trends in the velocity record. Strain rates are calculated from the velocity rates using SSPX, a software package often used to calculate strain rates in geology (Cardozo and Allmendinger, 2009). Section 2.2.3 describes how the velocity and strain rate uncertainties are estimated.

\section{Repeat stake measurements}

Stake positions are processed statically using NASA's APPS, which, as previously mentioned, implements a precise point positioning (PPP) algorithm. PPP, as compared to DD, does not require a nearby base station. As a result, PPP cannot achieve the same accuracy in position solutions as DD, but it can still provide position solutions at centimetre to decimetre level by utilising post-processed precise GPS satellite orbits and clock data (Zumberge and others, 1997).

To calculate the average velocity from the position estimates at a given stake, the best linear least-squares fit is determined for the position estimates. The slope of the fit is the velocity. This technique is also used to determine velocities at the GPS stations (see previous section). The error for the calculated velocity is the error of the fitted gradient (e.g., Taylor, 1997).

\subsubsection{Uncertainty estimates at the GPS stations}

Although TRACK provides position uncertainty estimates, these estimates are often considered unreliable as the reported uncertainties are relative to the assumed data noise limits in the L1 and L2 phases and the P1 and P2 ranges (Herring, 2006). The provided estimates are usually within a factor of two of real uncertainties (Herring, 2006). It is therefore important to develop independent assessments of uncertainty. 
This study determines uncertainties through two different methods. First, position uncertainties are estimated through processing the stationary rock station on Teichelmanns Rock (G07) as a kinematic station following the same methodology as was applied to the stations on the glacier. As this station is not moving, any deviations from its mean coordinates indicate measurement or processing error. Here these deviations are called "anomalies." The uncertainties on the glacier and at the rock site should be similar as the separation between these sites is 1-2 km. Consequently, both sites are subject to a similar ionosphere and satellite configuration throughout the day. In particular, when phase ambiguities cannot be resolved on the glacier, they frequently also cannot be resolved at G07.

Position uncertainties at G07 are calculated as one standard deviation of the coordinate anomalies in the east, north, and vertical directions. Figure 2.7 shows this process for one six-hour period on March 7. The velocity uncertainty is twice the position uncertainty for the six-hour period. When G07 is not operational, the mean position uncertainty is used as the position uncertainty at that time. Mean position uncertainty values for the east, north, and vertical coordinates are $0.7 \mathrm{~cm}, 0.9 \mathrm{~cm}$, and $2.4 \mathrm{~cm}$, respectively. TRACK reports slightly larger mean uncertainties at G07 of $1.0 \mathrm{~cm}, 1.1 \mathrm{~cm}$, and $2.4 \mathrm{~cm}$.

The second method assumes that the velocity uncertainty is equal to the uncertainty of the fitted gradient. As ice-flow velocities are calculated based on a linear-least-squares best fit to position estimates over a six-hour period, these data can be used to calculate a gradient uncertainty. This method is also used to estimate velocity uncertainties at the ablation stakes (Section 2.2.2). Figure 2.8 compares result from the "G07" and "gradient" methods. In general, estimated velocity uncertainties from the G07 method are greater than those determined by the gradient method. At G02, mean uncertainties derived from the G07 method are $2.0 \mathrm{~cm} \mathrm{~d}^{-1}, 2.3 \mathrm{~cm} \mathrm{~d}^{-1}$, and $5.2 \mathrm{~cm} \mathrm{~d}^{-1}$ in the east, north, and vertical coordinates. These values drop to $0.7 \mathrm{~cm} \mathrm{~d}^{-1}, 0.9 \mathrm{~cm} \mathrm{~d}^{-1}$, and $2.3 \mathrm{~cm} \mathrm{~d}^{-1}$ when the gradient method is used. At times, gradient estimates do exceed those predicted by G07. In particular, gradient estimates are much greater in the east direction at G01 and G03 (Figure 2.8). This is likely due to differences in the sky-view be- 


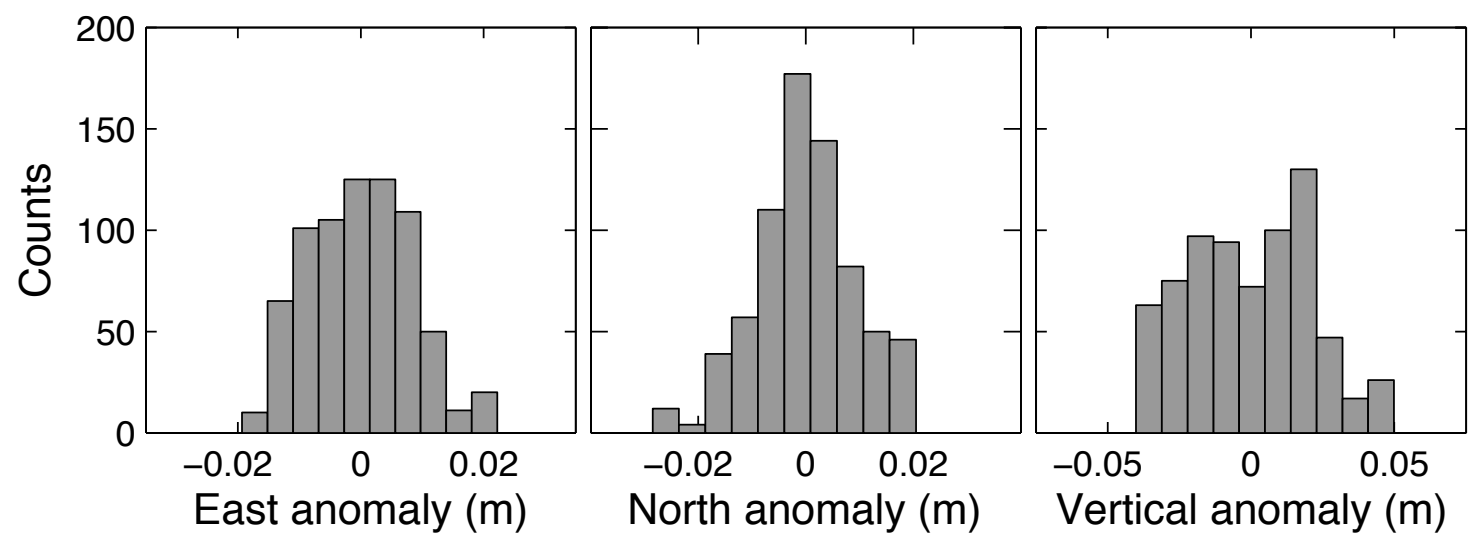

Figure 2.7: Coordinate anomalies at G07 for one six-hour period (12:00 to 18:00 on March 7). Position uncertainties over the six-hour period are estimated as one standard deviation of the coordinate anomalies. For the displayed data, this is equal to position uncertainties of $0.8 \mathrm{~cm}, 0.9 \mathrm{~cm}$, and $2.1 \mathrm{~cm}$ in the east, north, and vertical coordinates. Velocity uncertainties for the six-hour period are twice those values.

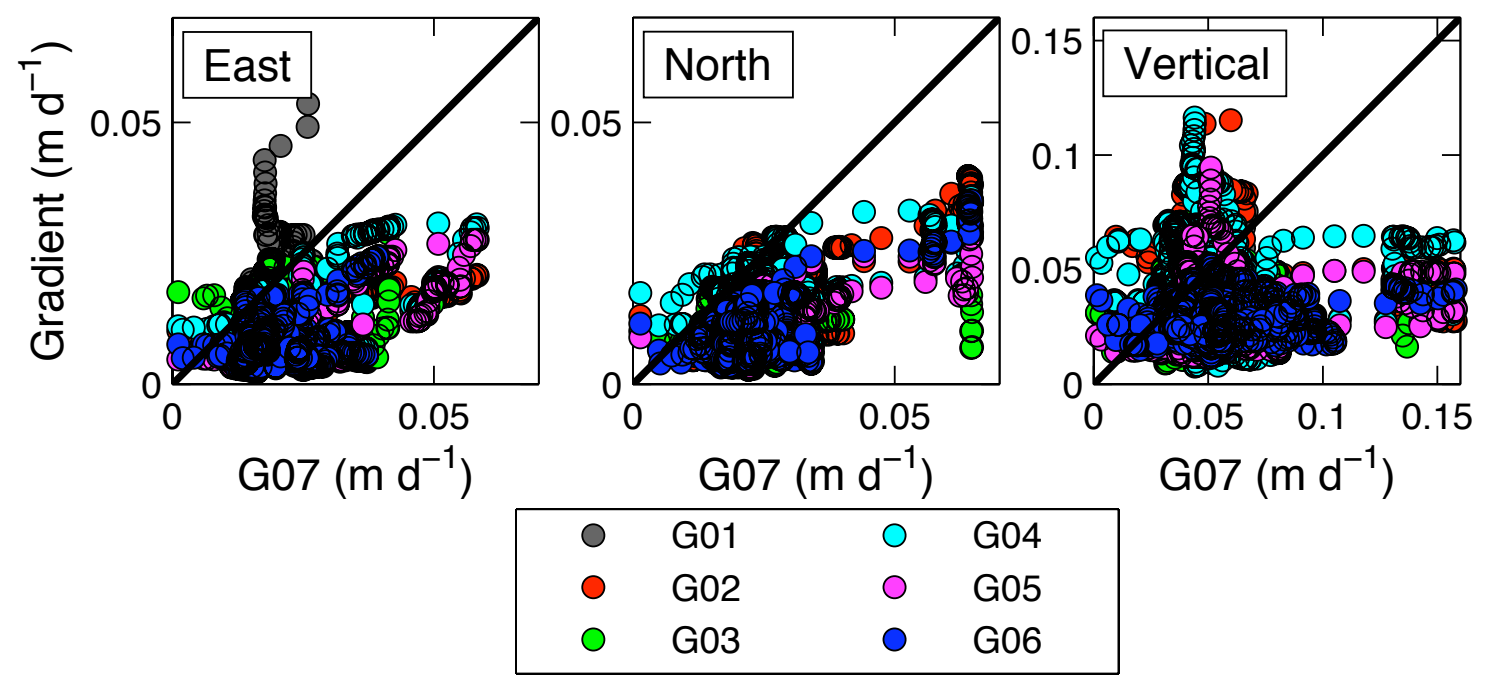

Figure 2.8: Velocity uncertainty estimates in the east, north, and vertical directions as determined through the "G07" and "gradient" methods. The colour of the dot signifies the GPS unit and the black lines denote a 1:1 ratio between the two methods. In general, estimated uncertainties from the gradient method are less than the values estimated by G07. However, the gradient estimates are significantly greater than G07 estimates at GPS stations G01 and G03 in the east direction. 

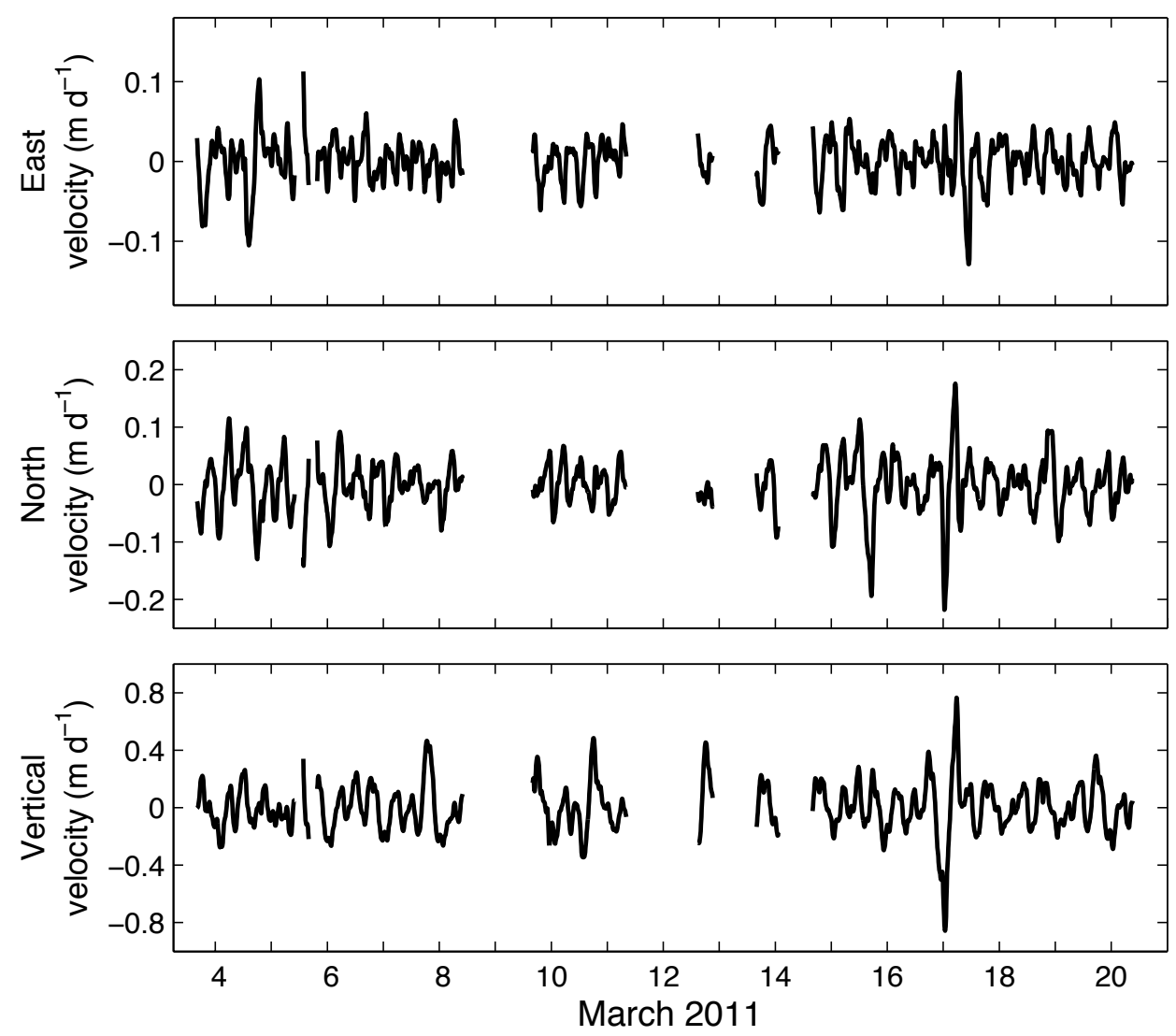

Figure 2.9: East, north, and vertical ice-flow velocities at G07. As this station is stationary, any deviations from its known location indicate processing error. The velocity uncertainties on the glacier are estimated from the position uncertainties at this site.

tween these stations on the glacier and Teichelmanns Rock, as G01 and G03 are less than $100 \mathrm{~m}$ to the east of a steep valley wall (Figure 2.1).

TRACK, the G07 method, and the gradient method report similar uncertainty estimates. As the G07 method provides in-situ measurements of uncertainty, this study reports those estimates. All reported uncertainty estimates are one-sigma standard deviations, unless stated otherwise. Uncertainty estimates for glacier speed and strain rate are determined through a formal error propagation (e.g., Taylor, 1997).

At times, velocity uncertainties are larger than those reported. This occurs when the position values at G07 are not normally distributed. These events can be detected in the calculated velocities at G07 (Figure 2.9). When large velocity variations at G07 coincide with large velocity variations on the glacier (e.g., on 
March 4), those velocity variations are not considered in explaining glacier dynamics. The large velocity variations likely result from poorly resolved integer ambiguities.

\subsection{Finite element glacier model}

To understand the link between surface velocity variations, water inputs, and processes at the glacier bed, the surface velocity measurements are compared to surface velocities calculated with a flowline model that incorporates both internal deformation and basal sliding. The applied friction law at the glacier bed depends on the subglacial water pressure (Schoof, 2005; Gagliardini and others, 2007), and as a result, this value can be adjusted to reproduce the measured surface velocities. The aim is to infer spatial and temporal variations in the subglacial water pressure from the velocity measurements. Several recent studies (e.g., JayAllemand and others, 2011; Flowers and others, 2011) have used this technique to understand changes in the subglacial water pressure during glacier surges.

\subsubsection{Governing equations}

The model runs in a Cartesian coordinate system, with $x$ as the horizontal direction and $z$ as the vertical direction. Glacier geomety is defined by the glacier surface $z_{s}(x)$ and bedrock $z_{b}(x)$ topographies (see Section 2.3.3). The flowline model solves the full Stokes equations using the finite element (FE) method, implemented in the open-source FE package Elmer (version 6.2). Mass and momentum are conserved, and inertia is neglected over the domain $z_{b} \leq z \leq z_{s}$ :

$$
\begin{gathered}
\nabla \cdot \vec{u}=0, \\
\nabla \cdot \vec{\sigma}+\rho \vec{g}+\vec{f}=0,
\end{gathered}
$$

where $\vec{u}=\left(u_{x}, 0, u_{z}\right)$ is the velocity vector, $\vec{\sigma}$ is the stress tensor, $\rho$ is the ice density, and $\vec{g}=(0,0,-g)$ is the gravity vector. The body force $\vec{f}$ accounts for lateral drag along the valley walls of a three-dimensional glacier in the flowline model (Jay- 


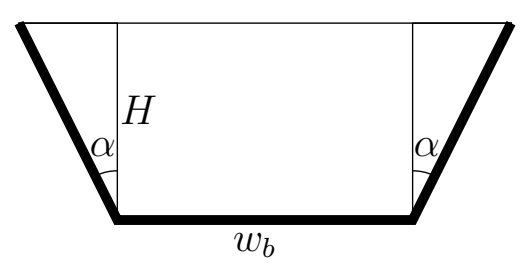

Figure 2.10: A trapezoidal geometry is used for the glacier cross section. The geometry is defined by the glacier height $H$, valley floor width $w_{b}$, and valley slope angle $\alpha$. The wetted perimeter, $P$, is the perimeter in bold.

Allemand and others, 2011):

$$
\vec{f}=-\rho \vec{g} \cdot \vec{t}_{s}(1-F) \vec{t}_{s}
$$

where $\vec{t}_{s}$ is the unit vector tangent to the glacier surface. The shape factor, $F=$ $F(x)$, depends on glacier geometry and varies with distance along the flowline:

$$
F(x)=\frac{S}{P H}
$$

where $S$ is the glacier cross-sectional area, $P$ is the glacier perimeter in contact with the bedrock (the "wetted" perimeter), and $H$ is the glacier height (Paterson, 1994). For an infinitely-wide glacier, the shape factor is 1 and the body force $\vec{f}$ is $(0,0,0)$ Newton, indicating that valley wall drag is negligible in this scenario (Equation 2.26). A narrow valley glacier, such as the Franz Josef Glacier, will have a much lower shape factor, and as a result lateral drag will be increased.

To estimate the shape factor, the glacier cross section is modelled as a trapezium (Figure 2.10). The side slope angle $\alpha$ and valley floor width $w_{b}$ are taken from Anderson (2004). Figure 2.11 shows the value of the shape factor along the flowline.

The rheology of ice can be described by Glen's flow law (Glen, 1955), which relates the strain rate tensor, $\overrightarrow{\dot{\epsilon}}$, to the deviatoric stress tensor, $\vec{\tau}$ :

$$
\overrightarrow{\dot{\epsilon}}=A \tau_{e}^{n-1} \vec{\tau}
$$

where $A$ is the flow law parameter, $n$ is the flow law exponent (usually set to 3 ), 


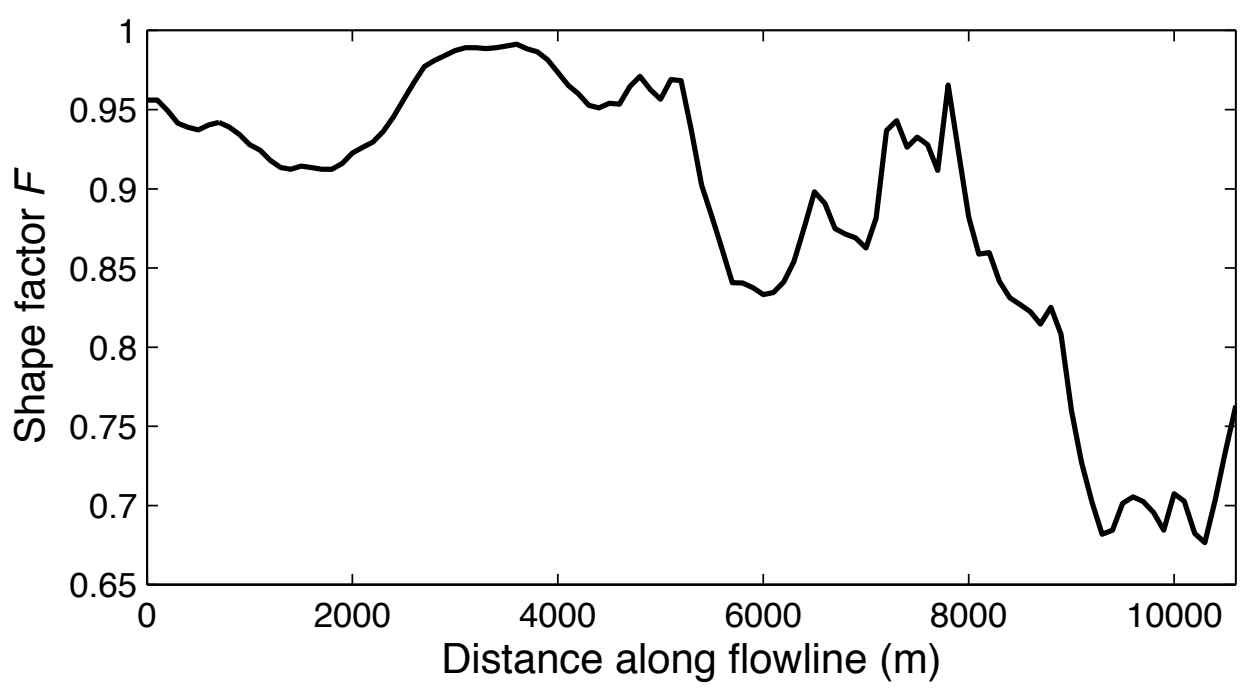

Figure 2.11: Shape factor $F$ along the glacier flowline. The shape factor is calculated using Equation 2.27 and the cross-sectional bed geometry shown in Figure 2.10.

and $\tau_{e}$ is the second invariant of the deviatoric stress tensor,

$$
\tau_{e}^{2}=\frac{\tau_{i j} \tau_{i j}}{2}
$$

The flow law parameter, $A$, depends on the crystal orientation, water content, and ice temperature through an Arrhenius relationship. As the Franz Josef Glacier is a temperate glacier, a value recommended for temperate ice $\left(A=2.4 \times 10^{-24} \mathrm{~Pa}^{-3}\right.$ $\mathrm{s}^{-1}$ ) is used in this study (Cuffey and Paterson, 2010).

\subsubsection{Boundary conditions}

The glacier surface is treated as a stress-free surface (e.g., Blatter, 1995):

$$
\vec{\sigma} \cdot \vec{n}_{s}=0 \quad \text { for } \quad z=z_{s}
$$

where $\vec{n}_{s}$ is the unit vector normal to the glacier surface.

At the glacier bed, a non-linear friction law is applied (Schoof, 2005; Gagliardini and others, 2007). This law depends on the subglacial water pressure and bedrock geometry. The benefit of this friction law over other friction laws (e.g., Weertman, 1957; Budd and others, 1979) is that it fulfils Iken's bound (Iken, 1981). 
In other words, the quantity $\tau_{b} / N$ reaches a maximum that depends only on the maximum positive slope of the glacier bed, $m_{\max }$, over a metre to decimetre scale. The value of $m_{\max }$ determines the subglacial water pressure necessary to drown obstacles at the bed and thereby increase basal drag at areas still in contact with the bedrock (Schoof, 2005). Assuming the post-peak exponent is equal to 1 in Gagliardini and others (2007),

$$
\frac{\tau_{b}}{N}=C\left(\frac{u_{b}^{(1-n)}}{C^{n} N^{n} A_{s}+u_{b}}\right)^{1 / n} u_{b} \quad \text { for } \quad z=z_{b}
$$

where $\tau_{b}$ is the basal drag, $u_{b}$ is the sliding velocity, $n$ is the flow law exponent, the constant $C$ is less than the maximum positive bedrock slope $\left(m_{\max }\right), A_{s}$ is the sliding parameter in the absence of cavitation, and $N$ is the basal effective pressure:

$$
N=\rho g H-P_{w}
$$

where $\rho$ is the density of ice, $g$ is the acceleration due to gravity, $H$ is the height of the ice column, and $P_{w}$ is the subglacial water pressure.

There are three unknowns $\left(A_{s}, C\right.$, and $\left.P_{w}\right)$ in Equations 2.31-2.32. The terms $C$ and $A_{s}$ vary spatially across the glacier bed but do not vary with time (Gagliardini and others, 2007). As a result, temporal changes in the sliding speed at a given location indicate changes in the subglacial water pressure. Section 3.3.1 describes how these values are estimated and the results of the flowline modelling. All simulations are run until steady state, and each time-step is simulated separately in the measured velocities.

\subsubsection{Glacier geometry and mesh}

The glacier model uses a flowline determined by Anderson (2004) for the Franz Josef Glacier (Figure 2.12). Although the study site covers only a small portion of the flowline model (Figure 2.12), the entire glacier is simulated to replicate the stresses and mass flux at the top of the study site. A mesh of the glacier geometry is generated using the open-source meshing tool Gmsh (version 2.5; Geuzaine and Remacle, 2009). The mesh is divided into Delaunay triangles, with 
a spacing of roughly $10 \mathrm{~m}$ between nodes. Glacier surface and bed elevations are determined every $100 \mathrm{~m}$ along the flowline.

To determine the glacier surface profile in 2011, elevation measurements taken during the field campaign in March 2011 are combined with the most recent DEM produced by the Shuttle Radar Topography Mission in 2000 (Figure 2.13). Ideally, only the in-situ measurements would be used, but these measurements cover only a small portion of the glacier surface. The SRTM data are offset by the difference between the in-situ elevation measurements and the SRTM measurements. The adjusted SRTM elevations are then used where there are no in-situ measurements from 2011.

Measurements of bed elevation exist for most of the study site and parts of the glacier nevé (Anderson, 2004), but do not exist for the rest of the glacier flowline (Figure 2.13). To estimate ice thickness where there are no measurements, a constant driving stress, $\tau_{x z}$, of $150 \mathrm{kPa}$ is assumed (Anderson, 2004). The ice thickness can then be calculated based on the 2011 surface profile:

$$
\tau_{x z}=-\rho g H \sin (\theta)
$$

where $H$ is the glacier thickness and $\theta$ is the glacier slope angle. This method assumes that glacier ice behaves as a perfectly plastic material (Oerlemans, 1997). A running mean of $500 \mathrm{~m}$ is applied to smooth between the measured and calculated ice thicknesses. The bed elevation is the surface elevation minus the ice thickness.

The glacier flowline is divided into two zones for varying boundary conditions at the bed (Figure 2.13). Zone 1 extends from the head of the glacier to $8000 \mathrm{~m}$, thereby covering the glacier outside of the study site. As no data exist to constrain the boundary conditions in this zone, the sensitivity of the glacier model must be tested for different boundary conditions in Zone 1 (see Section 3.3.2). Zone 2 starts at $8000 \mathrm{~m}$ and ends at the glacier terminus, thereby covering the area of interest in this study. 


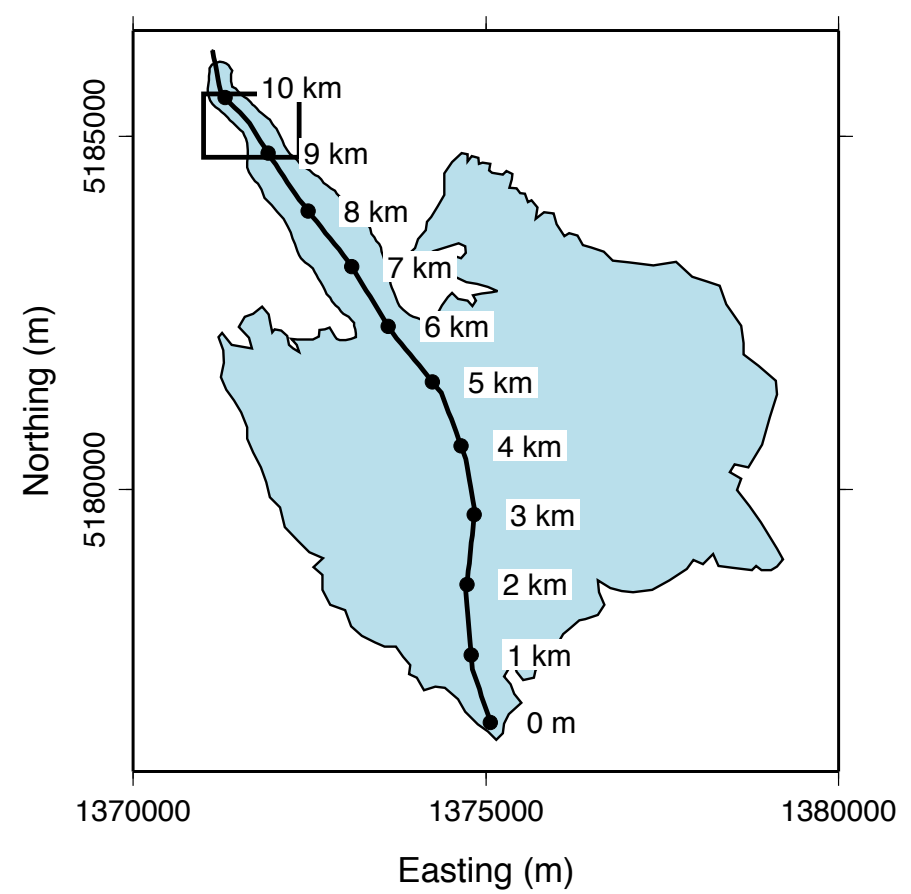

(a)

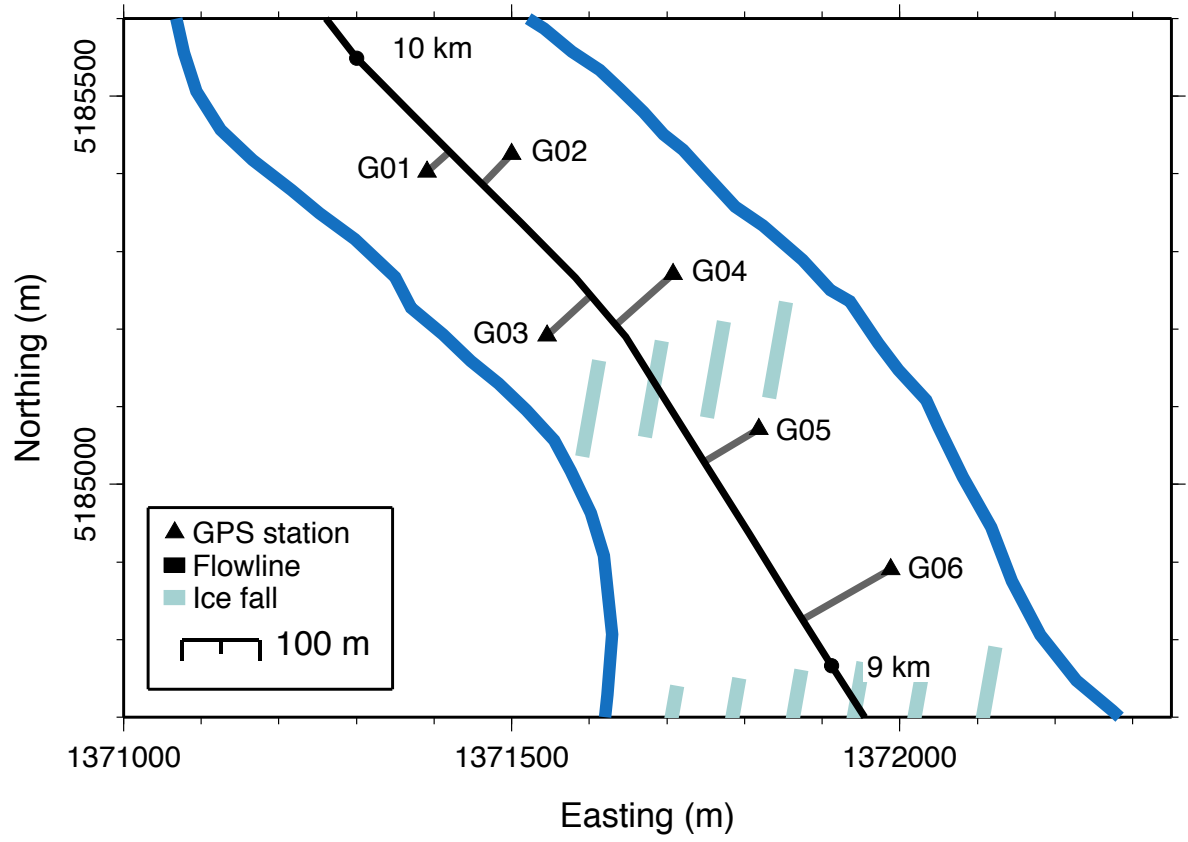

(b)

Figure 2.12: Glacier flowline. (a) Distance along the flowline from the glacier head is marked in kilometres. The black box is the focus of this study and is enlarged in (b). (b) Ice-flow velocity measurements at the GPS stations (black triangles) are projected onto the flowline (black line) at the location where they are a minimum distance from their original location. 


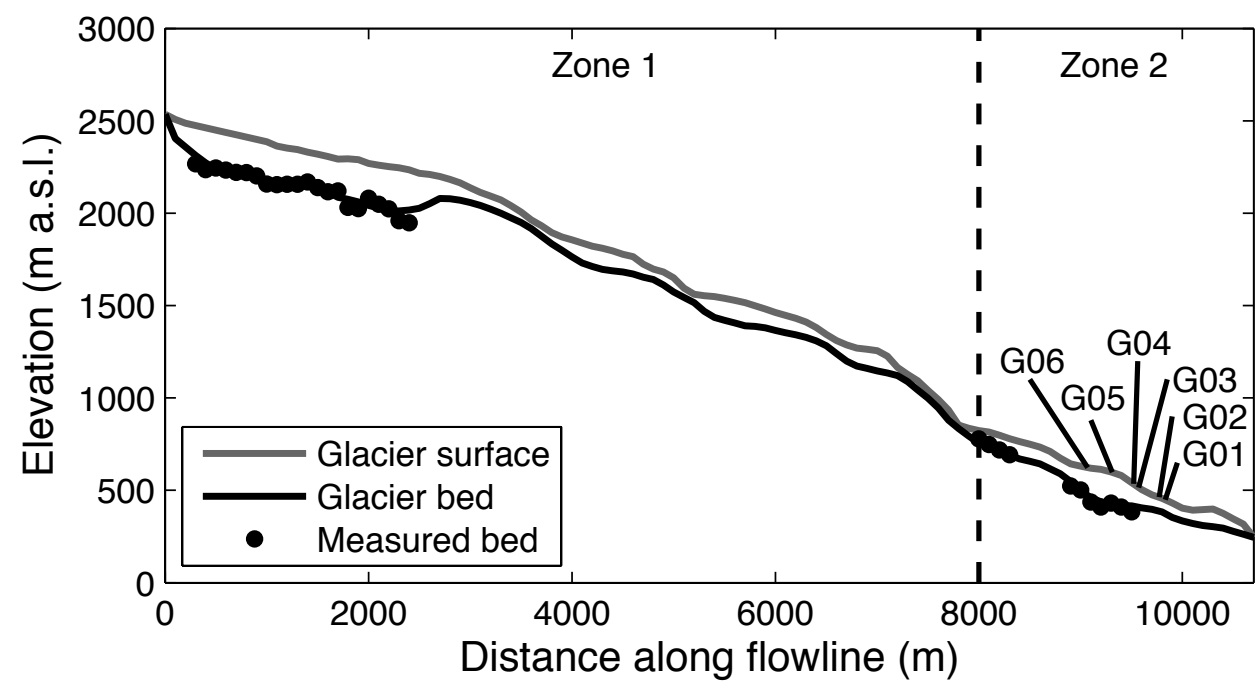

Figure 2.13: Glacier surface and bed elevations along the flowline (Figure 2.12). The glacier surface (grey line) is a combination of in-situ measurements from 2011 and adjusted SRTM measurements from 2000. The bed profile (black line) combines calculated and measured ice thicknesses (black dots). The dashed line indicates the border between Zones 1 and 2 .

\subsection{Summary}

In-situ measurements and glacier modelling are combined to investigate the relationship between water inputs and glacier speed. This informs us about the hydrology system beneath the glacier. The results will be detailed in the following chapter. 


\section{Chapter 3}

\section{Results}

In this chapter, I first describe the measured and modelled water inputs to the glacier system. From these data, the magnitude and timing of water inputs can be determined. I then examine the background ice-flow velocities and strain rates on the glacier, which illustrate the spatial variability of glacier flow. Afterwards, I present the temporal variations in ice-flow velocities on a diurnal and daily timescale and compare those velocity variations to the water inputs. Finally, results from the glacier flowline model are presented.

\subsection{Water inputs to the glacier bed}

\subsubsection{Measured rain events}

Rain event totals exceeded $10 \mathrm{~mm}$ on six occassions from March 3-20 (Figure 3.1). The largest measured rain event $(88 \mathrm{~mm}$ ) occurred from 16:00 on March 16 to 12:00 on March 17. Although the rain event two days earlier (March 15) was of lower magnitude $(77 \mathrm{~mm})$, the average precipitation rate during this event $\left(8 \mathrm{~mm} \mathrm{~h}^{-1}\right)$ was twice that of the event on March 16-17 $\left(4 \mathrm{~mm} \mathrm{~h}^{-1}\right)$. The longest dry spell was five days from March 6-11. 


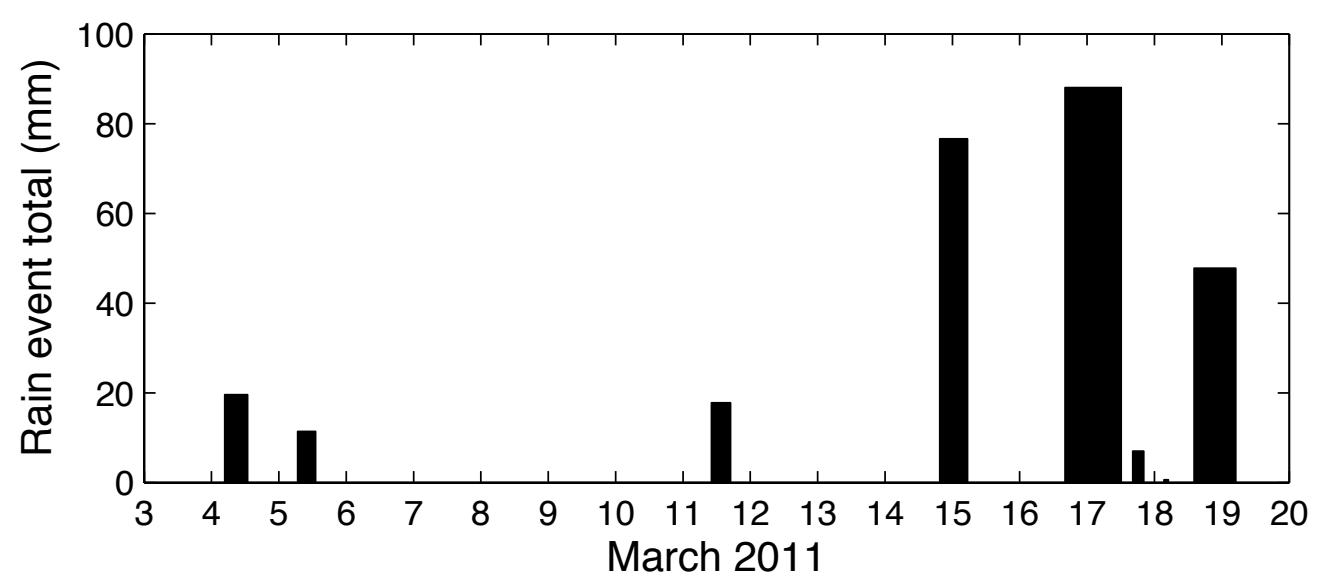

Figure 3.1: Rain event totals. The width of the bar indicates the duration of the rain event.

\subsubsection{Measured ablation rates}

Measured ablation rates are shown in Figures 3.2 and 3.3. The average measured ablation rate was $7 \pm 3 \mathrm{~cm}$ w.e. $\mathrm{d}^{-1}$ (approximately $25 \mathrm{~m}$ w.e. $\mathrm{a}^{-1}$ ). In general, ablation rates across the glacier were greatest $\left(10 \mathrm{~cm}\right.$ w.e. $\left.\mathrm{d}^{-1}\right)$ and most spatially variable from March 12-13. During this time, the highest measured air temperatures of the study period occurred (Figure 3.2).

Ablation rates were greater below the first ice fall $\left(8 \pm 1 \mathrm{~cm}\right.$ w.e. $\left.\mathrm{d}^{-1}\right)$ than above it $\left(6 \pm 1 \mathrm{~cm}\right.$ w.e. $\left.\mathrm{d}^{-1}\right)$. However, the lowest average ablation rate $\left(4 \pm 1 \mathrm{~cm}\right.$ w.e. $\left.\mathrm{d}^{-1}\right)$ occurred below the first ice fall at stake S09. This stake was located on debris-covered ice on the medial moraine (Table 2.2). Ablation rates at stakes S18-S20, which were also located on the medial moraine, were lower than ablation rates observed on nearby sediment-free ice (Figure 3.5).

\subsubsection{Energy balance model}

Measured and modelled ablation rates are compared in Figure 3.4. On average, the energy balance model underestimates the total measured ablation at each stake by $13 \pm 16 \%$. Despite this general bias, the energy balance model overestimates the average ablation rate at stake S09 on the medial moraine by $50 \%$. Figure 3.5 shows the measured and modelled ablation rates at the four debriscovered stakes (Table 2.2). The model produces similar ablation rates at all loca- 


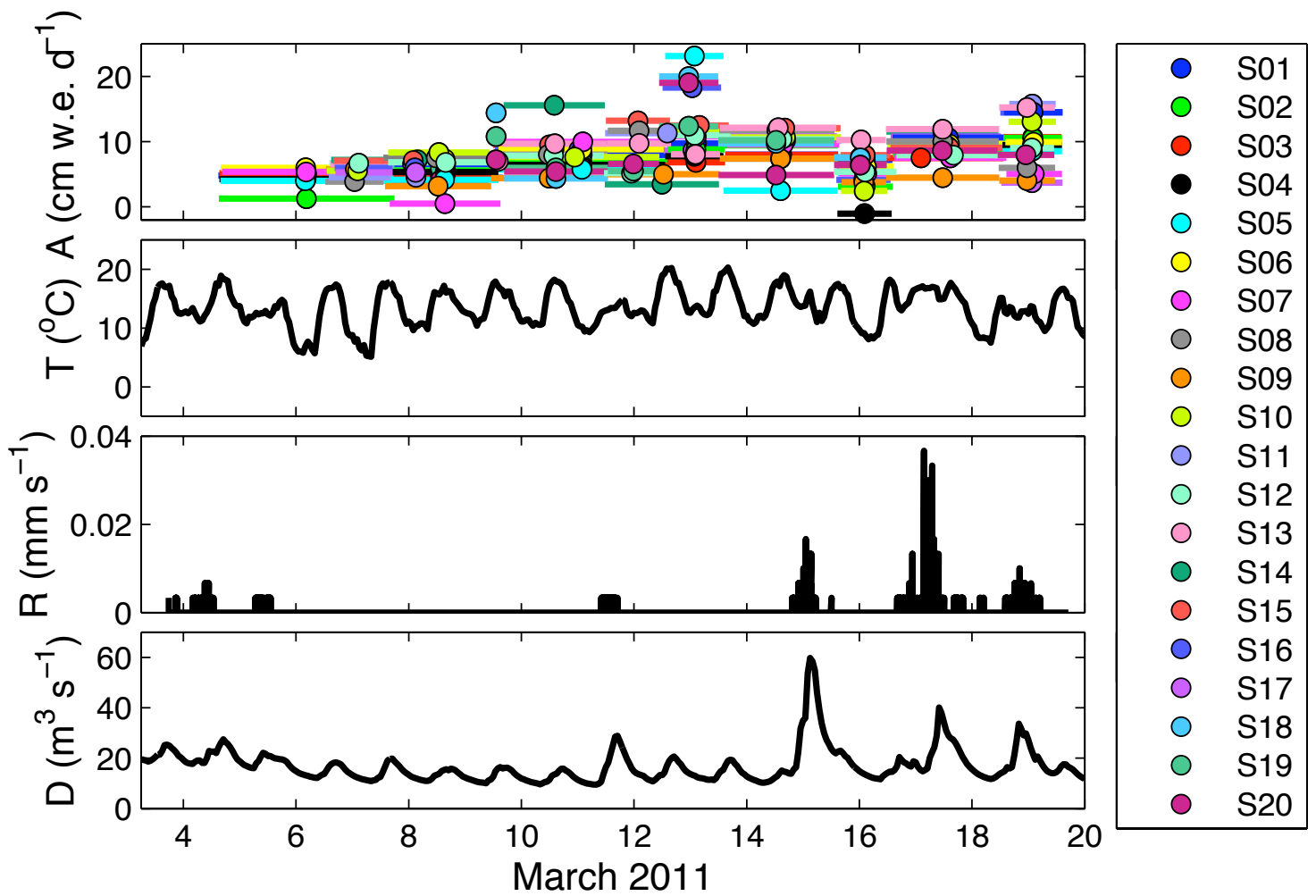

Figure 3.2: Measured ablation rates (A), NIWA temperature record (T) at Franz Josef Village, measured rain $(\mathrm{R})$ at the glacier terminus, and modelled discharge (D). The marker length in the first subplot indicates the time span over which ablation rates were averaged.

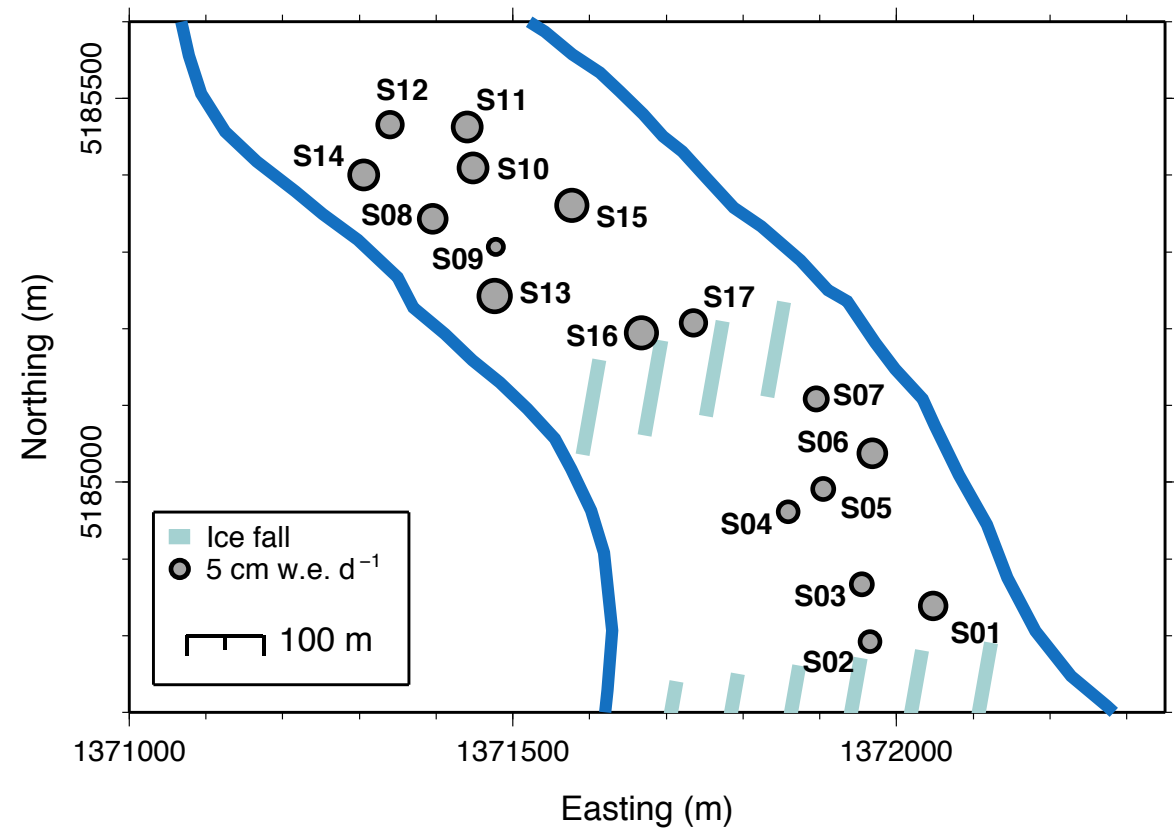

Figure 3.3: Spatial variability in ablation rates over the study period. Circle size indicates the magnitude of the average measured ablation rate. 


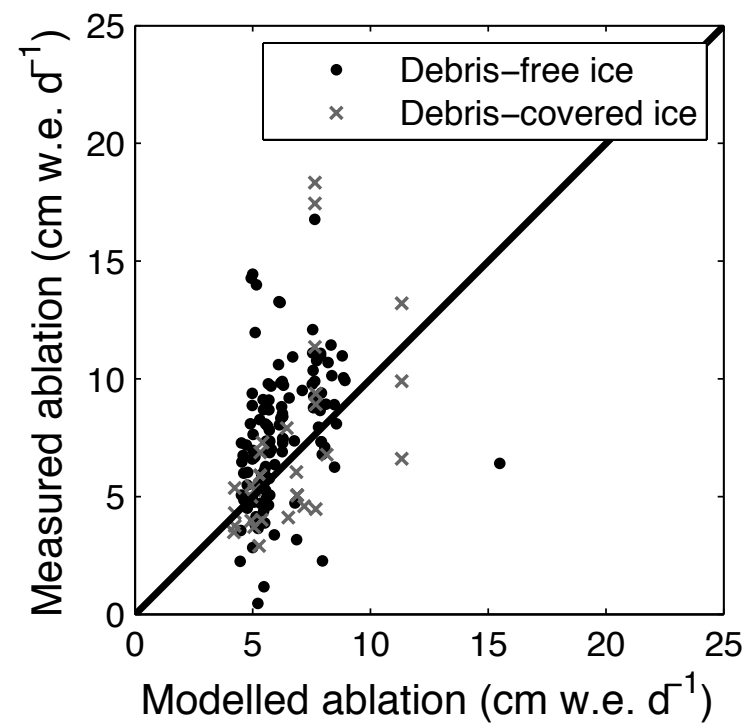

Figure 3.4: Modelled vs. measured ablation rates at debris-covered (grey crosses) and clear ice (black circles). The line indicates a 1:1 ratio. On average, the energy balance model underestimates the total measured ablation rate at each stake by $13 \pm 16 \%$.

tions on the medial moraine, whereas the measured rates indicate that ablation rates decreased with increasing sediment cover.

\subsubsection{Discharge model}

Figure 3.6 shows modelled discharge and river stage from April 2010 to April 2011. In January 2011, the Waiho Bridge had to be raised due to a large aggradation event, and as a result, river stage was not recorded after this time. When the two time-series overlap (April 2010 - January 2011), they are well correlated with an $\mathrm{R}^{2}$ value of 0.73 . This high correlation value is largely dependent on the relative timing of rain events in the two records, as the diurnal cycle in glacier melt does not appear in the stage record (Figure 3.7). A similar $\mathrm{R}^{2}$ correlation value (0.73) is also achieved by offsetting the modelled record two hours behind the stage measurements, suggesting that at times the modelled discharge peaks occurred before peaks in the stage record.

Modelled discharge events during March 2011 are shown in detail in Figure 3.2. On days without rain, maximum modelled discharge occurred at 18:00. Although the total precipitation during the rain event on March 15 was less than 


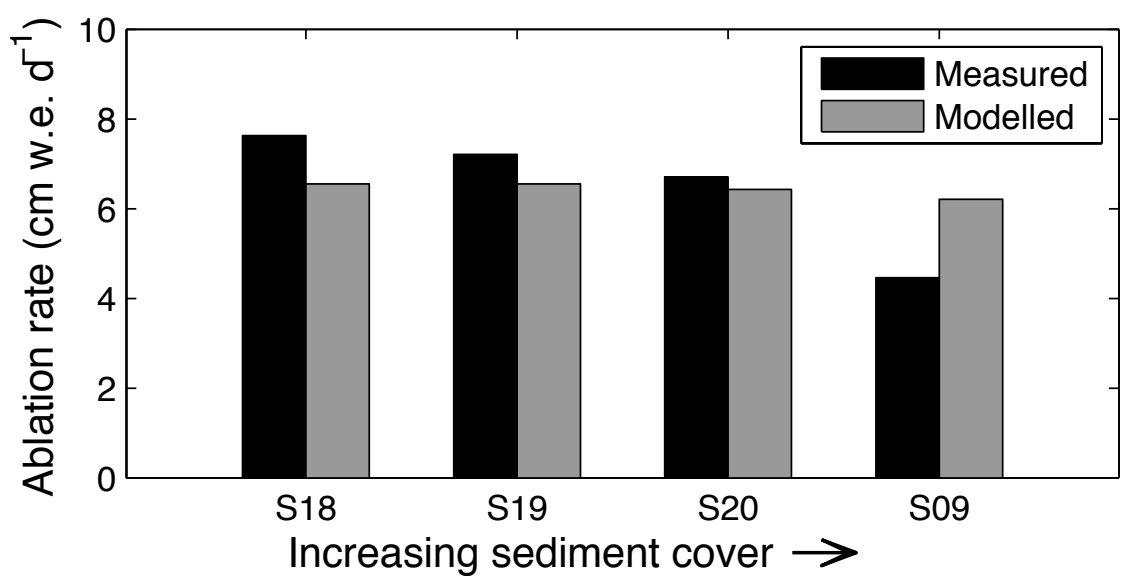

Figure 3.5: Average modelled (grey) and measured (black) ablation rates at the four sediment-covered stakes (S09, S18, S19,S20). Sediment cover increases along the $\mathrm{x}$-axis.

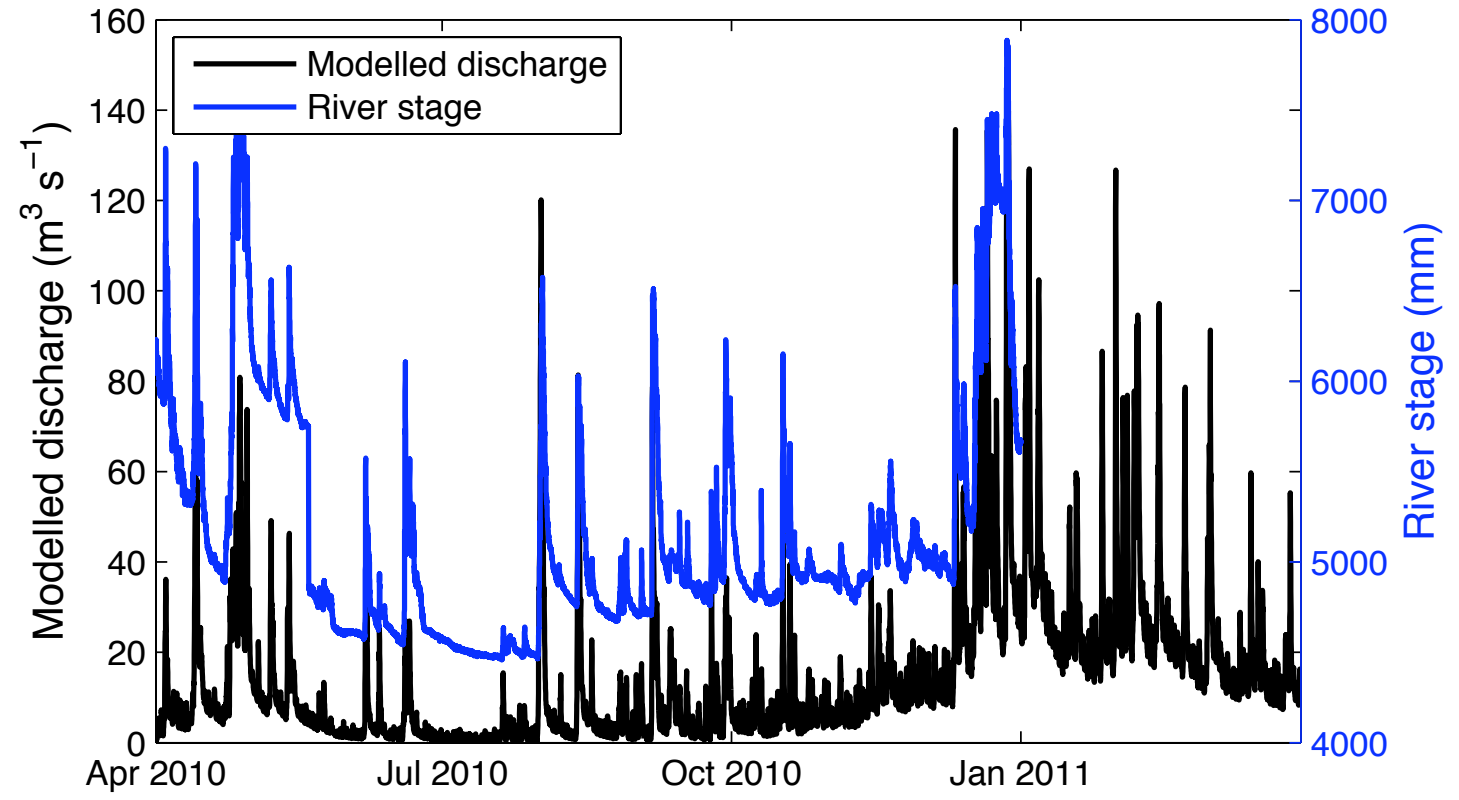

Figure 3.6: Modelled discharge (black line) vs. measured river stage at the Waiho Bridge (blue line). River stage was not recorded after January 2011. 


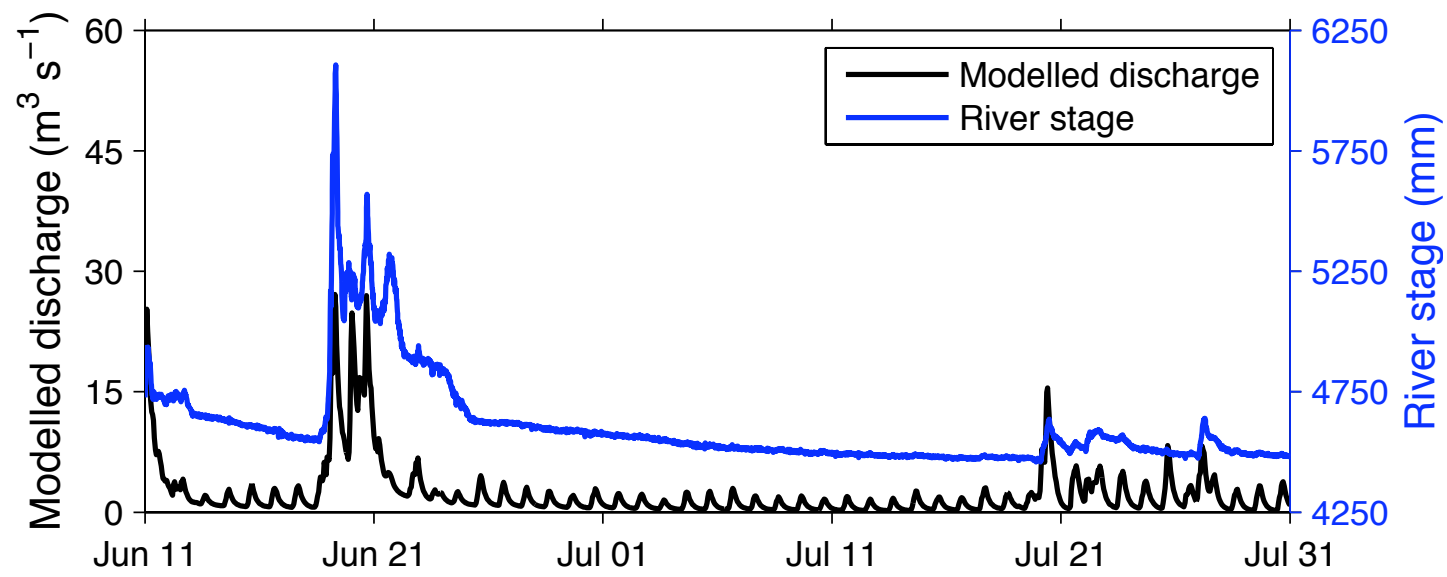

Figure 3.7: Modelled discharge (black line) vs. measured stage at the Waiho Bridge (blue line) in June and July 2010. The diurnal cycle in the modelled discharge does not appear in the stage record at the Waiho Bridge.

that on March 16-17 (Figure 3.1), the modelled discharge on March 15 was greater than that on March 16-17 (Figure 3.2). This is likely because the average intensity of the rain event on March $15\left(8 \mathrm{~mm} \mathrm{~h}^{-1}\right)$ was greater than the average intensity on March 16-17 (4 $\mathrm{mm} \mathrm{h}^{-1}$; Figure 3.1).

\subsection{Ice-flow velocities}

\subsubsection{Background ice-flow velocities and strain rates}

Average ice-flow velocities ranged from $0.22 \pm 0.11 \mathrm{~m} \mathrm{~d}^{-1}$ near the glacier terminus to $0.67 \pm 0.03 \mathrm{~m} \mathrm{~d}^{-1}$ above the first ice fall (Figure 3.8 and Table 3.1). In general, glacier flow was in a northwest direction, although slight spatial variations occurred across the glacier. At stake S06 above the first ice fall, the flow was more to the west. Near the glacier terminus, ice flow was towards the waterfall (Figure 3.8 and 2.2).

Figure 3.9 shows the background strain rates and principal axes of strain. Shearing occurred above the first ice fall and longitudinal compression occurred in the ice fall. Lower on the glacier, there was significant compression in the direction of the waterfall. Maximum calculated extension occurred along the eastern flank of the lower glacier $\left(1.3 \times 10^{-3} \pm 1.8 \times 10^{-3} \mathrm{~d}^{-1}\right)$, and maximum compression occurred in the direction of the waterfall $\left(2.2 \times 10^{-3} \pm 4.4 \times 10^{-4} \mathrm{~d}^{-1}\right)$. 


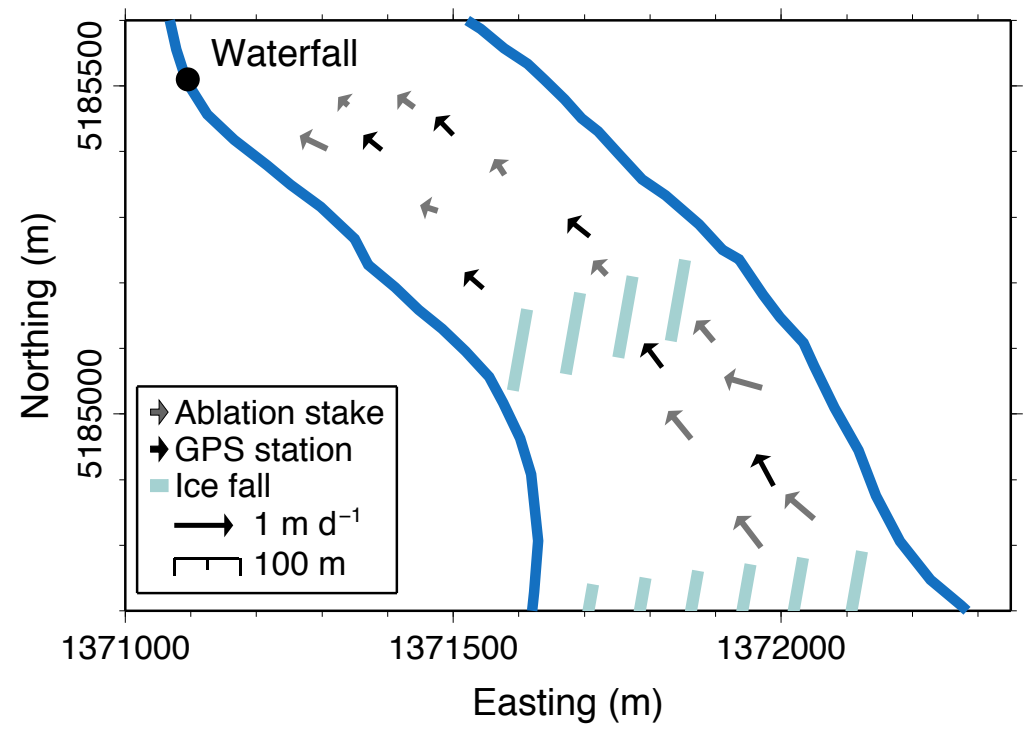

Figure 3.8: Average ice-flow velocities in March 2011. Grey and black vectors indicate stake and GPS locations, respectively. Ice-flow magnitudes and directions are reported in Table 3.1.

Table 3.1: Average ice-flow velocities in March 2011 as shown in Figure 3.8. Iceflow direction is reported in degrees anticlockwise from due east.

\begin{tabular}{|c|r|r|r|r|}
\hline Station & Easting & Northing & Velocity $\left(\mathbf{m ~ d}^{-1}\right)$ & Direction (deg) \\
\hline \hline G01 & 1371391 & 5185402 & $0.40 \pm 0.02$ & $141 \pm 3$ \\
\hline G02 & 1371500 & 5185425 & $0.42 \pm 0.02$ & $134 \pm 2$ \\
\hline G03 & 1371545 & 5185191 & $0.42 \pm 0.02$ & $139 \pm 2$ \\
\hline G04 & 1371708 & 5185271 & $0.48 \pm 0.02$ & $141 \pm 2$ \\
\hline G05 & 1371818 & 5185071 & $0.51 \pm 0.02$ & $127 \pm 2$ \\
\hline G06 & 1371988 & 5184890 & $0.62 \pm 0.02$ & $118 \pm 1$ \\
\hline S01 & 1372050 & 5184840 & $0.64 \pm 0.13$ & $140 \pm 11$ \\
\hline S02 & 1371970 & 5184797 & $0.67 \pm 0.03$ & $127 \pm 2$ \\
\hline S04 & 1371862 & 5184962 & $0.61 \pm 0.09$ & $129 \pm 10$ \\
\hline S06 & 1371971 & 5185040 & $0.67 \pm 0.16$ & $164 \pm 6$ \\
\hline S07 & 1371897 & 5185111 & $0.46 \pm 0.12$ & $130 \pm 17$ \\
\hline S09 & 1371476 & 5185309 & $0.31 \pm 0.10$ & $162 \pm 24$ \\
\hline S11 & 1371440 & 5185467 & $0.36 \pm 0.30$ & $144 \pm 37$ \\
\hline S12 & 1371340 & 5185470 & $0.22 \pm 0.11$ & $140 \pm 31$ \\
\hline S14 & 1371308 & 5185404 & $0.51 \pm 0.28$ & $154 \pm 17$ \\
\hline S15 & 1371578 & 5185364 & $0.33 \pm 0.11$ & $123 \pm 27$ \\
\hline S17 & 1371734 & 5185212 & $0.33 \pm 0.11$ & $133 \pm 19$ \\
\hline
\end{tabular}




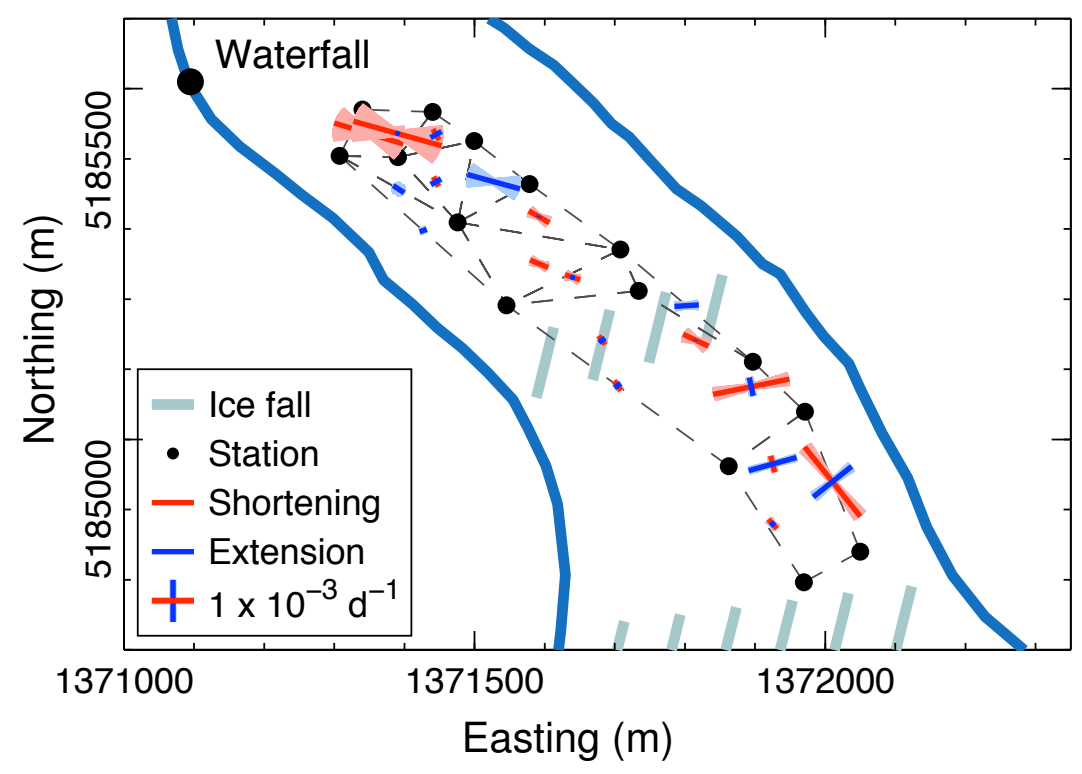

Figure 3.9: Background strain rates in March 2011. Red and blue lines indicate the principal axes of shortening and extension, respectively. Shaded red and blue angles indicate one sigma uncertainty estimates in the direction of the principal axes.

\subsubsection{Short-term variations}

\section{Overview}

Figure 3.10 shows the horizontal glacier speed at the six GPS stations. Ice-flow velocities ranged from $30-60 \%$ above average velocities at the beginning of the study period, following a large rain event that occurred two days before the stations were installed (Figure 3.10). At GPS station G02, which was the only station to remain operational throughout the study period, ice-flow velocities then decreased until March 9, when they reached a relatively constant velocity. Minimum ice-flow velocities ( 0.23 to $\left.0.45 \mathrm{~m} \mathrm{~d}^{-1}\right)$ occurred on March 13-14, with the timing depending on when GPS stations were operational during that time. On March 15, ice-flow velocities increased during a rain event. Another major increase in ice-flow velocities coincided with a rain event on March 16-17. 

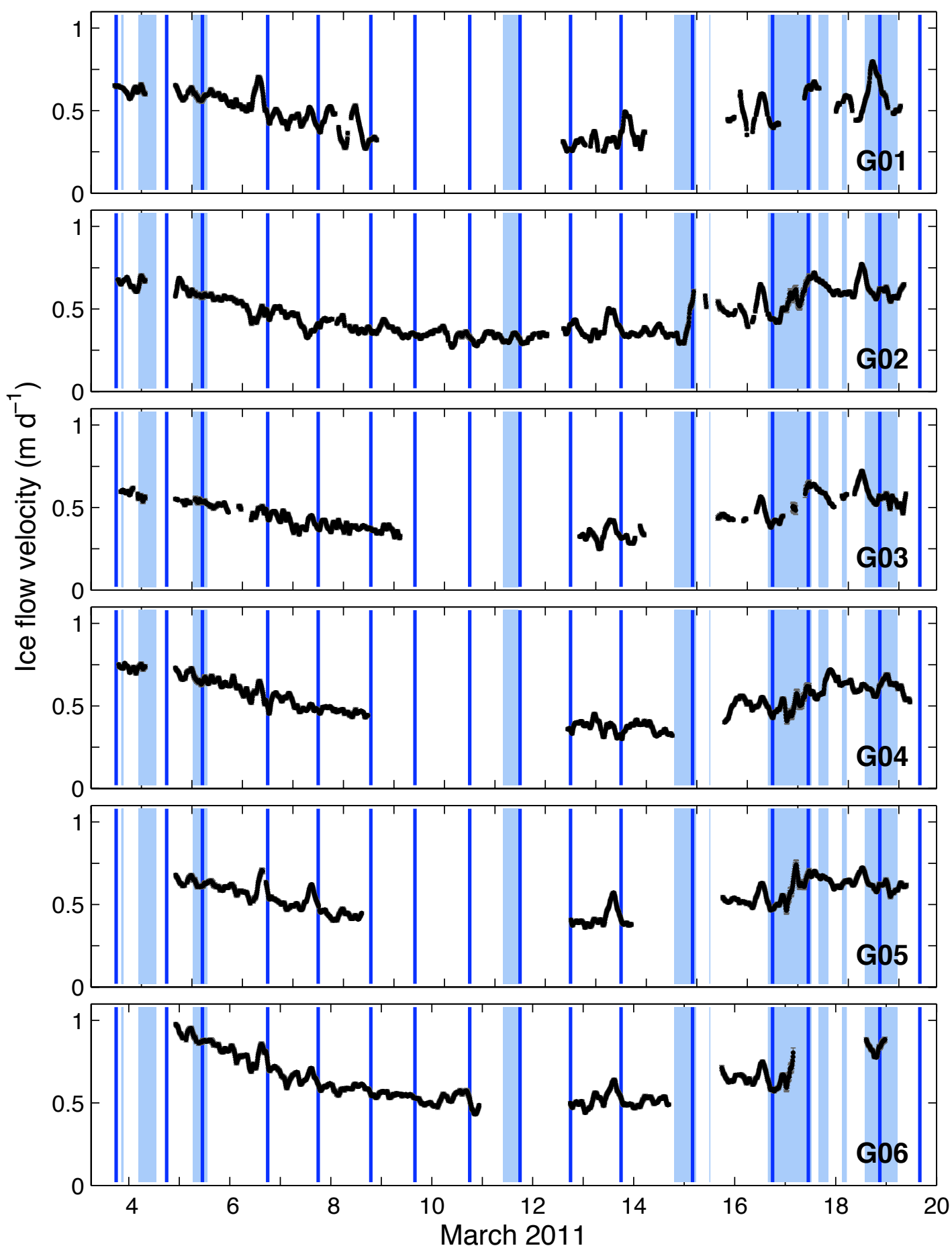

Figure 3.10: Horizontal glacier speed at the six GPS stations. Grey error bars are one sigma uncertainty estimates and are often smaller than the size of the marker. Dark blue lines indicate peak modelled discharge (Figure 3.6) and light blue bars indicate periods of rain (Figure 3.1). 
Table 3.2: Ice-flow velocity increases after the four largest rain events (Figure 3.1). Velocity increases are relative to the velocity before the rain event. Grey cells indicate that the GPS station was not operational during that time.

\begin{tabular}{|l|r|r|r|r|r|r|r|}
\hline Rain event & Rain total & G01 & G02 & G03 & G04 & G05 & G06 \\
\hline \hline Mar. 11 & $18 \mathrm{~mm}$ & & $19 \pm 1 \%$ & & & & \\
\hline Mar. 14-15 & $77 \mathrm{~mm}$ & & $75 \pm 3 \%$ & & & & \\
\hline Mar. 16-17 & $88 \mathrm{~mm}$ & $49 \pm 2 \%$ & $53 \pm 1 \%$ & $58 \pm 2 \%$ & $27 \pm 1 \%$ & $48 \pm 2 \%$ & \\
\hline Mar. 18-19 & $48 \mathrm{~mm}$ & $2 \pm 1 \%$ & $-10 \pm 1 \%$ & $-10 \pm 1 \%$ & $11 \pm 1 \%$ & $-4 \pm 1 \%$ & \\
\hline
\end{tabular}

\section{Rain events}

Table 3.2 reports increases in ice-flow velocities during the four largest rain events, which ranged in total precipitation from 18 to $88 \mathrm{~mm}$ (Figure 3.1). To determine the velocity increase, the peak ice-flow velocity associated with the rain event is compared to the velocity directly before the event. During all events, peak iceflow velocities occurred within $2 \pm 2$ hours of peak modelled discharge. The longest time period between peak ice-flow velocities and peak modelled discharge was 8 hours at station G05 on March 16-17. Ice-flow velocities did not increase noticeably during rain events of $11 \mathrm{~mm}$ or less.

Station G02 was the only operational station during the rain event on March 11 (18 mm over 7 hours), which resulted in a velocity increase of $19 \pm 1 \%$. During the most intense rainstorm of the study period on March 14-15 (77 mm over 10 hours), velocities increased by up to $75 \pm 3 \%$ at G02. This increase was the greatest measured velocity increase of the study period. Although the other stations were not operational at this time, the velocities recorded before and after this event indicate that velocities increased by at least $20-50 \%$ at all stations (Figure 3.10).

During the largest rain event on March 16-17 (88 mm over 20 hours), ice-flow velocities increased at all five operational stations, from $27 \pm 1 \%$ at G04 to $58 \pm 2 \%$ at G03. On March 18-19 (48 mm over 15 hours), ice-flow velocities increased at stations G01 ( $2 \pm 1 \%)$ and G04 (11 $\pm 1 \%)$ but did not increase at the other stations. The GPS stations were removed right after this event, so it is possible that glacier velocity increased at the other stations at a later time. 


\section{Diurnal events}

Diurnal variations in ice-flow velocities are superimposed on the long-term trend in ice-flow velocities. To isolate these variations, the daily-averaged ice-flow velocities are removed from Figure 3.10. Figure 3.11 shows the resulting detrended velocities as a percentage of the daily velocity. If a diurnal variation in ice-flow velocities is a result of the diurnal melt cycle, peak ice-flow velocities should be reached slightly before peak discharge (18:00), as subglacial water pressures should be greatest at this time (e.g., Iken and Bindschadler, 1986). Figure 3.12 shows the timing of peak ice-flow velocities on a given day. If peak ice-flow velocities occurred between 12:00 and 18:00, a diurnal cycle is reported on that day.

Table 3.3 reports the diurnal cycles determined through this method. Diurnal cycles are only determined on rain-free days or on days when rain occurred after peak diurnal discharge (18:00). On March 6 and 16, all operational stations showed a diurnal cycle, with velocity increases ranging from $10-32 \%$ above the daily mean ice-flow velocities. Peak velocities occurred from 14:00-15:00 on March 6 and from 12:00-13:00 on March 16. At stations G05 and G06, a diurnal cycle occurred on all rain-free days, with peak velocities reached from 14:00-15:00. On March 8-10, the diurnal signal was very weak at G06 (5-10\% above mean daily ice-flow velocities) and not present at any other operational station. A diurnal cycle occurred at station G02 on all rain-free days after March 13, with peak velocities ranging from $15-32 \%$ above average daily ice-flow velocities.

\section{Short-term variations in ice-flow direction}

In addition to short-term variations in glacier speed, this study also find variations in the direction of glacier flow. Figure 3.13 shows the flow direction at G02 and at Teichelmanns Rock on a given day. Flow direction is reported as degrees anticlockwise from due east. All stations on the glacier showed a diurnal periodicity in flow direction, with the flow direction changing around the time of peak modelled discharge at the glacier terminus. If this diurnal signal was a result of glacier dynamics, the flow direction at Teichelmanns Rock should be random. Instead, it followed a semidiurnal periodicity, with the flow direction also changing 


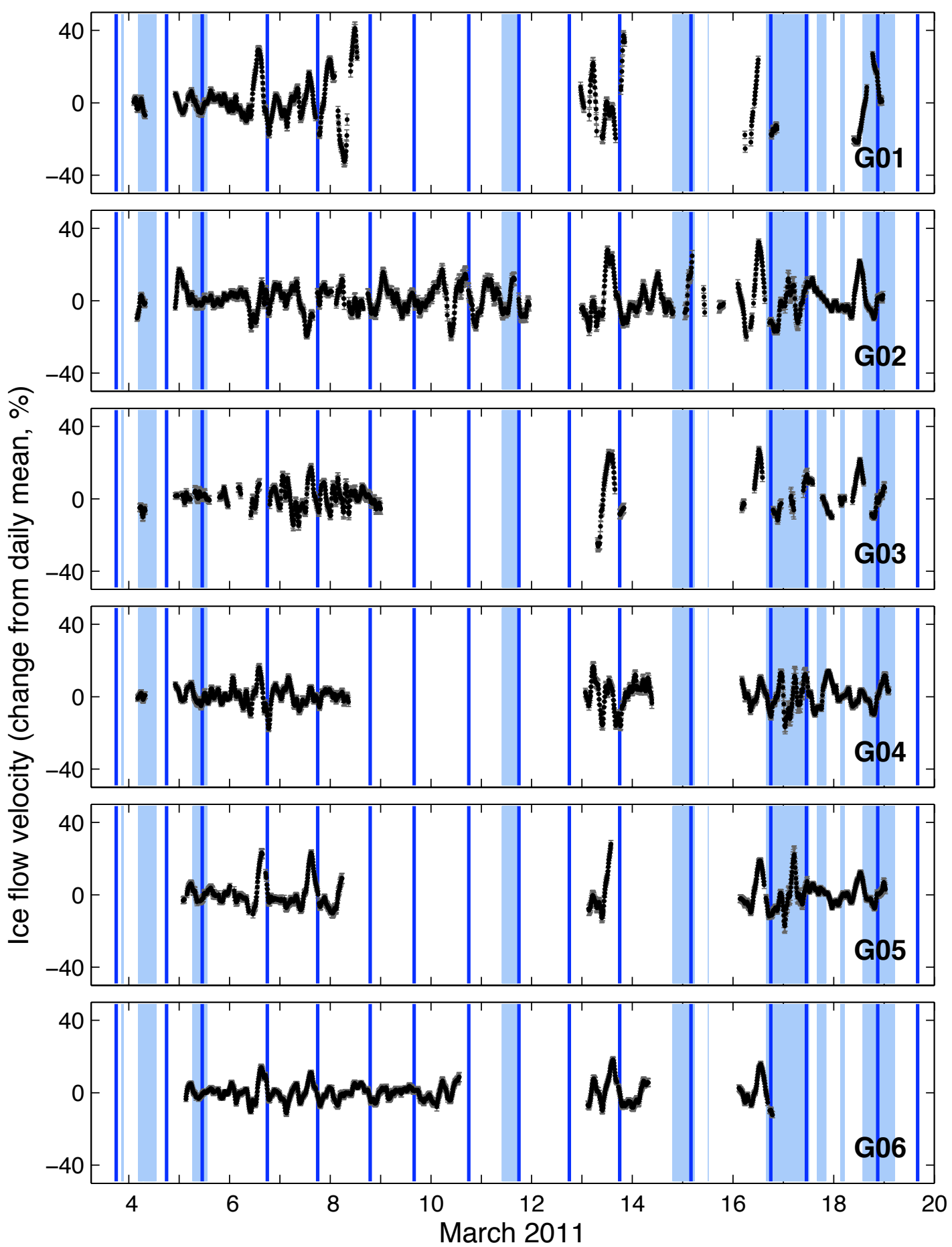

Figure 3.11: Changes in ice-flow velocities (\%) from the daily mean. If a diurnal variation in ice-flow velocities occurs on the glacier, it should be apparent in this figure. Dark blue lines indicate peak discharge and light blue bars indicate periods of rain. Grey error bars are one sigma uncertainty estimates. 


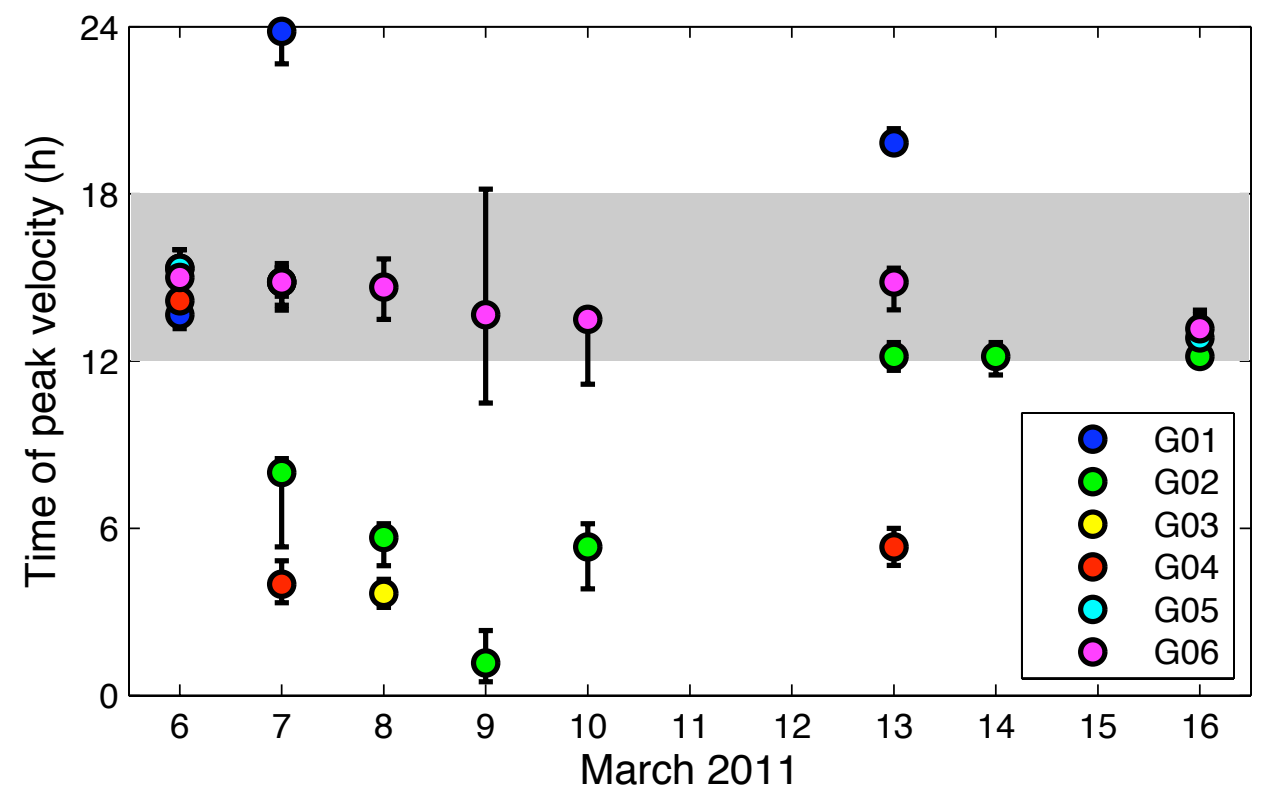

Figure 3.12: Time of peak, detrended ice-flow velocities (Figure 3.11) on rain-free days. If a diurnal variation in ice-flow velocities exists, peak velocities should occur slightly before peak discharge. This would be between the hours of 12:00 and 18:00 (grey bar). When peak velocities fall within this timeframe, a diurnal cycle in ice-flow velocities is reported on that day (Table 3.3).

Table 3.3: Diurnal variations in ice-flow velocities from March 6-16. Precipitation occurred on March 11 and 15, and as a result, diurnal variations are not assessed on those days. Diurnal cycles are reported on days when the peak ice-flow velocity falls between 12:00 and 18:00 (Figure 3.12). The velocity increase is reported as a percentage increase from the average daily velocity. Grey cells indicate that the GPS station was not operational during that time, and blank cells indicate that a diurnal cycle did not occur at that station.

\begin{tabular}{|c|c|c|c|c|c|c|}
\hline Date & G01 & G02 & G03 & G04 & G05 & G06 \\
\hline 6 & $29 \pm 2 \%$ & $10 \pm 3 \%$ & & $16 \pm 2 \%$ & $23 \pm 3 \%$ & $14 \pm 2 \%$ \\
\hline 7 & $14 \pm 2 \%$ & & $17 \pm 2 \%$ & & $23 \pm 2 \%$ & $11 \pm 1 \%$ \\
\hline 8 & & & & & & $5 \pm 1 \%$ \\
\hline 9 & & & & & & $4 \pm 2 \%$ \\
\hline 10 & & & & & & $9 \pm 3 \%$ \\
\hline 11 & \multicolumn{6}{|c|}{ Rain } \\
\hline 12 & & & & & & \\
\hline 13 & & $28 \pm 2 \%$ & & & & $18 \pm 2 \%$ \\
\hline 14 & & $15 \pm 2 \%$ & & & & \\
\hline 15 & \multicolumn{6}{|c|}{ Rain } \\
\hline 16 & & $32 \pm 2 \%$ & & & $18 \pm 2 \%$ & $16 \pm 2 \%$ \\
\hline
\end{tabular}




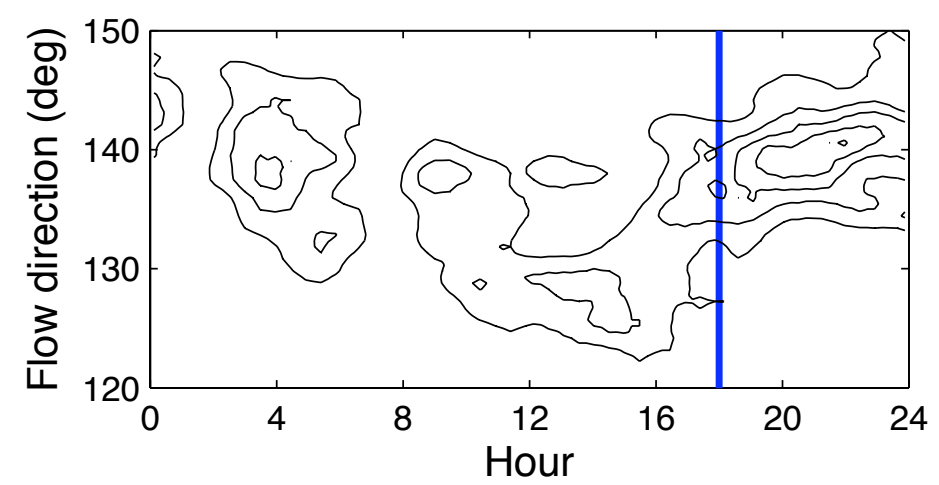

(a) G02

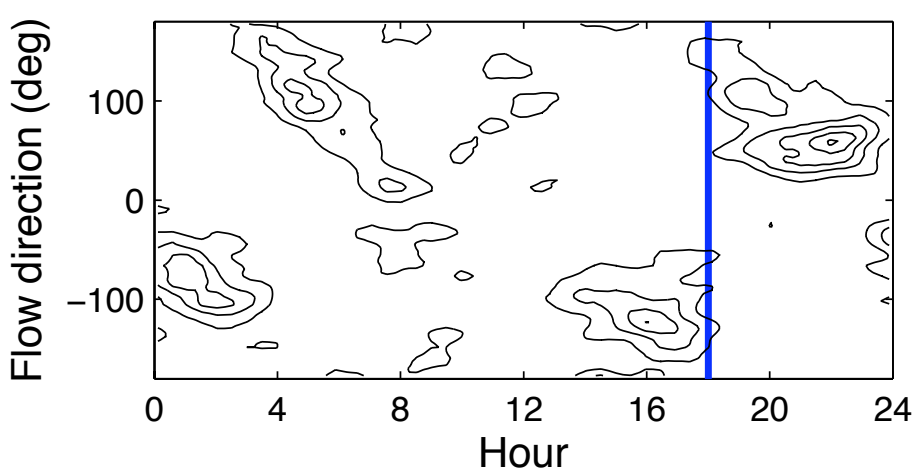

(b) Teichelmanns Rock (G07)

Figure 3.13: Velocity direction at (a) G02 and at (b) Teichelmanns Rock (G07) as a function of hour during the day. Direction is reported as degrees anticlockwise from due east. Contour lines indicate the measurement density at a given direction and hour during the day. Blue lines indicate peak modelled discharge. As the direction variations on the glacier occurred around the time of peak discharge, these variations could easily have been interpreted in terms of glacier dynamics.

around the time of peak discharge.

As azimuth variations were present both on the glacier and at the rock site, the azimuth variations likely represent a GPS processing artefact rather than glacier dynamics. A diurnal periodicity in the estimated atmospheric delays by TRACK further supports this conclusion (Tom Herring, personal communication). Azimuth is a particularly sensitive parameter in GPS position estimates, and spurious diurnal and semidiurnal signals can indicate mismodelling of the solid Earth tides, inadequacies in troposphere and ionosphere modelling, atmospheric tides, or multipath effects (e.g., Araszkiewicz and others, 2009; Hefty and Igondova, 2010). Diurnal and semidiurnal direction variations are therefore not interpeted any further in this study. 


\subsection{Glacier model}

In this section, I first describe the sensitivity of the glacier flowline model to varying parameters and boundary conditions. I then present the modelled subglacial water pressures which best match the measured velocities.

\subsubsection{Sensitivity to parameters $A_{s}$ and $C$}

To understand changes in the subglacial water pressure $P_{w}$ over the study period, the parameters $C$ and $A_{s}$ (Equation 2.31) must first be determined. These parameters do not vary with time. To determine $A_{s}$ (the sliding coefficient without cavitation), it is assumed that the lowest measured ice-flow velocities in March 2011 occurred in the absence of cavitation $\left(P_{w}=0\right)$. The lowest measured ice-flow velocities at stations G01, G02, G04, and G05 provide similar estimates of the $A_{s}$ parameter $\left(1.18 \times 10^{-21} \mathrm{~m} \mathrm{~Pa}^{-3} \mathrm{~s}^{-1}\right.$; Figures 3.14). Stations G03 and G06, which do not provide similar estimates, are neglected when calculating the $A_{s}$ value, as this study requires an $A_{s}$ value that is most representative of the entire study site (Figure 3.15). Possible reasons for this difference will be discussed later (see Sections 3.3.3 and 4.2.2).

The constant $C$, which is less than the local positive bedrock slope, is more difficult to determine, as it depends on the bedrock roughness and geometry (Gagliardini and others, 2007). Following other studies (Jay-Allemand and others, 2011; Flowers and others, 2011), this value is varied to determine several combinations of $A_{s}$ and $C$ values that match the lowest measured ice-flow velocities (Figure 3.16). As illustrated in Figure 3.17, the chosen combination impacts the relationship between the subglacial water pressure and glacier speed, particularly as the subglacial water pressure increases (Equation 2.31). However, it should not alter the results of this study, as the glacier flowline model is used qualitatively to assess spatial and temporal variations in the subglacial water pressure, rather than to determine absolute values. Values of $C=0.50$ and $A_{s}=1.18 \times 10^{-21} \mathrm{~m} \mathrm{~Pa}^{-3} \mathrm{~s}^{-1}$ are assumed for all future simulations (Figure 3.18). 

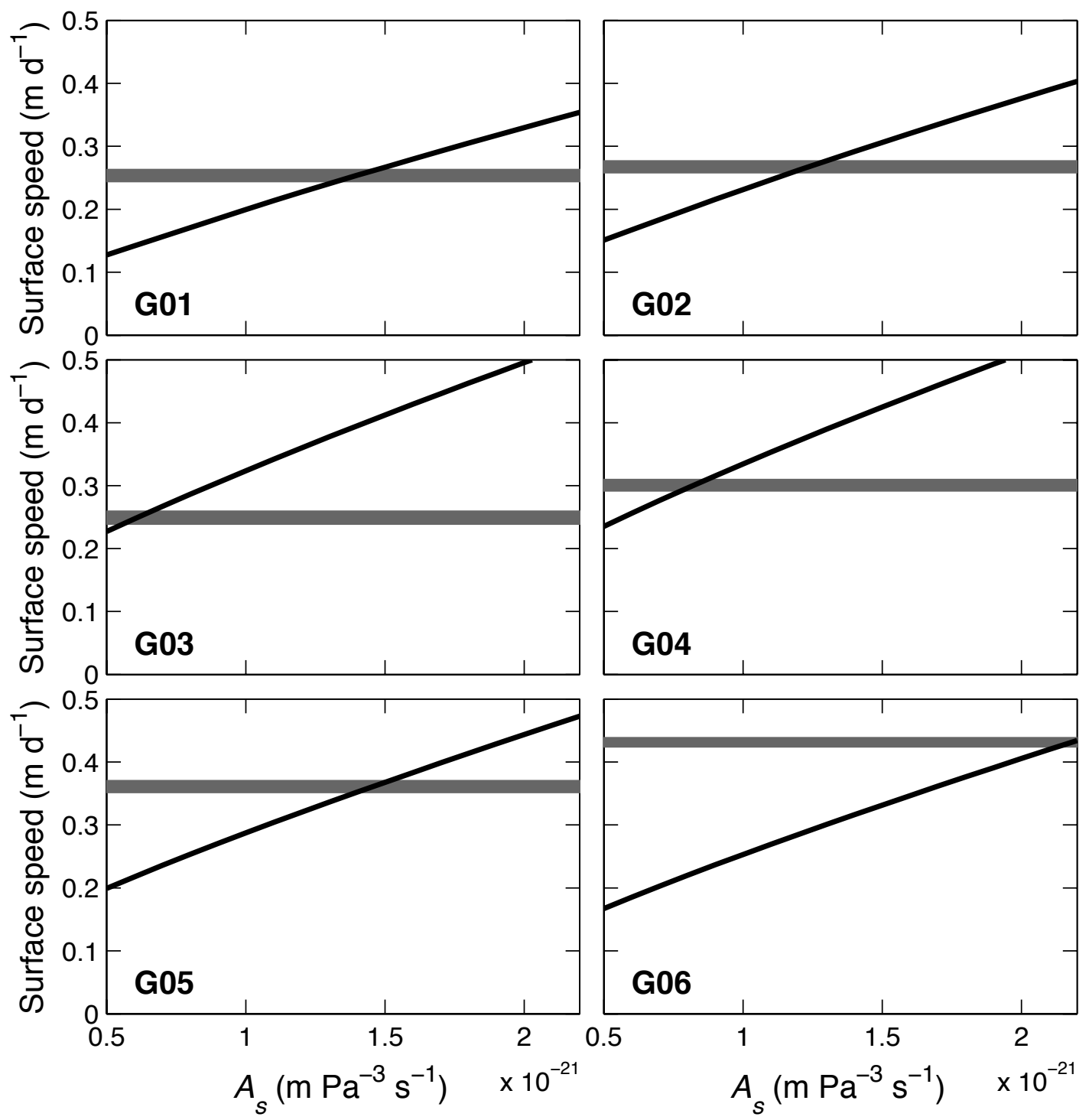

Figure 3.14: Estimated $A_{s}$ values at all six GPS stations. Grey lines indicate the lowest measured velocities, and the black lines indicate the modelled ice-flow velocities as a function of the $A_{s}$ value. The intersection of the grey and black lines represents the best-fit $A_{s}$ value at that station. Stations G01, G02, G04, and G05 are used to determine a spatially-uniform $A_{s}$ value across the study site through a least squares approach. Stations G03 and G06 are neglected as they provide an estimated $A_{s}$ value that differs significantly from the other stations. The parameter $C$ is set to 0.50 in all calculations. 


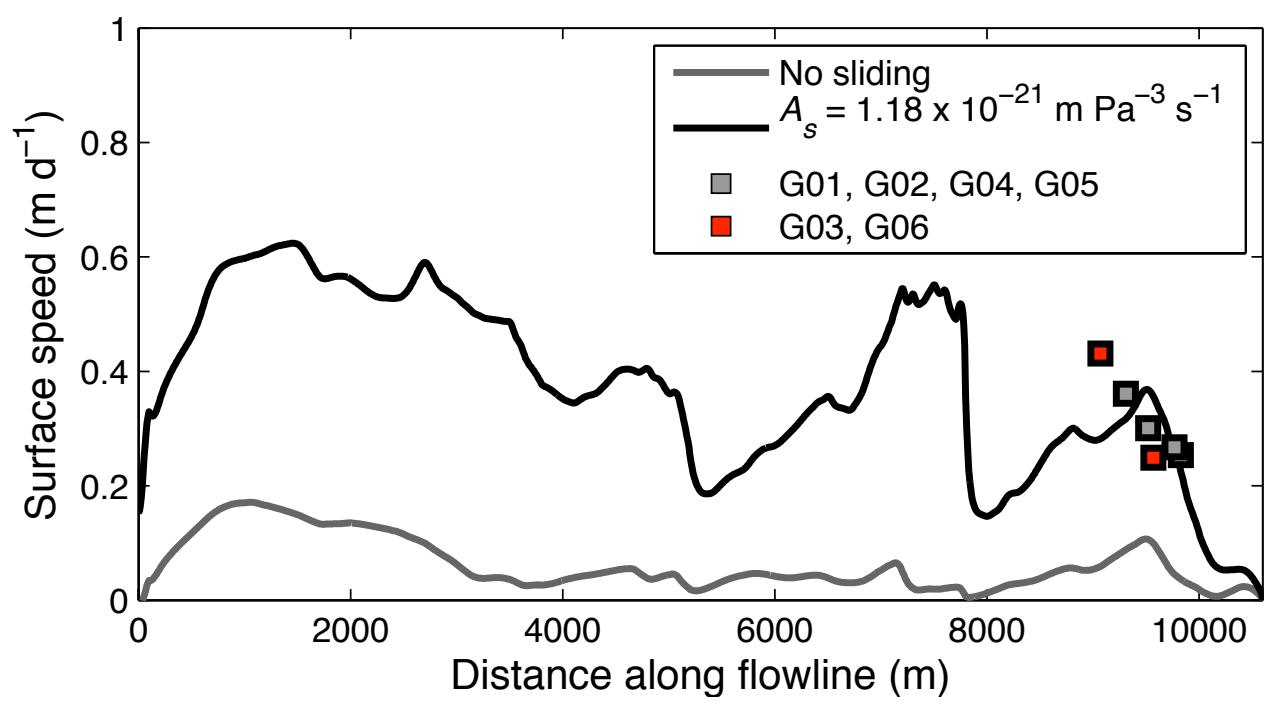

Figure 3.15: Glacier surface speed along the flowline, with $P_{w}=0 \mathrm{MPa}$. The grey rectangles indicate the lowest measured ice-flow velocities at G01, G02, G04, and $\mathrm{G} 05$, and the red rectangles represent G03 and G06. Assuming the parameter $C$ is constant at 0.50 along the flowline, the best-fit $A_{s}$ value is $1.18 \times 10^{-21} \mathrm{~m} \mathrm{~Pa}^{-3} \mathrm{~s}^{-1}$.

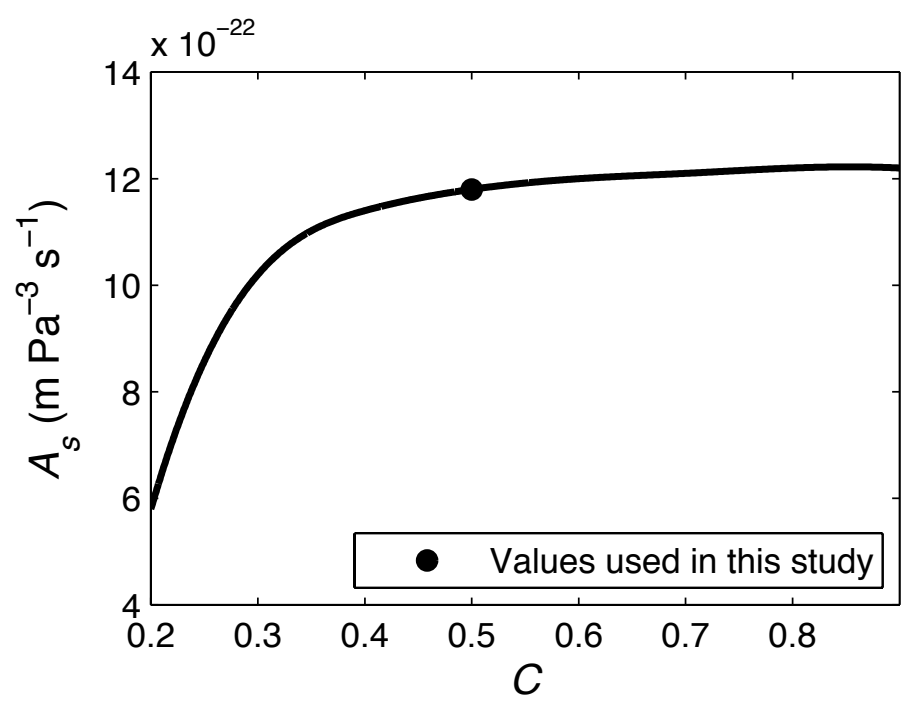

Figure 3.16: Best-fit combinations of $A_{s}$ and $C$ values. For all future simulations, $C=0.50$ and $A_{s}=1.18 \times 10^{-21} \mathrm{~m} \mathrm{~Pa}^{-3} \mathrm{~s}^{-1}$ are assumed (black dot). 


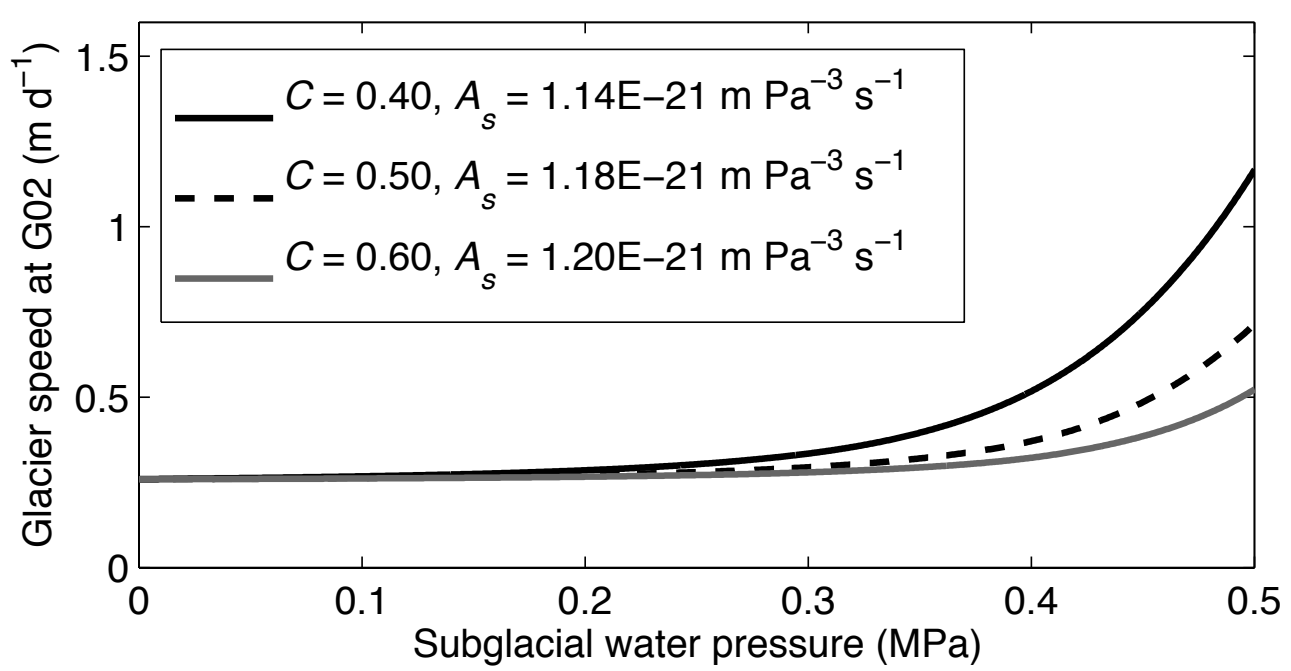

Figure 3.17: Glacier speed as a function of the subglacial water pressure at G02 for different combinations of $A_{s}$ and $C$ values.

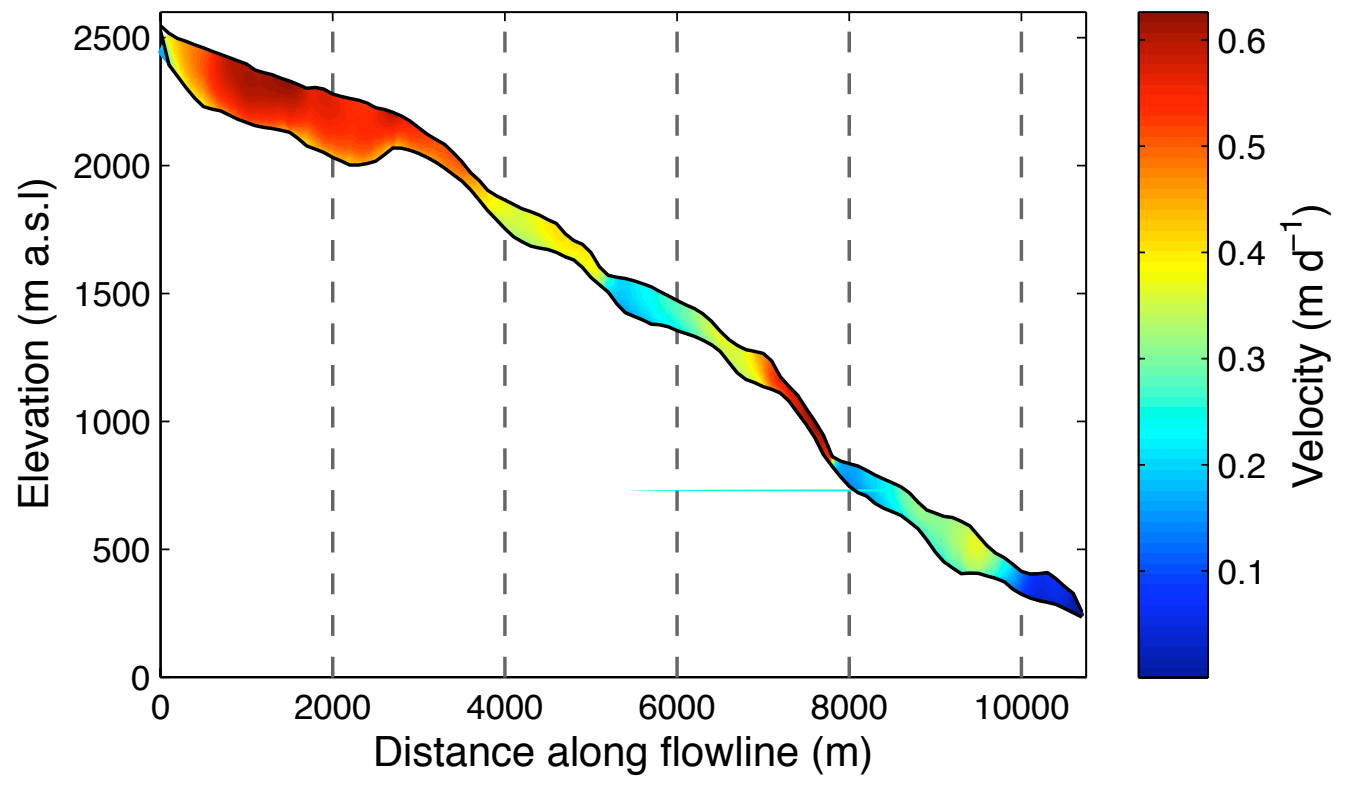

Figure 3.18: Modelled velocities along the flowline (Figure 2.13). Color indicates the magnitude of the velocity. In this figure, $C=0.50$ and $A_{s}=1.18 \times 10^{-} 21 \mathrm{~m} \mathrm{~Pa}^{-3} \mathrm{~s}^{-1}$. The subglacial water pressure, $P_{w}$, is set to $0 \mathrm{MPa}$. 


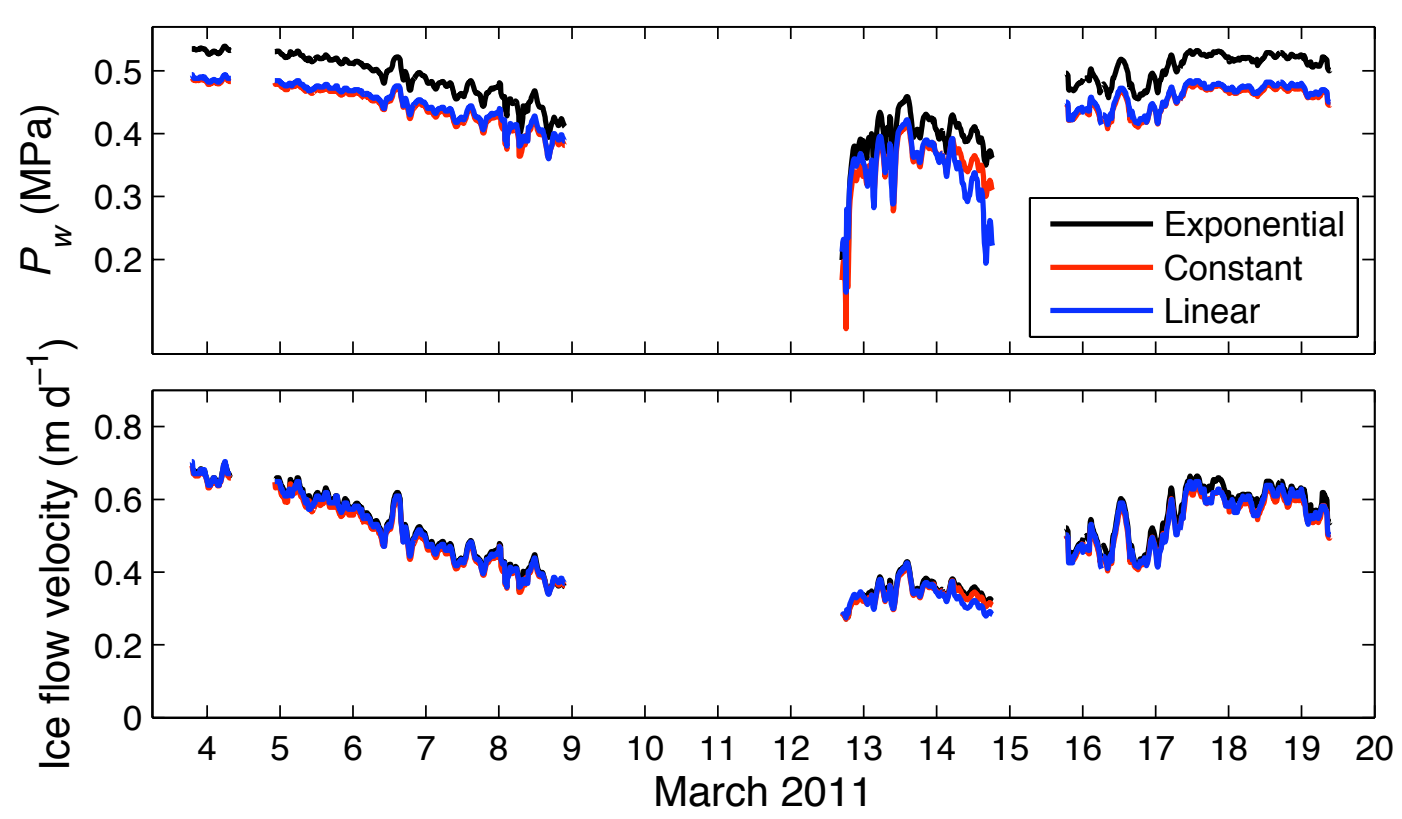

Figure 3.19: Sensitivity of the model results to exponentially-decreasing (black), linearly-decreasing (blue), and constant flotation fractions (red) in Zone 1 at station G02. The applied function changes the subglacial water pressure required to produce a given ice-flow velocity (top panel), but does not significantly alter the modelled ice-flow velocities (bottom panel).

\subsubsection{Sensitivity to boundary conditions in Zone 1}

As no data exists to constrain the boundary conditions outside of the study site (Zone 1 in Figure 2.13), the sensitivity of the model to the subglacial water pressure must be tested in this zone. Rather than vary the subglacial water pressure directly, several functions are applied that vary the flotation fraction $\left(P_{w} / \rho g H\right)$ across Zone 1. The flotation fraction is varied instead of the subglacial water pressure, as the ice thickness changes from $20 \mathrm{~m}$ to $250 \mathrm{~m}$ in this zone and certain areas would be afloat if the subglacial water pressure was varied (Figure 2.13). Figure 3.19 shows the subglacial water pressures and modelled ice-flow velocities at station G02 for exponentially-decreasing, linearly-decreasing, and constant flotation fractions in Zone 1. At the zone boundary $(x=8000 \mathrm{~m})$, the flotation fraction is set to the average flotation fraction in Zone 2 for all functions. The exponentially-decreasing and linearly-decreasing functions then describe how the flotation fraction decreases along the flowline to zero at the glacier head $(x=0 \mathrm{~m})$. Although the applied flotation fraction alters the best-fit subglacial 
water pressure, it does not greatly alter the modelled ice-flow velocities at G02 (Figure 3.19). Furthermore, it does not change the conclusions about the spatial distribution of subglacial water pressures in Section 3.3.3. A similar result occurs when the magnitudes of the flotation fraction and sliding coefficient are varied or the location of the zone boundary (Figure 2.13) is shifted from $x=8000 \mathrm{~m}$ to $x=9000 \mathrm{~m}$ along the flowline. Consequently, a linearly-decreasing flotation fraction is applied in Zone 1 for all subsequent experiments.

\subsubsection{Modelled subglacial water pressures}

The glacier flowline model reproduces measured ice-flow velocities at stations G01, G02, G04, and G05 to within $9 \pm 8 \%$ assuming a spatially-uniform subglacial water pressure across the study site (Figure 3.20). The model captures both the diurnal and daily variations in glacier flow but does not always capture the magnitude or timing of glacier speed-up events (Figure 3.10).

At the other two stations (G03 and G06), the model reproduces the temporal variability in ice-flow velocities but does not capture the total magnitude (Figure 3.20). At G06, the model underestimates the total magnitude by $32 \pm 11 \%$. There are several possible explanations for this: (1) the sliding coefficient without cavitation, $A_{s}$, is higher at G06 than at the other stations (Figure 3.14), (2) the subglacial water pressure is higher at this location, (3) the model does not adequately capture the glacier dynamics at G06, or (4) the bedrock topography is inadequate in this area. To explain the measured velocities at stations G05 and G06 in Figure 3.15 with a spatially-variable sliding coefficient, the sliding coefficient would need to be at least one order of magnitude greater at G06 than at G05. Similarly, the subglacial water pressure would need to be at least twice that of G05 at G06. Both of these scenarios seem unlikely, which might suggest that the bedrock topography in this area is inadequate or that the flowline model does not adequately capture the glacier dynamics. To estimate ice thickness near G06, a constant driving stress was assumed (Equation 2.33; Figure 2.13). This assumption is likely not valid near an ice fall, where compressive and extensional flow dominate. If the ice was 50-100 metres thicker at this location, the ice-flow 

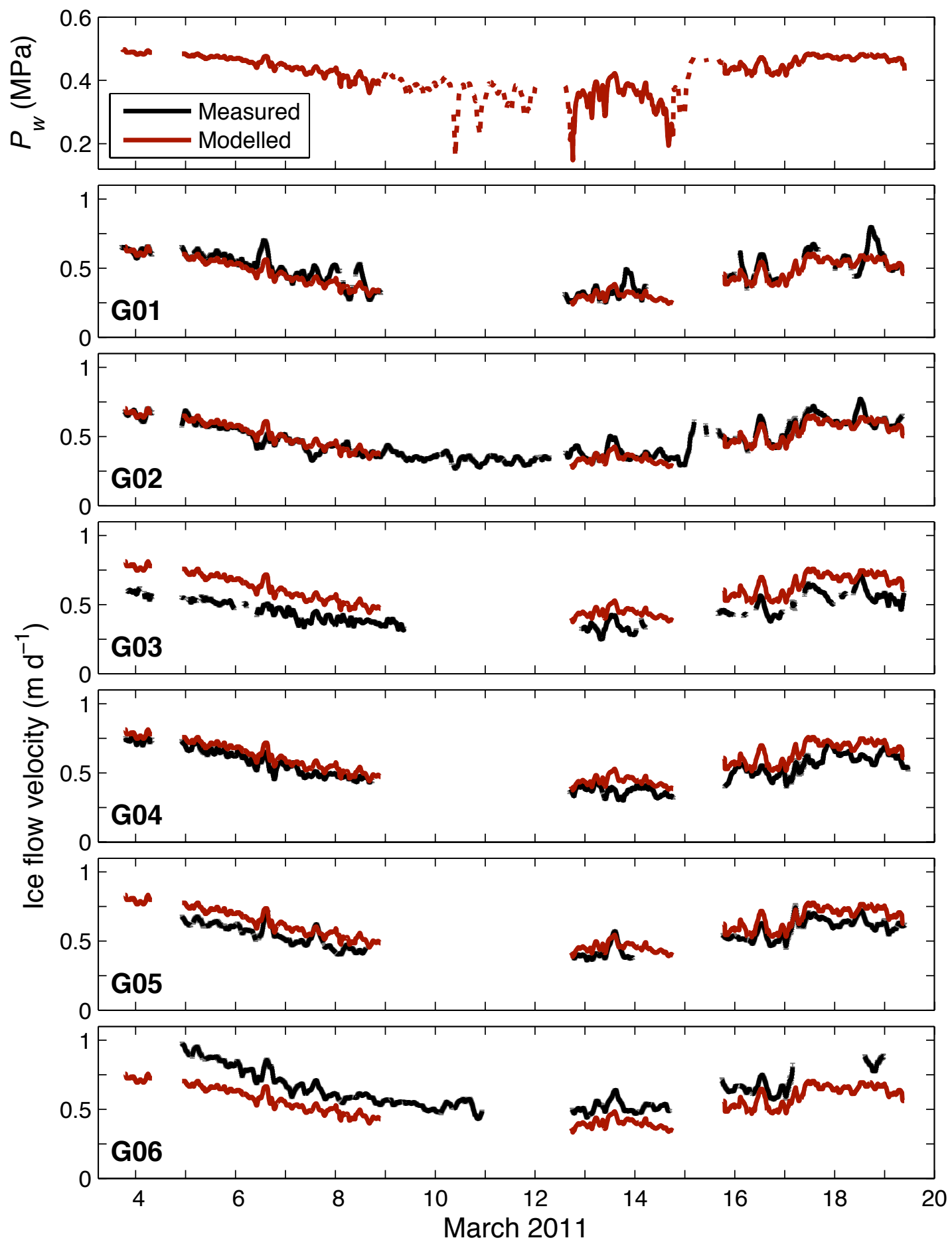

Figure 3.20: Modelled velocities (red lines) at the GPS stations assuming a spatially-uniform subglacial water pressure that best reproduces measured velocities (black lines) at stations G01, G02, G04, and G05 (top panel). The flowline model simulates each time-step separately, and these results are then combined together to form a timeseries. Modelled velocities agree well with observations at all stations other than G03 and G06. The dashed red lines indicate that G02 was the only station used to estimate subglacial water pressures during that time. 
velocities at G06 could be explained with a spatially-uniform subglacial water pressure. Alternatively, the glacier width in this area decreases by about half, and the flowline model may not adequately capture the resulting dynamics (Figure 2.12). Although the flowline model does account for increased valley wall drag as a result of a narrower valley (Equation 2.26), it does not account for the transverse compression and the consequent increase in mass flux, which would lead to higher velocities at G06. At G03, ice-flow velocities are overestimated by $25 \pm 5 \%$ by the model. Again, this could be a result of spatial variations in the sliding coefficient, subglacial water pressure, bedrock topography, or valley wall drag (see Section 4.2.2).

\subsection{Summary of key results}

1. The energy balance model underestimates the average measured ablation rate at each stake by $13 \pm 16 \%$. However, at stake S09 on the medial moraine, it overestimates the ablation rate by $50 \%$.

2. The modelled discharge curve matches well with the measured stage record at the Waiho Bridge, with a $\mathrm{R}^{2}$ correlation value of 0.73 with a lag of 2 hours and with no lag. Diurnal melt cycles appear in the modelled discharge curve but do not appear in the stage record.

3. Glacier speed increased during rain events of $>11 \mathrm{~mm}$, with a maximum recorded increase of $75 \pm 3 \%$ on March 15 during the most intense rainstorm of the study period (77 $\mathrm{mm}$ over 10 hours).

4. Diurnal cycles in glacier speed (4-32\%) occurred at all operational stations on March 6 and March 16. The two stations above the first ice fall (G05 and G06) showed a diurnal cycle on all rain-free days when they were operational, with peak ice-flow velocities reached from 14:00-15:00.

5. Ice-flow velocities at stations G01, G02, G04, and G05 can be reproduced with a full Stokes glacier flowline model assuming a spatially-uniform but 
temporally-varying subglacial water pressure. The model underestimates ice-flow velocities at G06 by $32 \pm 11 \%$ and overestimates ice-flow velocities at G03 by $25 \pm 5 \%$. 


\section{Chapter 4}

\section{Discussion}

In this chapter, I first discuss the water inputs and background ice-flow velocities. This is followed by a discussion of the measured glacier speed-up events and modelled subglacial water pressures. I then use these results to infer the subglacial drainage system of the Franz Josef Glacier. Finally, I consider the results of this study in the context of our current understanding of glacier dynamics.

\subsection{Glacier dynamics of the Franz Josef Glacier}

\subsubsection{Water inputs}

The ablation stake measurements, energy balance model, and discharge model indicate that significant water entered the glacier system throughout the study period. This study measured an average ablation rate of approximately $25 \mathrm{~m}$ w.e. $\mathrm{a}^{-1}$, which falls within the range of measured ablation rates on the Franz Josef Glacier (Anderson, 2004; Anderson and others, 2006) and on the nearby Fox Glacier (Purdie and others, 2008).

Measured ablation rates varied spatially across the glacier tongue. Ablation rates were approximately $30 \%$ greater below the first ice fall than above it, likely due to warmer temperatures at lower altitudes or enhanced diffuse radiation from nearby slopes as the valley narrows towards the glacier terminus (Figure 3.3). Lower ablation rates were also measured on debris-covered ice, as debris 
cover provides an insulating layer (Nakawo and Young, 1981). Debris cover is not taken into account in the energy balance model, and consequently, the model cannot account for these differences (Figure 3.5). As a result, the energy balance model does not always capture the spatial variations in glacier melt, particularly in debris-covered areas. Spatial variations in water inputs can be important for explaining spatial variations in glacier flow (e.g., Nienow, 1994; Mair and others, 2002), but are neglected in the modelling component of this study, as a lumpedsum discharge model is used.

Although the discharge model does not capture the spatial variations in water inputs, it does reproduce the observed temporal variations. Diurnal melt cycles and rain events can be identified in the modelled discharge record (Figure 3.6). As no data exist to tune the storage constants to the Franz Josef catchment and instead values for Brewster Glacier are used (Anderson and others, 2010), the timing and magnitude of these events may be unreliable. However, the discharge and stage records peak at similar times during rain events, indicating that the discharge model is adequately predicting these events. This suggests either that the storage constants for the Franz Josef and Brewster glaciers are similar or that the discharge model is relatively insensitive to the chosen storage constants (Hock and Noetzli, 1997). The modelled diurnal cycles, on the other hand, do not appear in the stage record at the Waiho Bridge (Figure 3.7). It is possible that this occurs because the diurnal cycles are smaller than the stage resolution. Alternatively, the Callery River basin, which also feeds into the Waiho River, may provide a discharge signal that is out of phase with the water input from the Franz Josef catchment, thereby masking the diurnal signal.

\subsubsection{Glacier motion}

Measured ice-flow velocities in this study $\left(0.22 \pm 0.11 \mathrm{~m} \mathrm{~d}^{-1}\right.$ to $0.67 \pm 0.03 \mathrm{~m} \mathrm{~d}^{-1}$; Figure 3.8) are similar to previously-recorded velocities on the snout of the Franz Josef Glacier (Gunn, 1964; Anderson, 2004; Herman and others, 2011). The flowline modelling indicates that about $55-90 \%$ of the total velocity was due to glacier sliding, similar to but slightly higher than rates suggested by Anderson (2004). 
In general, ice-flow velocities decreased towards the glacier terminus. However, ice-flow velocities at the stake directly below the first ice fall (S17) were lower than measured velocities 100-200 m further downstream, likely due to the stake's location in an area of compressive flow (Figure 3.9; Paterson, 1994). Near the glacier terminus, glacier flow was diverted towards the waterfall (Figure 3.8). Significant water enters the glacier at this location, causing substantial subglacial melt and basal calving (Fountain and Walder, 1998). As a result, ice flows in to replace the melted ice and frequent ice collapses occur due to undercutting near the waterfall.

\subsection{Glacier speed-up events on the Franz Josef Glacier}

\subsubsection{Measured glacier speed-up events}

Previous studies (e.g., Iken and Bindschadler, 1986; Mair and others, 2001) have found a relationship between short-term increases in water inputs and glacier velocity. At the Franz Josef Glacier, this study finds increases in glacier velocity of up to $75 \%$ above background values in response to diurnal melt cycles and rain events. Peak ice-flow velocities occurred within $2 \pm 2$ hours of peak modelled discharge during rain events and within $4 \pm 1$ hours during diurnal melt cycles, suggesting an almost instantaneous response to increased water inputs.

In general, greater increases in glacier speed occurred in response to larger water inputs to the glacier system (Figure 4.1). Increases in glacier speed during diurnal melt cycles were often smaller (4-32\%) than increases during rain events $(19-75 \%)$. The largest velocity increase $(75 \pm 3 \%)$ occurred at the only operational station on March 14-15 (G02), during the most intense rainstorm and largest modelled discharge event of the study period (77 mm over 10 hours; Figure 3.2). As a larger but less intense rainstorm ( $88 \mathrm{~mm}$ over 20 hours) caused a smaller change in ice-flow velocities, it is suggested that the rain intensity is more important than the total precipitation in driving glacier speed-up events (Table 3.2). Despite the general trend of larger water inputs leading to larger velocity increases (Figure 


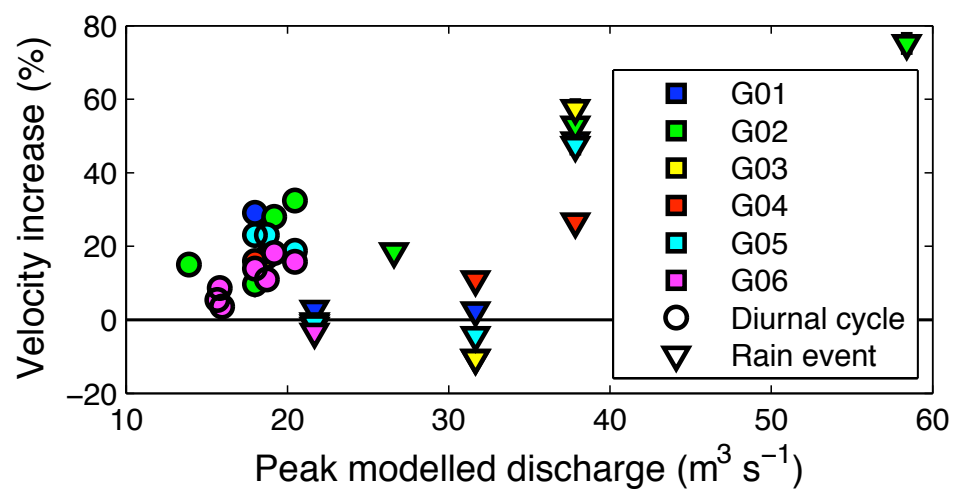

Figure 4.1: Velocity percent increase as a function of modelled discharge. Circles and triangles indicate diurnal cycles and rain events, respectively. Plotted discharge values are the peak discharge reached during the event.

4.1), velocity increases during the rain event with a modelled peak discharge of $32 \mathrm{~m} \mathrm{~s}^{-1}$ on March 18-19 were lower than velocity increases during smaller discharge events. This may be because ice-flow velocities still remained high following a discharge event of $38 \mathrm{~m} \mathrm{~s}^{-1}$ one day earlier (Figures 3.2 and 3.10).

It is difficult to compare the magnitude of glacier speed-up events on the Franz Josef Glacier to those of other glaciers, as ice-flow velocities are averaged over different time intervals in other studies. Furthermore, the full range of possible velocity increases may not have occurred at the Franz Josef Glacier during the study period. With that said, Purdie and others (2008) found velocity increases of up to $44 \%$ at Fox Glacier, suggesting that the Fox and Franz Josef Glaciers, which are subject to similar ablation and precipitation rates, may respond similarly to water inputs. A basic comparison to several continental glaciers, such as Findelengletcher (300\% of background speed; Iken, 1974) and Midtdalsbreen (900\% of background speed; Iken and Bindschadler, 1986), could suggest that the magnitudes of speed-up events are lower at the Franz Josef Glacier than at a typical continental glacier. This may be because ice-flow velocities are already much higher at the Franz Josef Glacier, and as a result, the relative changes are smaller even if the changes in absolute magnitude are similar (Andersen and others, 2011). Alternatively, it could suggest that the Franz Josef Glacier is not as sensitive to increased water inputs, as the subglacial drainage system is already well-developed (Kamb, 1987). 


\subsubsection{Modelled subglacial water pressures}

As glacier speed-up events coincided with large water inputs to the glacier system, it can be inferred that subglacial water pressures increased during these events (Kamb, 1987; Iken and others, 1983). The glacier flowline modelling supports this finding. Ice-flow velocities at four of the six GPS stations can be explained by a spatially-uniform but temporally-varying subglacial water pressure (Figure 3.20). Although the magnitudes of the modelled subglacial water pressures are unreliable (Figures 3.16 and 3.17), the modelling shows that perturbations in the subglacial water pressure occurred over a long enough distance that the stations behaved similarly. This is different from other glaciers, such as Haut Glacier d'Arolla, where spatial variations in the subglacial water pressure have been found over length scales of less than $100 \mathrm{~m}$ (Hubbard and others, 1995). It is possible, however, that the flowline modelling cannot capture these smaller-scale spatial variations as the ice column smooths basal perturbations before they reach the surface (Balise and Raymond, 1985; Kamb and Echelmeyer, 1986).

Assuming a spatially-uniform subglacial water pressure, the flowline model produces ice-flow velocities that are within $9 \pm 8 \%$ of the measured values at G01, G02, G04, and G05. Several explanations could account for the small differences between the modelled and measured ice-flow velocities. First, the differences might be due to the station's projected thickness on the glacier flowline being different from its real value, as variations in the ice thickness impact the effective pressure (Equation 2.32) and thereby the relationship between subglacial water pressure and basal sliding (Equation 2.31). Furthermore, it is possible that the glacier flowline model does not capture the physics of glacier sliding at the Franz Josef Glacier. For instance, a stick-slip process (Fischer and others, 1999) might explain the spatially-variable peaks in ice-flow velocities after the rain event on March 16-17.

Ice-flow velocities at the other two stations-G03 and G06-cannot be explained with a spatially-uniform subglacial water pressure. For both sites, minimum iceflow velocities indicate a sliding coefficient in the absence of cavitation, $A_{s}$, that varies from the other four stations (Figure 3.14). Several explanations could ac- 
count for the differences between modelled and measured ice-flow velocities at these sites. First, the glacier flowline model may assume an inaccurate ice thickness at the two stations. This could be because the ice thickness at the GPS station differs from its projected location on the flowline or because the bed profile is poorly constrained (Figure 2.13). Second, the sliding coefficient without cavitation, $A_{s}$, may not be spatially-uniform across the lower glacier (Figure 3.14). Third, the subglacial water pressure may not be spatially-uniform. Finally, the flowline model may not adequately capture the dynamics of a three-dimensional glacier. At G06, the model underestimates ice-flow velocities by $32 \pm 11 \%$ but captures the temporal variations in ice-flow velocities. It is suggested that this is a result of (1) the poorly constrained bed topography in this area or (2) a significant decrease in the glacier width near G06, which is not fully accounted for in the flowline model (Figure 2.13; Section 3.3.3).

At G03, the model overestimates ice-flow velocities by $25 \pm 5 \%$, but again, it captures the temporal variations in ice-flow velocities. In addition to the previouslyproposed explanations, the model misfit at G03 could also be explained by enhanced valley wall drag or a more channelised subglacial drainage system near G03. As station G03 is very close to the valley wall, valley wall drag may be greater at this site than at the glacier flowline, which would translate into a lower velocity at G03 than at the flowline. Furthermore, the subglacial water pressure may be lower at this location than at the other sites. It is suspected that a large subglacial channel flows on the true left of the glacier (near G01 and G03) due to the presence of an exposed subglacial channel further upstream and the large waterfall lower on the glacier (Figure 2.1). If the true left of the glacier was more channelised than the true right of the glacier, this would cause lower subglacial water pressures at G03 and potentially explain the lower ice-flow velocities at this site (Mair and others, 2001).

\subsubsection{Inferred subglacial hydrology}

Glacier speed-up events occur when the subglacial drainage system cannot accommodate the increased water input to the glacier system and the subglacial 
water pressure increases (Kamb, 1987; Iken and others, 1983). This relationship is well-documented at many mountain glaciers around the world, such as Haut Glacier d'Arolla (Hubbard and others, 1995; Mair and others, 2001) and Findelengletscher (Iken and Bindschadler, 1986). More recently, glacier speed-up events have been observed on the Greenland Ice Sheet in response to diurnal melt cycles (Shepherd and others, 2009) and supraglacial lake drainage events (Zwally and others, 2002; Das and others, 2008) as well as on the East Antarctic Ice Sheet due to subglacial lake drainage events (Stearns and others, 2008).

At the Franz Josef Glacier, the relationship between water inputs and glacier speed-up events is perhaps more surprising, as large water inputs enter a welldeveloped subglacial drainage system throughout the year (Figure 3.6). Two possible scenarios are suggested to explain the occurrence of glacier speed-up events on the Franz Josef Glacier. First, the subglacial drainage system develops quickly, but it also shuts down quickly due to the high rates of ice advection and glacier creep at the Franz Josef Glacier. As ice is advected downstream, channels become blocked and new drainage pathways must be created. This prevents the subglacial drainage system from becoming well-developed. Many small jökulhlaups (subglacial outburst floods) have been observed on the Franz Josef Glacier, which indicate a blockage of a subglacial channel by ice collapse and the re-routing of subglacial water over the glacier surface (Davies and others, 2003; Goodsell and others, 2005). As a result, these events indicate that the subglacial drainage system can shut down quickly but also that the large water inputs can quickly create new drainage pathways.

The second scenario is that glacier speed-up events simply occur because of the variability in water inputs to the glacier system. Schoof (2010) recently proposed this concept to explain enhanced glacier flow on the Greenland Ice Sheet. Through numerical modelling, he showed that glacier speed-up events occur as a result of temporary spikes in water inputs, even if the subglacial drainage system is well-developed. This happens because channel size adjusts slowly, and as a result, the drainage system must accommodate the sudden increase in water through an increase in the hydraulic gradient rather than in the channel size, 
which leads to higher subglacial water pressures in the drainage system.

With the data available in this study, it is not possible to determine which of these two scenarios is the most likely for the Franz Josef Glacier. With that said, the results of this study show that glacier surface velocities are more sensitive to the rain intensity than the total precipitation during a rain event (Figure 4.1; Section 4.2.1), which would support the variability scenario. To better understand glacier speed-up events on the Franz Josef Glacier, a dye-tracing experiment would be needed to provide information about the capacity and evolution of the subglacial drainage system over time (e.g., Nienow and others, 1998; Werder and others, 2009). If the subglacial drainage system does not evolve or shutdown during or after glacier speed-up events, this would suggest that the variability in water inputs is the primary driver in glacier speed-up events on the Franz Josef Glacier.

\subsection{Glacier speed-up events in overall glacier motion}

The role of glacier speed-up events in overall glacier motion is still poorly understood. Several recent studies (Van de Wal and others, 2008; Sundal and others, 2011) have suggested that high ice-flow velocities during glacier speed-up events are offset by lower ice-flow velocities due to a more efficient drainage system after the event, and as a result, increased water inputs do not cause ice acceleration over the long term. If this is the case, then climate change will not lead to enhanced glacier motion through a positive feedback system of faster ice advection to lower altitudes and greater glacier melt (Parizek and Alley, 2004). In contrast, at the Franz Josef Glacier, this study finds that speed-up events can occur even when the subglacial drainage system is well-developed, suggesting that these events may contribute to faster glacier flow.

These potentially-opposing results can be rationalised if glacier speed-up events occur because of the variability in water inputs, rather than the mean water input to the glacier system (Section 4.2.3; Schoof, 2010). From this result, we might then expect faster glacier flow if water inputs become more variable over the next century. However, if the total water entering glacier systems increases 
but the variability does not increase, then glacier speed-up events may not become more frequent in the future. One of the remaining unknowns, however, is how much glacier speed-up events can contribute to glacier flow, mass loss, and sea level rise. Can the influence of these events on the major ice sheets help explain multimetre per century rises in sea level in the past (e.g., Overpeck and others, 2006), and what effect will they have in the future? A study into the contributions of seasonal and short-term variations in glacier flow to the overall rate of glacier flow would provide insight into the potential implications of increased water inputs in the future. 


\section{Chapter 5}

\section{Conclusions}

This study combines observational data, an energy balance model, and a full Stokes glacier flowline model to understand glacier speed-up events on the Franz Josef Glacier. Glacier speed-up events occurred at all survey locations on the lower glacier and ranged in magnitude from 2-75\% above background ice-flow velocities. With a glacier flowline model, measured ice-flow velocities were reproduced to within $9 \pm 8 \%$ at four of the six GPS stations with a spatially-uniform but temporally-varying subglacial water pressure. At the other two stations, it was hypothesised that the model could not reproduce the measured ice-flow velocities due to unaccounted valley wall drag, a poorly determined ice thickness, or glacier dynamics that were not taken into account in the flowline model. These results indicate that perturbations in the subglacial water pressure occurred over a long enough distance that all GPS stations on the lower glacier behaved similarly to increased water inputs.

\subsection{Answered research questions}

From the results of this study, the research questions outlined in Section 1.3.2 can now be addressed: 
1. How do ice-flow velocities vary spatially and temporally across the lower Franz Josef Glacier? Are there daily or diurnal variations in ice-flow velocities?

Glacier flow varied both spatially and temporally across the glacier tongue. Spatially, ice-flow velocities decreased towards the glacier terminus, with the exception of lower ice-flow velocities in an area of compressive flow directly below the first ice fall. Temporally, increases in ice-flow velocities occurred in response to both diurnal melt cycles (4-32\% above background velocities) and rain events (2-75\% above background velocities).

2. Why do ice-flow velocities vary at this glacier? What do these results suggest about the subglacial hydrology of the Franz Josef Glacier?

During glacier speed-up events, peak ice-flow velocities occurred within eight hours of peak modelled discharge, suggesting a relationship between water inputs and short-term variations in glacier speed. This relationship is well-documented at other glaciers (e.g., Iken and Bindschadler, 1986; Mair and others, 2001; Naruse and others, 1992) and suggests that subglacial water pressures likely increased during these events. The glacier flowline modelling in this study supports this finding. Ice-flow velocities at four of the six stations can be reproduced to within $9 \pm 8 \%$ with a temporally-varying but spatially-uniform subglacial water pressure. This might suggest a spatially-uniform subglacial drainage system across the lower glacier, as basal water pressure perturbations occurred over a long enough distance that the GPS stations behaved similarly.

\section{How do the dynamics of the Franz Josef Glacier differ from those of other glaciers, and what does this tell us about glacier dynamics in general?}

The identification of glacier speed-up events on the Franz Josef Glacier is perhaps surprising, as the subglacial drainage system is likely well-developed. Two possible scenarios are proposed to explain the occurrence of glacier speed-up events on the Franz Josef Glacier: (1) the subglacial drainage system develops quickly but also shuts down quickly due to high rates of glacier creep and ice advection 
and (2) the variability in water inputs, rather than the mean water input to the glacier system, drives glacier speed-up events (Schoof, 2010).

The latter scenario has potential implications for both the Franz Josef Glacier and the major ice sheets in a warming climate. If the variability in water inputs increases as a result of more frequent rain events and stronger diurnal melt cycles, we might expect glacier speed-up events to become more frequent in the future. The resulting ice acceleration could then cause faster ice advection to lower altitudes and greater glacier melt, potentially leading to a positive feedback system (Parizek and Alley, 2004). Future studies should address the importance of this mechanism in glacier mass loss and thereby sea level rise.

\subsection{Future work}

The role of glacier speed-up events in overall glacier motion is still poorly understood. When glacier speed-up events occur, they are often followed by a period of lower ice-flow velocities after the subglacial drainage system becomes well-developed. These lower velocities can offset the higher velocities during the glacier speed-up event, and thereby negate the effects of enhanced glacier flow in response to water inputs on overall glacier motion (Sundal and others, 2011; Van de Wal and others, 2008). At the Franz Josef Glacier, glacier speedup events occur even though the subglacial drainage system is well-developed, which suggests that these events may contribute to overall glacier motion. A long-term study into the contributions of short-term velocity variations to overall glacier motion is important in understanding the potential effects of more frequent diurnal cycles and rain events (e.g., Schuenemann and Cassano, 2010) on glacier mass balance in the 21st century. 


\section{References}

Alley, R. B., 1993. In search of ice-stream sticky spots, Journal of Glaciology, 39(133), $447-454$.

Andersen, M., M. Nettles, P. Elosegui, T. Larsen, G. Hamilton and L. Stearns, 2011. Quantitative estimates of velocity sensitivity to surface melt variations at a large Greenland outlet glacier, Journal of Glaciology, 57(204), 609-620.

Anderson, B., 2004. The response of Ka Roimata o Hine Hukatere Franz Josef Glacier to climate change, PhD thesis, University of Canterbury, Christchurch, New Zealand.

Anderson, B., W. Lawson, I. Owens and B. Goodsell, 2006. Past and future mass balance of 'Ka Roimata o Hine Hukatere' Franz Josef Glacier, New Zealand, Journal of Glaciology, 52(179), 597-607.

Anderson, B., A. Mackintosh, D. Stumm, L. George, T. Kerr, A. Winter-Billington and S. Fitzsimons, 2010. Climate sensitivity of a high-precipitation glacier in New Zealand, Journal of Glaciology, 56(195), 114-128.

Anderson, B., A. Mackintosh and I. Willis, in prep. Diurnal to decadal ice velocity variations on Franz Josef Glacier (Ka Roimata o Hine Hukatere), South Westland, New Zealand.

Araszkiewicz, A., J. Bogusz and M. Figurski, 2009. Investigation on tidal components in GPS coordinates, Artificial Satellites, 44(2), 67-74.

Arnold, N., I. Willis, M. Sharp, K. Richards and W. Lawson, 1996. A distributed surface energy-balance model for a small valley glacier. I. Development and testing for Haut Glacier d'Arolla, Valais, Switzerland, Journal of Glaciology, 42(140), 77-89.

Baker, D., H. Escher-Vetter, H. Moser, H. Oerter and O. Reinwarth, 1982. A glacier discharge model based on results from field studies of energy balance, water storage and flow, Hydrological Aspects of Alpine and High-Mountain Areas, 103112.

Balise, M. and C. Raymond, 1985. Transfer of basal sliding variations to the surface of a linearly viscous glacier, Journal of Glaciology, 31(109), 308-318.

Bindschadler, R., 1983. The importance of pressurized subglacial water in separation and sliding at the glacier bed, Journal of Glaciology, 29(101), 3-19. 
Blatter, H., 1995. Velocity and stress fields in grounded glaciers: a simple algorithm for including deviatoric stress gradients, Journal of Glaciology, 41(138), 333-344.

Brutsaert, W., 1982. Evaporation into the atmosphere: theory, history, and applications, vol. 1, Kluwer Academic Publishers, The Netherlands.

Budd, W., P. Keage and N. Blundy, 1979. Empirical studies of ice sliding, Journal of Glaciology, 23(89), 157-170.

Cardozo, N. and R. Allmendinger, 2009. SSPX: A program to compute strain from displacement/velocity data, Computers E Geosciences, 35(6), 1343-1357.

Chen, G., 1998. GPS Kinematic Position for the Airborne Laser Altimetry at Long Valley, California, PhD thesis, Department of Earth, Atmospheric, and Planetary Sciences, Massachusetts Institute of Technology.

Corripio, J., 2003. Vectorial algebra algorithms for calculating terrain parameters from DEMs and solar radiation modelling in mountainous terrain, International Journal of Geographical Information Science, 17(1), 1-23.

Cuffey, K. and W. Paterson, 2010. The physics of glaciers, Elsevier, Oxford, 4th ed.

Das, S., I. Joughin, M. Behn, I. Howat, M. King, D. Lizarralde and M. Bhatia, 2008. Fracture propagation to the base of the Greenland Ice Sheet during supraglacial lake drainage, Science, 320, 778-781.

Davies, T., 1997. Long-term management of facilities on an active alluvial fan Waiho River fan, Westland, New Zealand, Journal of Hydrology New Zealand, 36, 127-145.

Davies, T., C. Smart and J. Turnbull, 2003. Water and sediment outbursts from advanced Franz Josef glacier, New Zealand, Earth Surface Processes and Landforms, 28(10), 1081-1096.

Dozier, J., 1980. A clear-sky spectral solar radiation model for snow-covered mountainous terrain, Water Resources Research, 16(4), 709-718.

Fischer, U. and G. Clarke, 1997. Stick slip sliding behaviour at the base of a glacier, Annals of Glaciology, 24, 390-396.

Fischer, U., G. Clarke and H. Blatter, 1999. Evidence for temporally varying sticky spots at the base of Trapridge Glacier, Yukon Territory, Canada, Journal of Glaciology, 45(150), 352-360.

Flowers, G., N. Roux, S. Pimentel and C. Schoof, 2011. Present dynamics and future prognosis of a slowly surging glacier, The Cryosphere, 5, 299-313.

Fountain, A. and J. Walder, 1998. Water flow through temperate glaciers, Review of Geophysics, 36(3), 299-328. 
Gagliardini, O., D. Cohen, P. Raback and T. Zwinger, 2007. Finite-element modeling of subglacial cavities and related friction law, Journal of Geophysical Research, 112(F2), F02027.

Garnier, A., BJ.and Ohmura, 1968. A method of calculating the direct shortwave radiation income of slopes., Journal of Applied Meteorology, 7, 796-800.

Geuzaine, C. and J. Remacle, 2009. Gmsh: A 3-D finite element mesh generator with built-in pre-and post-processing facilities, International Journal for Numerical Methods in Engineering, 79(11), 1309-1331.

Glen, J., 1955. The creep of polycrystalline ice, Proceedings of the Royal Society of London, Series A, Mathematical and Physical Sciences, 228(1175), 519-538.

Goodsell, B., B. Anderson, W. Lawson and I. Owens, 2005. Outburst flooding at Franz Josef Glacier, South Westland, New Zealand, New Zealand Journal of Geology and Geophysics, 48, 95-104.

Gudmundsson, G. and M. Raymond, 2008. On the limit to resolution and information on basal properties obtainable from surface data on ice streams, The Cryosphere, 2, 167-178.

Gunn, B.M., 1964. Flow rates and secondary structures of Fox and Franz Josef Glaciers, New Zealand, Journal of Glaciology, 5, 173-190.

Hansen, J., 2007. Scientific reticence and sea level rise, Environmental Research Letters, 2, 024002.

Harbor, J., M. Sharp, L. Copland, B. Hubbard, P. Nienow and D. Mair, 1997. The influence of subglacial drainage conditions on the velocity distribution within a glacier cross-section, Geology, 25, 739-742.

Hefty, J. and M. Igondova, 2010. Diurnal and semi-diurnal coordinate variations observed in EUREF permanent GPS network - a case study for period from 2004.0 to 2006.9, Contributions to Geophysics and Geodesy, 40(3), 225-247.

Herman, F., B. Anderson and S. Leprince, 2011. Mountain glacier velocity variation during a retreat/advance cycle quantified using sub-pixel analysis of ASTER images, Journal of Glaciology, 57(202), 197-207.

Herring, T., 2006. TRACK: GPS differential phase kinematic positioning program, v. 1.13, http://geoweb.mit.edu/ simon/gtgk/help/track.hlp.htm, Massachusetts Institute of Technology, Cambridge, MA.

Hock, R., 2005. Glacier melt: a review of processes and their modelling, Progress in Physical Geography, 29(3), 362-391.

Hock, R. and C. Noetzli, 1997. Areal melt and discharge modelling of Storglaciären, Sweden, Annals of Glaciology, 24, 211-216. 
Hooke, R., J. Brzozowski and C. Bronge, 1983. Seasonal variations in surface velocity, Storglaciären, Sweden, Geografiska Annaler. Series A. Physical Geography, 65(3/4), 263-277.

Hooke, R., P. Calla, P. Holmlund, M. Nilsson and A. Stroeven, 1989. A 3 year record of seasonal variations in surface velocity, Storglaciären, Sweden, Journal of Glaciology, 35(120), 235-247.

Hubbard, A., 1997. Modelling climate, topography and palaeoglacier fluctuations in the Chilean Andes, Earth Surface Processes and Landforms, 22(1), 79-92.

Hubbard, B., M. Sharp, I. Willis, M. Nielson and C. Smart, 1995. Borehole waterlevel variations and structure of the subglacial hydrological system of Haut Glacier d'Arolla, Valais, Switzerland, Journal of Glaciology, 41, 572-283.

Iken, A., 1974. Velocity fluctuations of an Arctic valley glacier: a study of the White Glacier, Axel Heiberg Island, Canadian Arctic Archipelago, Axel Heiberg Island Research Reports, McGill University, Montreal, Canada, chap. 5 Glaciology.

Iken, A., 1981. The effect of the subglacial water pressure on the sliding velocity of a glacier in an idealized numerical model, Journal of Glaciology, 27, 407-421.

Iken, A. and R. Bindschadler, 1986. Combined measurements of subglacial water pressure and surface velocity of Findelengletscher, Switzerland: conclusions about drainage system and sliding mechanism, Journal of Glaciology, 32(110), 101-119.

Iken, A., H. Röthlisberger, A. Flotron and W. Haeberli, 1983. The uplift of Unteraagletscher at the beginning of the melt season-A consequence of water storage at the bed?, Journal of Glaciology, 29, 28-47.

Iken, A. and M. Truffer, 1997. The relationship between subglacial water pressure and velocity of Findelengletscher, Switzerland, during its advance and retreat, Journal of Glaciology, 43(144), 328-338.

Jansson, P., 1995. Water pressure and basal sliding on Storglaciären, northern Sweden, Journal of Glaciology, 41(138), 232-240.

Jay-Allemand, M., F. Gillet-Chaulet, O. Gagliardini and M. Nodet, 2011. Investigating changes in basal conditions of Variegated Glacier prior and during its 1982-1983 surge, The Cryosphere, 5, 659-672.

Kamb, B., 1987. Glacier surge mechanism based on linked cavity configuration of the basal water conduit system, Journal of Geophysical Research, 92(B9), 90839099 .

Kamb, B. and K. Echelmeyer, 1986. Stress-gradient coupling in glacier flow: I. Longitudinal averaging of the influence of ice thickness and surface slope, Journal of Glaciology, 32(111), 267-284. 
King, R. and Y. Bock, 2010. Documentation for the GAMIT GPS analysis software, v10.4, Massachusetts Institute of Technology, Cambridge, MA.

Konzelmann, T., R. van de Wal, W. Greuell, R. Bintanja, E. Henneken and A. AbeOuchi, 1994. Parameterization of global and longwave incoming radiation for the Greenland ice sheet, Global and Planetary change, 9(1-2), 143-164.

Lemke, P., J. Ren, R. Alley, I. Allison, J. Carrasco, G. Flato, Y. Fujii, G. Kaser, P. Mote, R. Thomas and T. Zhang, 2007. Observations: Changes in Snow, Ice, and Frozen Ground, Solomon, S. D., D. Qin, M. Manning, Z. Chen, M. Marquis, K. B. Averyt, M. Tignor and H. L. Miller, eds., Climate Change 2007: The Physical Basis. Contribution of Working Group I to the Fourth Assessment Report of the Intergovernmental Panel on Climate Change, Cambridge University Press, Cambridge, United Kingdom and New York, NY, USA.

Lliboutry, L., 1958. Contribution à la théorie du frottement des glaciers sur leur lit, Comptes rendus de l'Académie des sciences, 247(3), 318-320.

Lliboutry, L., 1968. General theory of subglacial cavitation and sliding of temperate glaciers, Journal of Glaciology, 7, 21-58.

Mair, D., P. Nienow, I. Willis and M. Sharp, 2001. Spatial patterns of glacier motion during a high-velocity event: Haut Glacier d'Arolla, Switzerland, Journal of Glaciology, 47(156), 9-20.

Mair, D., M. Sharp and I. Willis, 2002. Evidence for basal cavity opening from analysis of surface uplift during a high-velocity event: Haut Glacier d'Arolla, Switzerland, Journal of Glaciology, 48(161), 208-216.

Melbourne, W., 1985. The case for ranging in GPS-based geodetic systems, Proceedings of the First International Symposium on Precise Positioning with the Global Positioning System, Rookville, Maryland, vol. 1, 373-386.

Nakawo, M. and G. Young, 1981. Field experiments to determine the effect of a debris layer on ablation of glacier ice, Annals of Glaciology, 2(1), 85-91.

Naruse, R., H. Fukami and M. Aniya, 1992. Short-term variations in flow velocity of Glaciar Soler, Patagonia, Chile, Journal of Glaciology, 38(128), 152-156.

Neale, S. and B. Fitzharris, 1997. Energy balance and synoptic climatology of a melting snowpack in the Southern Alps, New Zealand, International Journal of Climatology, 17(14), 1595-1609.

Nienow, P., 1994. Dye-tracer investigations of glacier hydrological systems, PhD thesis, University of Cambridge, Cambridge, England.

Nienow, P., A. Hubbard, B. Hubbard, D. Chandler, D. Mair, M. Sharp and I. Willis, 2005. Hydrological controls on diurnal ice flow variability in valley glaciers, Journal of Geophysical Research, 110(F4), F04002. 
Nienow, P., M. Sharp and I. Willis, 1998. Seasonal changes in the morphology of the subglacial drainage system, Haut Glacier d'Arolla, Switzerland, Earth Surface Processes and Landforms, 23(9), 825-843.

Nye, J., 1970. Glacier sliding without cavitation in a linear viscous approximation, Proceedings of the Royal Society of London, Mathematical and Physical Sciences, 315(1522), 381.

Nye, J., 1973. Water at the bed of a glacier, IUGG-AIHS Symposium on the Hydrology of Glaciers, International Association of Scientific Hydrology, Cambridge, Publication 95, 189-194.

Oerlemans, J., 1992. Climate sensitivity of glaciers in southern Norway: application of an energy-balance model to Nigardsbreen, Hellstugubreen and Alfotbreen, Journal of Glaciology, 38, 223-232.

Oerlemans, J., 1997. Climate sensitivity of Franz Josef Glacier, New Zealand, as revealed by numerical modeling, Arctic and Alpine Research, 29(2), 233-239.

Oerlemans, J. and W. Knap, 1998. A 1 year record of global radiation and albedo in the ablation zone of Morteratschgletscher, Switzerland, Journal of Glaciology, 44(147).

Oke, T., 1987. Boundary layer climates, Routledge Press, London, 2nd ed.

Overpeck, J., B. Otto-Bliesner, G. Miller, D. Muhs, R. Alley and J. Kiehl, 2006. Paleoclimatic evidence for future ice-sheet instability and rapid sea-level rise, Science, 311(5768), 1747.

Parizek, B. and R. Alley, 2004. Implications of increased Greenland surface melt under global-warming scenarios: ice-sheet simulations, Quaternary Science Reviews, 23(9-10), 1013-1027.

Paterson, W.S.B., 1994. The physics of glaciers, Reed Education and Professional Published Ltd, Oxford, 3rd ed.

Pfeffer, W., J. Harper and S. O'Neel, 2008. Kinematic constraints on glacier contributions to 21st-century sea-level rise, Science, 321(5894), 1340.

Plummer, M. and F. Phillips, 2003. A 2-D numerical model of snow/ice energy balance and ice flow for paleoclimatic interpretation of glacial geomorphic features, Quaternary Science Reviews, 22(14), 1389-1406.

Purdie, H., M. Brook and I. Fuller, 2008. Seasonal variation in ablation and surface velocity on a temperate maritime glacier: Fox Glacier, New Zealand, Arctic, Antarctic, and Alpine Research, 40(1), 140-147.

Raymond, C., R. Benedict, W. Harrison, K. Echelmeyer and M. Sturm, 1995. Hydrological discharges and motion of Fels and Black Rapids Glaciers, Alaska, USA: implications for the structure of their drainage systems, Journal of Glaciology, 41(138), 290-304. 
Röthlisberger, H., 1972. Water in intra- and subglacial channels, Journal of Glaciology, 11(62), 177-204.

Röthlisberger, H., 1976. Thermal consequences of the pressure fluctuations in intra- and subglacial water drainage channels, Journal of Glaciology, 16, 309-10.

Schoof, C., 2005. The effect of cavitation on glacier sliding, Proceedings of the Royal Society A: Mathematical, Physical and Engineering Science, 461(2055), 609.

Schoof, C., 2010. Ice-sheet acceleration driven by melt supply variability, Nature, 468(7325), 803-806.

Schuenemann, K. and J. Cassano, 2010. Changes in synoptic weather patterns and Greenland precipitation in the 20th and 21st centuries: 2. Analysis of 21st century atmospheric changes using self-organizing maps, Journal of Geophysical Research, 115(D5), D05108.

Shepherd, A., A. Hubbard, P. Nienow, M. King, M. McMillan and I. Joughin, 2009. Greenland ice sheet motion coupled with daily melting in late summer, Geophysical Research Letters, 36(1), L01501.

Stearns, L., B. Smith and G. Hamilton, 2008. Increased flow speed on a large East Antarctic outlet glacier caused by subglacial floods, Nature Geoscience, 1(12), 827-831.

Stuart, S., 2011. Observations and modelling of precipitation in the Southern Alps of New Zealand, PhD thesis, Victoria University of Wellington, Wellington, New Zealand.

Sundal, A., A. Shepherd, P. Nienow, E. Hanna, S. Palmer and P. Huybrechts, 2011. Melt-induced speed-up of Greenland ice sheet offset by efficient subglacial drainage, Nature, 469, 521-524.

Taylor, J., 1997. An introduction to Error Analysis, University Science Books, Sausalito, CA, USA, 2nd ed.

Truffer, M., 2004. The basal speed of valley glaciers: an inverse approach, Journal of Glaciology, 50(169), 236-242.

Vincent, C., A. Soruco, D. Six and E. Le Meur, 2009. Glacier thickening and decay analysis from 50 years of glaciological observations performed on Glacier d'Argentiere, Mont Blanc area, France, Annals of Glaciology, 50(50), 73-79.

Van de Wal, R., W. Boot, M. Van den Broeke, C. Smeets, C. Reijmer, J. Donker and J. Oerlemans, 2008. Large and rapid melt-induced velocity changes in the ablation zone of the Greenland Ice Sheet, Science, 321(5885), 111-113.

Walder, J., 1982. Stability of sheet flow of water beneath temperate glaciers and implications for glacier surging, Journal of Glaciology, 28(99), 273-293.

Warren, S., 1982. Optical properties of snow, Review of Geophysics, 20(1), 67-89. 
Weertman, J., 1957. On the sliding of glaciers, Journal of Glaciology, 3, 33-38.

Weertman, J., 1964. The theory of glacier sliding, Journal of Glaciology, 5, 287-303.

Werder, M., A. Loye and M. Funk, 2009. Dye tracing a jokulhlaup: I. Subglacial water transit speed and water-storage mechanism, Journal of Glaciology, 55(193), 889-898.

Willis, I., 1995. Intra-annual variations in glacier motion: a review, Progress in Physical Geography, 19(1), 61-106.

Wiscombe, W. and S. Warren, 1980. A model for the spectral albedo of snow. I: Pure snow, Journal of Atmospheric Science, 37(12), 2712-2733.

Wubbena, G., 1985. Software developments for geodetic positioning with GPS using TI-4100 code and carrier measurements, Proceedings of the First International Symposium on Precise Positioning with the Global Positioning System, Rookville, Maryland, vol. 1, 408-412.

Zumberge, J., M. Heflin, D. Jefferson, M. Watkins and F. Webb, 1997. Precise point positioning for the efficient and robust analysis of GPS data from large networks, Journal of Geophysical Research, 102(B3), 5005-5017.

Zwally, H., W. Abdalati, T. Herring, K. Larson, J. Saba and K. Steffen, 2002. Surface melt-induced acceleration of Greenland ice-sheet flow, Science, 297(5579), 218. 